\title{
Transcriptional control of cardiac fatty acid metabolism by PPARs
}

Citation for published version (APA):

Gilde, A. J. (2004). Transcriptional control of cardiac fatty acid metabolism by PPARs. [Doctoral Thesis, Maastricht University]. Ponsen \& Looijen B.V. https://doi.org/10.26481/dis.20041001ag

Document status and date:

Published: 01/01/2004

DOI:

10.26481/dis.20041001ag

Document Version:

Publisher's PDF, also known as Version of record

\section{Please check the document version of this publication:}

- A submitted manuscript is the version of the article upon submission and before peer-review. There can be important differences between the submitted version and the official published version of record.

People interested in the research are advised to contact the author for the final version of the publication, or visit the DOI to the publisher's website.

- The final author version and the galley proof are versions of the publication after peer review.

- The final published version features the final layout of the paper including the volume, issue and page numbers.

Link to publication

\footnotetext{
General rights rights.

- You may freely distribute the URL identifying the publication in the public portal. please follow below link for the End User Agreement:

www.umlib.nl/taverne-license

Take down policy

If you believe that this document breaches copyright please contact us at:

repository@maastrichtuniversity.nl

providing details and we will investigate your claim.
}

Copyright and moral rights for the publications made accessible in the public portal are retained by the authors and/or other copyright owners and it is a condition of accessing publications that users recognise and abide by the legal requirements associated with these

- Users may download and print one copy of any publication from the public portal for the purpose of private study or research.

- You may not further distribute the material or use it for any profit-making activity or commercial gain

If the publication is distributed under the terms of Article $25 \mathrm{fa}$ of the Dutch Copyright Act, indicated by the "Taverne" license above, 


\title{
Transcriptional Control of
}

\section{Cardiac Fatty Acid Metabolism}

\author{
by PPARs
}

Transcriptie Regulatie van Vetzuur Metabolisme door PPARs in het Hart 
Printed by Ponsen \& Looijen B.V. Wageningen

ISBN 90-6464-875-1

Design: Andries Gilde, Maastricht 2004 


\section{Transcriptional Control of Cardiac Fatty Acid Metabolism by PPARs}

\section{PROEFSCHRIFT}

ter verkrijging van de graad van doctor aan de Universiteit Maastricht, op gezag van de Rector Magnificus, Prof. mr. G.P.M.F. Mols volgens het besluit van het College van Decanen, in het openbaar te verdedigen op vrijdag 1 oktober 2004 om 12.00 uur

door

Andries Jan Gilde 


\section{Promotor:}

Prof. dr. G.J. van der Vusse

\section{Copromotor:}

Dr. M. van Bilsen

\section{Beoordelingscommissie:}

Prof. dr. H.A.J. Struijker Boudier (voorzitter)

Prof. dr. T.W.A. de Bruin

Prof. dr. ir. A.M.W.J. Schols

Prof. dr. L.H. Snoeckx

Prof. dr. B. Staels (Institut Pasteur de Lille, France)

The studies described in this thesis were supported by a grant of the Netherlands Heart Foundation (NHF-1998T015). Financial support by the Netherlands Heart Foundation for the publication of this thesis is gratefully acknowledged.

Financial support by GlaxoSmithKline for the publication of this thesis is gratefully acknowledged. 
The greatest obstacle to discovery is not ignorance-it is the illusion of knowledge. Daniel J Boorstin 


\section{CO-AUTHORS}

Marc van Bilsen, Department of Physiology, CARIM, Maastricht University, The Netherlands.

Karin AJM van der Lee, Department of Pbysiology, CARIM, Maastricbt University, The Netherlands.

Martijn Lindhout, Department of Physiology, CARIM, Maastricht University, The Netherlands.

Pascal Smeets, Department of Physiology, CARIM, Maastricht University, The Netherlands.

Ger J van der Vusse, Department of Pbysiology, CARIM, Maastricht University, The Netherlands.

Peter HM Willemsen, Department of Physiology, CARIM, Maastricht University, The Netberlands.

Joris Hoeks ${ }^{2}$, Departments of Human Biology, NUTRIM,.Maastricht University, The Netherlands.

Patrick Schrauwen ${ }^{2}$, Departments of Human Biology, NUTRIM,.Maastricht University, The Netherlands.

Matthijs KC Hesselink ${ }^{3}$, Movement Sciences, NUTRIM,.Maastricht University, The Netberlands.

Carley R Benton ${ }^{4}$, Department of Kinesiology, University of Waterloo, Ontario, Canada.

Arend Bonen ${ }^{5}$, Department of Human Biology and Nutritional Sciences, University of Guelph, Ontario, Canada.

Giulia Chinetti ${ }^{6}$, U 545 INSERM, Département d'Athérosclerose, Institut Pasteur de Lille and Faculté de Pharmacie, Université de Lille 2, France..

Bart Staels' ${ }^{6}$, 545 INSERM, Département d'Athérosclerose, Institut Pasteur de Lille and Faculté de Pharmacie, Université de Lille 2, France.

Feike $\mathbf{R}$ van der Leij ${ }^{7}$, Department of Pediatrics, Beatrix Children's Hospital, University of Groningen, the Netherlands. 


\section{CONTENTS}

CHAPTER 1.

General Introduction

CHAPTER 2.

Peroxisome Proliferator Activated Receptors (PPARs):

regulators of gene expression in heart and skeletal muscle

CHAPTER 3.

PPAR-dependent and PPAR-independent changes in cardiac gene expression

CHAPTER 4.

$\alpha_{1}$-Adrenergic and Thyroid Hormone-induced phenotypic and metabolic alterations in neonatal cardiomyocytes

CHAPTER 5.

PPAR $\alpha$ and PPAR $\beta / \delta$, but not PPAR $\gamma$, modulate the expression of genes involved in cardiac lipid metabolism

CHAPTER 6.

Differential promoter regulation by PPAR isoforms in cardiomyocytes and HEK293 cells

CHAPTER 7.

General Discussion

SUMMARY

SAMENVATTING

DANKWOORD 



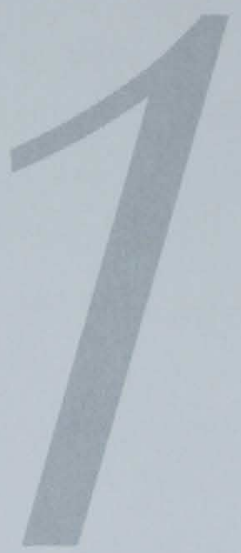

GENERAL INTRODUCTION 


\subsection{Fatty acids and cardiac energy conversion}

The heart provides the body with oxygen-rich blood via the systemic circulation.

Nutrients reach the blood stream during post-prandial absorption from the small intestines or after release from adipocytes and liver. Like any other organ in the body also the cardiac muscle itself relies on oxygen and energy substrates to function properly. Blood flowing through the coronary arteries supplies these nutrients to the cardiomyocytes.

Roughly $65 \%$ of the energy generated by the heart originates from the oxidation of long-chain fatty acids (FA) and 30\% from glucose ${ }^{1,2}$. The remaining $5 \%$ is provided by lactate, amino acids, and ketone bodies. Figure 1 depicts the uptake and metabolic fate of FA inside the cardiomyocyte. In short, blood-borne FA either bound to albumin or released from the triacylglycerol core of lipoproteins, cross the endothelium and attached to albumin the interstitial compartment. When FA reach the plasma membrane of the cardiac muscle cell they either pass the membrane by means of diffusion ${ }^{3}$ or facilitated transport by certain membraneassociated proteins, among which Fatty Acid Translocase/CD364 (FAT/CD36). Inside the cell, FA readily bind to cytoplasmic Fatty Acid-Binding Protein (FABPc) facilitating their intracellular transport ${ }^{5}$. At the level of the mitochondrial outer membrane, Co-enzyme A (CoA) is attached to the carboxyl-group of FA by catalytic action of Acyl-CoA Synthetase (ACS). Thereafter, Muscle-type Carnitine Palmitoyl Transferase I and II (MCPT-I and MCPT-II) mediate the transport of the acyl chain across the mitochondrial inner membrane. In a sequence of enzymatic reactions referred to as $\beta$-oxidation acyl-CoA is degraded to acetyl-CoA. The acetyl units are oxidized in the citric acid cycle and respiratory chain to generate ATP2. Under normal conditions FA metabolism is tightly controlled in order to cope with fluctuations in cardiac energy demand.

\subsection{Regulation of cardiac fatty acid metabolism}

Since FA metabolism is closely linked to energy demand of the heart, and mismatch between FA supply and utilization readily results in intracellular accumulation of FA or their derivatives ("lipotoxicity") 6 , myocardial FA homeostasis is tightly regulated. As discussed above and shown in Figure 1.1, a number of different proteins are involved in the process of FA 
uptake and conversion, providing multiple opportunities to regulate FA metabolism. In general, acute and chronic regulatory mechanisms have to be considered.

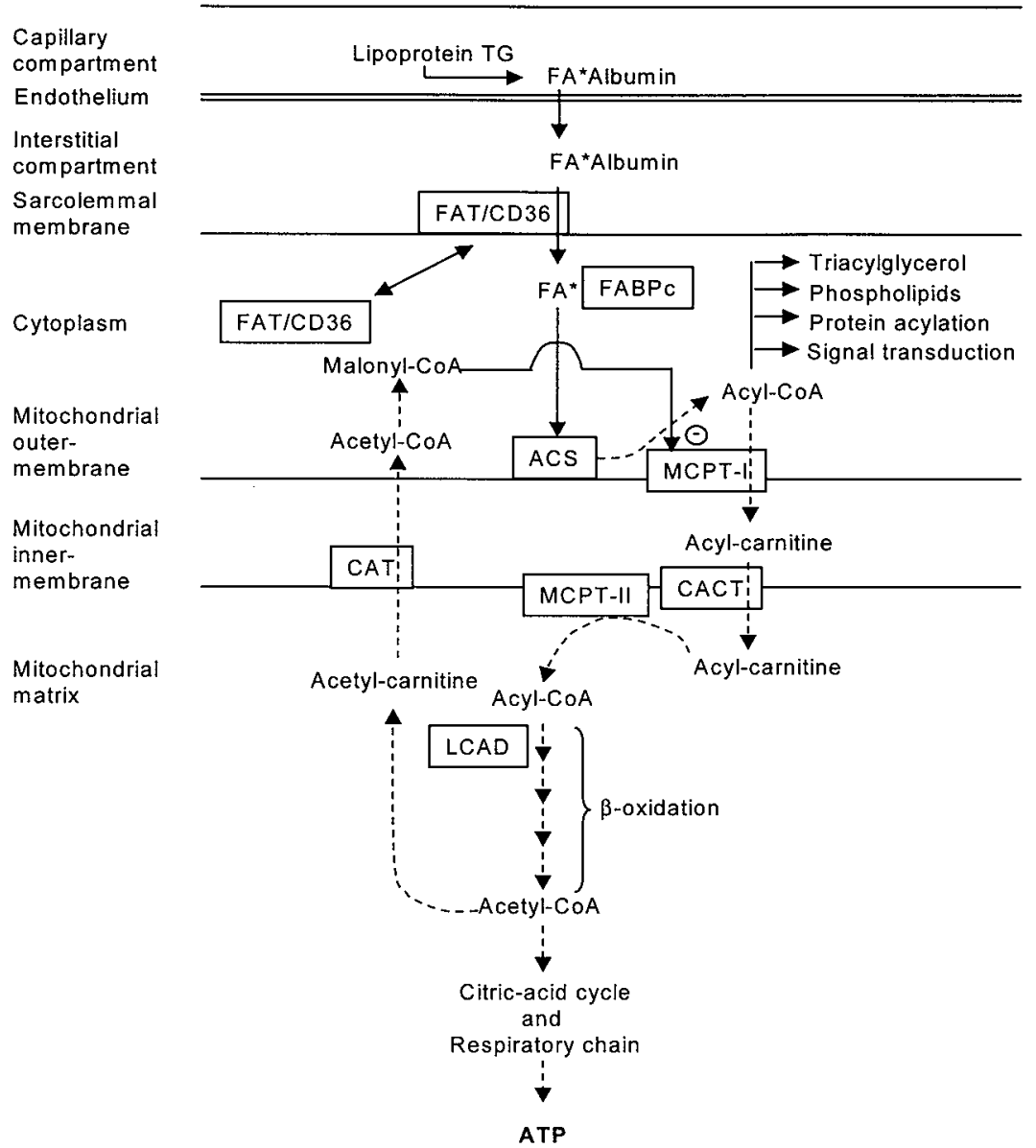

Figure 1.1

Uptake and metabolism of long-chain fatty acids (FA) in the cardiomyocyte.

Abbreviations used: triacylglycerol (TG), Fatty Acid Translocase/CD36 (FAT), cytoplasmic Fatty Acid-Binding Protein (FABPc), Co-enzyme A (CoA), Acyl-CoA Synthetase (ACS), Muscle-type Carnitine Palmitoyl Transferase I and II (MCPT-I, MCPT-II), Carnitine/Acylcarnitine Translocase (CACD), Long-Chain-acyl-CoA Dehydrogenases (LCAD), Carnitine Acetyl Transferase (CAT), Adenosine Tri-Phosphate (ATP).

Acute regulation may occur at the level of uptake of FA from the extra-cellular compartment. Both increased blood plasma levels of FA and increased sarcolemmal presence of FAT/CD36 result in enhanced uptake of FA by the cardiac muscle cell ${ }^{7}$. FAT/CD36, like the glucose transport protein GLUT4, is located both in the plasma membrane and in 
cytoplasmic vesicles 8,9 . Hormonal stimulation, e.g. by insulin, and increased contractile activity translocate FAT/CD36 to the plasma membrane and, hence, increase the trans-sarcolemmal transport capacity for $F A^{8}$. Inside the cardiac myocyte $F A$ oxidation is modulated by the action of a number of (co-) factors. Increased cytoplasmic malonyl-CoA concentrations, for instance, negatively affect FA oxidation by inhibiting MCPT- ${ }^{10}$. Furthermore, the ratio $\mathrm{NAD}^{+} / \mathrm{NADH}$ is a potent regulator of $\beta$-oxidation activity ${ }^{2}$. FA oxidation can be inhibited by enhanced supply of competing substrates such as glucose, lactate and ketone bodies ${ }^{11}, 12$. The activity of transport proteins and enzymes can also be regulated by post-translational modification such as phosphorylation, glycosylation or acylation. Whether these modifications play a crucial role in the acute regulation of cardiac FA utilization is incompletely understood.

In the long-term regulation of myocardial FA metabolism is mainly achieved by up or down-regulation of the expression of proteins involved in the uptake and intracellular degradation of blood-borne $\mathrm{FA}^{13}$. This regulatory mechanism requires stimulation or repression of the rate of DNA transcription into mRNA and subsequent protein synthesis. Evidence has been obtained that Peroxisome Proliferator-Activated Receptors, PPARs, are involved in the expression of FA handling genes. PPARs are ligand-activated transcription factors belonging to the family of nuclear hormone receptors ${ }^{14}$. PPARs hetero-dimerize with the Retinoic $\mathrm{X}$ Receptor (RXR) to form a transcriptionally active complex (Fig. 1.2). In addition to the specific effect of ligands, the transcriptional activity of the PPAR/RXR dimer is subject to regulation by co-activator and co-repressor proteins. Since the latter proteins are involved in multiple transcriptional processes, the transcriptional activity mediated by PPAR can be manipulated via sequestration of the co-activators or co-repressors by other nuclear receptors.

Long-chain FA serve as natural ligands for the PPARs ${ }^{15,16}$. Accordingly, the heart is able to regulate FA metabolism at the transcriptional level by adjusting the availability of FA to the receptors. In other words, "FA begets FA metabolism"13, 17. It is, however, unknown whether increased availability of FA in blood plasma as a result of diabetes, fasting, or high-fat diet modulates the expression of FA handling genes to the same extent and whether differences exist in the response to enhanced FA load between organs with a high $\beta$-oxidation activity, such as liver and heart. In addition, it is largely unknown which of the three PPAR isoforms $(\alpha$, $\beta / \delta$, or $\gamma$ ) are involved in the transcriptional regulation of cardiac lipid metabolism. 


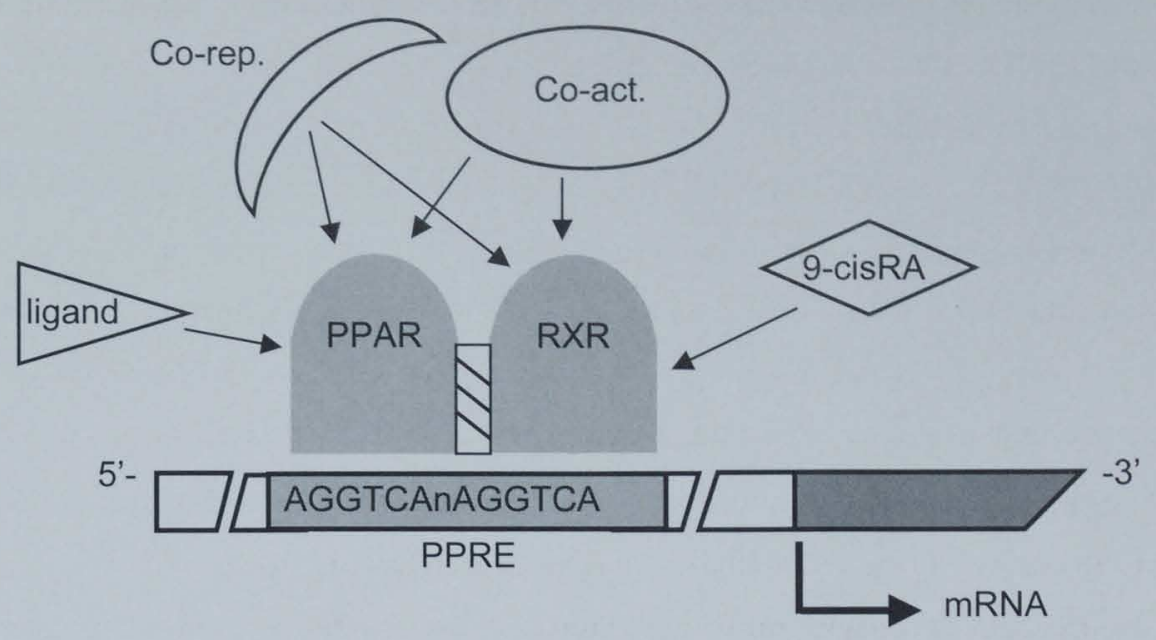

Figure 1.2

Schematic representation of transcriptional regulation by Peroxisome Proliferator-Activated Receptors (PPARs).

Abbreviations used: Peroxisome Proliferator-Activated Receptor (PPAR), Retinoic X Receptor (RXR), 9-cis-retinoic acid (9cisRA), PPAR Responsive Element (PPRE), co-repressor (co-rep.), co-activator (co-act.).

\subsection{Relationship between fatty acid metabolism and cardiac bypertrophy and failure}

In general, cardiac hypertrophy is an adaptation of the heart to prolonged hormonal or hemodynamic changes due to hypertension or regional cardiac infarction, and may be a prelude towards the development of overt heart failure. Since cardiomyocytes have lost the ability of cell division, the increase in heart mass is due to hypertrophic growth of individual cardiomyocytes which is stimulated by increased mechanical load, and/or neurohumoral and auto/paracrine factors, such as angiotensin II, catecholamines, endothelin-1, and triiodothyronine ${ }^{18}$. Cardiac hypertrophy and failure, among others, are characterised by alterations in substrate metabolism ${ }^{19}, 20$. While the normal heart heavily relies on FA oxidation for its energy, the current paradigm reads that the hypertrophic and failing heart has shifted from FA to glucose as a principal energy source ${ }^{21}$. It has been suggested that this nutritional shift contributes to impaired energy conversion in the affected heart and to a decline in mechanical performance. It is, however, unclear which mechanism is underlying the shift in nutrient utilisation and to what extent the decline in FA oxidation is a causal factor in the 
progression from hypertrophy to failure. Moreover, the significance of PPARs in this process is incompletely understood.

\subsection{Objectives of this thesis}

On basis of the uncertainties mentioned above and lack of information on important aspects of the role of PPAR in FA homeostasis in the normal and hypertrophied/failing heart, the following aims were addressed in the present thesis.

- To obtain insight in the effect of increased supply of FA to heart on the expression of FA handling genes.

- To explore the involvement of the transcriptional regulator PPAR in modulating gene expression and FA oxidation in in vitro models of cardiac hypertrophy.

- To study the role of the three PPAR isoforms, $\operatorname{PP} A R \alpha, \operatorname{PPAR} \beta / \delta$, and PPAR $\gamma$, in gene expression and FA oxidation in the cardiac context.

- To investigate the mechanisms underlying the regulatory effects of PPAR $\alpha$ and PPAR $\beta / \delta$ on the promoter of MCPT-1, a key enzyme in cardiac FA utilization.

\subsection{Outline of this thesis}

- The current chapter is an introduction describing the significance of F $\Lambda$ metabolism for the normal and hypertrophied/failing heart with special reference to the role of PPAR therein. The objectives of the study are described and the outline of the thesis is presented.

- In Chapter 2 the state of the art concerning the involvement of PPAR in transcriptional regulation in heart and skeletal muscle is reviewed.

- Chapter 3 presents information about the transcription of genes involved in $\mathrm{F} \Lambda$ and glucose handling in the heart of in vivo models which are hallmarked by alterations in FA supply i.e. fasting, Streptozotocin-induced Type I diabetes, high-fat feeding with long-chain or medium-chain FA, and treatment with the synthetic $P P \Lambda R \alpha$ ligand $W_{y}-14,643$. 
- Chapter 4 summarizes the alterations in expression of FA handling genes and FA metabolism in two distinct in vitro models for cardiac hypertrophy, i.e., chronic exposure to

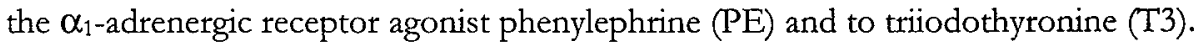

- Chapter 5 elucidates the role of the three PPAR isoforms in transcriptional regulation and FA metabolism in the neonatal rat cardiomyocyte.

- In Chapter 6 the results of a preliminary study regarding the transcriptional regulation of the MCPT-1 promoter by PPAR $\alpha$ and PPAR $\beta / \delta$ are presented. Possible differences in coactivator requirement are investigated in both cardiomyocytes and non-cardiomyocytes.

- This thesis ends with a General Discussion (Chapter 7), in which the experimental findings obtained are placed in a broader perspective and future lines of research are formulated. 


\section{REFERENCES}

1. Taegtmeyer $\mathrm{H}$, Hems $\mathrm{R}$ and Krebs HA. Utilization of energy-providing substrates in the isolated working rat heart. Biochem J. 1980;186:701-711.

2. Van der Vusse GJ, Glatz JFC, Stam HCG and Reneman RS. Fatty acid homeostasis in the normoxic and ischemic heart. Pbysiol Rev. 1992;72:881-940.

3. Hamilton JA and Kamp F. How are free fatty acids transported in membranes? Is it by proteins or by free diffusion through the lipids? Diabetes. 1999;48:2255-2269.

4. Bonen A, Dyck DJ and Luiken JJ. Skeletal muscle fatty acid transport and transporters. Adv Exp Med Biol. 1998;441:193-205.

5. Glatz JF and Storch J. Unravelling the significance of cellular Fatty Acid-Binding Proteins. Curr Opin Lipidol. 2001;12:267-274.

6. Unger RH. Lipotoxic diseases. Annu Rev Med. 2002;53:319-336.

7. Van der Vusse GJ, van Bilsen $M$ and Glatz JFC. Cardiac fatty acid uptake and transport in health and disease. Cardiovasc Res. 2000;45:279-293.

8. Luiken JJ, Dyck DJ, Han XX, Tandon NN, Arumugam Y, Glatz JF and Bonen A. Insulin induces the translocation of the Fatty Acid Transporter FAT/CD36 to the plasma membrane. Am J Pbysiol. 2002;282:E491-495.

9. Luiken JJ, Coort SL, Willems J, Coumans WA, Bonen A, van der Vusse GJ and Glatz JF. Contraction-induced Fatty Acid Translocase/CD36 Translocation in rat cardiac myocytes is mediated through AMP-Activated Protein Kinase signaling. Diabetes. 2003;52:1627-1634.

10. McGarry JD. Malonyl-CoA and Carnitine Palmitoyltransferase I: An expanding partnership. Biochem Soc Trans. 1995;23:481-485.

11. Taegtmeyer H, McNulty $\mathrm{P}$ and Young ME. Adaptation and Maladaptation of the heart in diabetes: Part I: General Concepts. Circulation. 2002;105:1727-1733.

12. Van der Vusse GJ and de Groot MJ. Interrelationship between Lactate and cardiac fatty Acid metabolism. Mol Cell Biochem. 1992;116:11-17.

13. Van Bilsen M, van der Vusse GJ and Reneman RS. Transcriptional regulation of metabolic processes: Implications for cardiac metabolism. Pflügers Arch. 1998;437:2-14.

14. Desvergne B and Wahli W. Peroxisome Proliferator-Activated Receptors: nuclear control of metabolism. Endocrine Rev. 1999;20:649-688.

15. Krey G, Braissant O, L-Horset F, Kalkhoven E, Perroud M, Parker MG and Wahli W. Fatty Acids, Eicosanoids, and Hypolipidemic Agents identified as ligands of Peroxisome Proliferator-Activated Receptors by coactivator-dependent receptor ligand assay. Mol Endocrinol. 1997;11:779-791.

16. Van Bilsen M, van der Vusse GJ, Gilde AJ, Lindhout $M$ and van der Lee KA. Peroxisome Proliferator-Activated Receptors: lipid binding proteins controling gene expression. Mol Cell Biochem. 2002;239:131-138.

17. Van der Lee KAJM, Vork MM, De Vries JE, Willemsen PHM, Glatz JFC, Reneman RS, Van der Vusse GJ and Van Bilsen M. Long-chain fatty acid-induced changes in gene expression in neonatal cardiac myocytes. J Lipid Res. 2000;41:41-47.

18. Hefti MA, Harder BA, Eppenberger HM and Schaub MC. Signaling pathways in cardiac myocyte hypertrophy. J Mol Cell Cardiol. 1997;29:2873-2892.

19. Allard MF, Schonekess BO, Henning SL, English DR and Lopaschuk GD. Contribution of oxidative metabolism and glycolysis to ATP production in hypertrophied hearts. Am J Pbysiol. 1994;267:H742-H750.

20. Van Bilsen M, Smeets PJ, Gilde AJ and van der Vusse GJ. Metabolic remodelling of the failing heart: The Cardiac Burn-out Syndrome? Cardiovasc Res. 2004;61:218-226.

21. Taegtmeyer H. Energy metabolism of the heart: From basic concepts to clinical applications. Curr Probl Cardiol. 1994;19:59-113. 


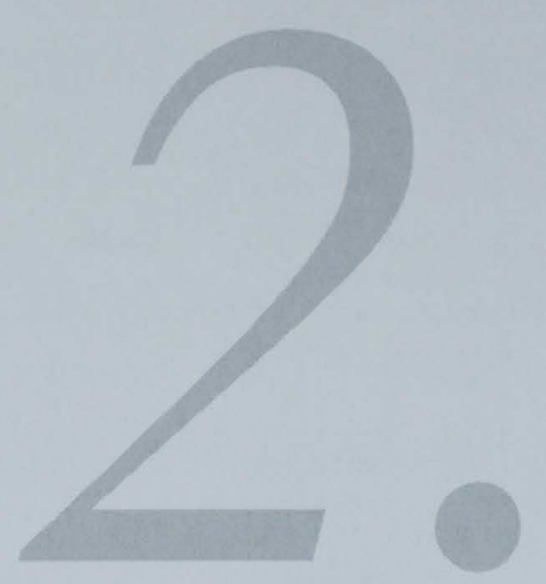

PEROXISOME PROLIFERATOR-ACTIVATED RECEPTORS (PPARs): REGULATORS OF GENE EXPRESSION IN HEART AND SKELETAL MUSCLE

Andries J. Gilde and Marc van Bilsen

Acta Physiologica Scandinavica 2003;178:425-434 


\subsection{ABSTRACT}

The Peroxisome Proliferator-Activated Receptors (PPARs) are members of the nuclear hormone receptor superfamily. The three isoforms $(\operatorname{PPAR} \alpha, \beta / \delta$ and $\gamma$ ) have been implicated in the regulation of the expression of genes involved in lipid metabolism. Although their prominent tole in lipid homeostasis is well established, the way in which the activity of each of the PPAR isoforms is regulated under physiological and pathological conditions is still subject of intensive research. In skeletal as well as cardiac muscle cells it has been demonstrated that the expression of a large panel of proteins involved in the transport and metabolic conversion of fatty acids is under control of PPARs. The pivotal role of the PPAR $\alpha$ isoform in cardiac fatty acid metabolism has been confirmed in PPAR $\alpha$-null mice. The exact role of PPAR $\beta / \delta$ in the regulation of muscle metabolism is still a matter of debate. Whereas several studies provided evidence to support the notion that $\operatorname{PPAR} \alpha$ and $\operatorname{PPAR} \beta / \delta$ have redundant roles, other studies suggest that PPAR $\alpha$ activity is counteracted by PPAR $\beta / \delta$. Marked effects of bona fide PPAR $\gamma$ ligands (the anti-diabetic thiazolidinediones) on skeletal and cardiac muscle function and phenotype, have also been reported. However, next to activating PPAR $\gamma$, the thiazolidinediones do affect other cellular processes as well. To date it is being realised that the control of the trans-activating capacity of each of the PPAR isoforms is multi-factorial and, in addition to ligand availability, depends on such factors as isoform-specific phosphorylation and selective interaction with various proteins acting either as co-activator or co-repressor. 


\subsection{INTRODUCTION}

In 1990 Issemann and Green ${ }^{1}$ reported the discovery of a ligand-activated transcription factor, that specifically interacted with drugs that were known to cause peroxisomal proliferation in liver. Accordingly this transcription factor was referred to as Peroxisome Proliferator-Activated Receptor (PPAR). Since the discovery of this PPAR, later referred to as $\operatorname{PPAR} \alpha$, two other PPAR isoforms have been cloned, i.e. PPAR $\beta / \delta$ (also called nuclear hormone receptor 1/ NUC-1 or Fatty Acid Activated Receptor / FAAR) and PPAR $\gamma$. Each isoform was found to be encoded by a different gene. The existence of splice variants of PPAR $\gamma$ and, more recently, of PPAR $\alpha$ has been demonstrated ${ }^{2,3}$. The splice variants of the $\gamma$ isoform, PPAR $\gamma 1$ and PPAR $\gamma 2$ respectively, are generated by alternative promoter usage and splicing. PPAR $\gamma 2$ is exclusively expressed in fat tissue and contains a 30 amino acids long extension at the $\mathrm{N}$-terminus ${ }^{2}$. The PPAR $\alpha$ splice variant lacks exon $6^{3}$. This gives rise to a premature stopcodon and, as a result, a truncated protein lacking a large part of the ligand binding region ${ }^{3}$. To date there is some controversy whether the truncated splice variant is expressed in all species,4. Furthermore, in the PPAR $\alpha$ and PPAR $\gamma$ genes several polymorphisms have been identified, some of which are linked to an altered phenotype ${ }^{5}$.

As the PPARs are members of the family of nuclear hormone receptors, like for instance the Thyroid hormone- and Retinoic Acid Receptor, they share a close structural homology (Fig. 2.1) ${ }^{6}$. The amino-terminal A/B domain is least conserved and includes a ligand-independent transactivation function (AF-1), containing putative phosphorylation sites. The DNA-binding domain is highly conserved and includes two zinc finger motifs. The carboxyl-terminal ligand-binding domain encompasses a ligand-dependent transactivation function (AF-2). In addition to ligand binding, this region is required for nuclear localisation, receptor dimerisation and the interaction with proteins acting as co-activators or repressors.

The PPARs form heterodimers with the Retinoid-X-Receptor (RXR)7. The PPAR/RXR heterodimer binds to a DNA consensus sequence, the so-called Peroxisome Proliferator Response Element (PPRE) or Fatty Acid Response Element (FARE). A PPRE is formed by a direct repeat of 6 nucleotides, separated by one spacer nucleotide (DR-1) and has the consensus sequence AGGTCA n AGGTCA, with PPAR and RXR each binding to one of the half-sites. 
By now a large number of genes encoding for proteins involved in lipid metabolism have been shown to be PPAR-responsive. This includes proteins directly involved in inter-organ lipid transport (apolipoproteins A-I, A-II, C-III), in lipid uptake (e.g. lipoprotein lipase, fatty acid translocase, fatty acid transport protein), and in fatty acid metabolism (e.g. Acyl-CoA Oxidase, Acyl-CoA Synthetase, Carnitine Palmitoyl-Transferase-I, Long-Chain Acyl-CoA Dehydrogenase). Other PPAR-responsive genes are the mitochondrial Uncoupling Proteins, Malonyl-CoA Decarboxylase and the Pyruvate Dehydrogenase Kinase isoform PDK48-10. Interestingly these gene products are thought to be involved in the regulation of the flux through, and cross talk between, the glucose and fatty acid metabolic pathways. For instance, by controlling the degree of phosphorylation of the Pyruvate Dehydrogenase (PDH) complex, PDK4 plays a regulatory role in the control of the flux of glucose metabolites into the mitochondria and, hence, indirectly in fatty acid oxidation rate. In this way crosstalk between glucose and fatty oxidation pathways, via PPAR, is being established.

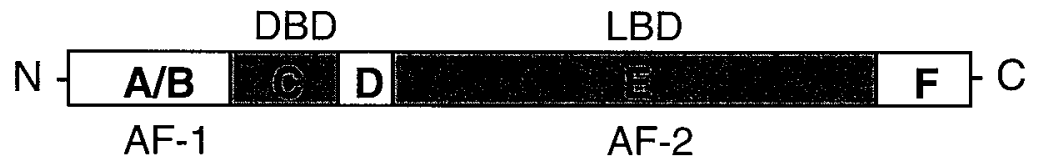

Figure 2.1

Schematic representation of the nuclear hormone receptor domain structure. The $\mathrm{N}$-terminal $\mathrm{A} / \mathrm{B}$ domain contains a ligand-independent transactivation function (AF-1). The $\mathrm{C}$ domain is the DNA-binding domain (DBD) consisting of two zinc fingers. The hinge region (D dom ain) allows the receptor to change conformation. The $E$ domain is the ligand -binding domain (LBD) and includes a ligand-dependent transactivation function ( $A F-2)$. The function of the $C$-terminal $F$ domain is unknown.

\subsection{PPAR ISOFORM EXPRESSION IN CARDIAC AND SKELETAL MUSCLE}

The expression of the three PPAR isoforms is tissue restricted. PPAR $\alpha$ is relatively abundant in tissues with a high oxidative capacity, like liver, kidney, and heart. PPAR $\gamma 1$ expression is confined to a limited number of tissues, primarily adipose tissue, and vascular cells. In contrast, the expression of $\operatorname{PPAR} \beta / \delta$ appears to be ubiquitous. 
The presence of both PPAR $\alpha$ and PPAR $\beta / \delta$ in the cardiac muscle has been firmly established. Whether or not PPARy is being expressed in cardiac muscle cells has been controversial ${ }^{11-14}$, suggesting that, if present at all, the amount of PPAR $\gamma$ in these cells is probably low. In line with this notion the detection of PPAR $\gamma$ mRNA in isolated cardiac myocytes was not possible by conventional northern blotting, but required more sensitive techniques such as RT-PCR. Recently Escher et al.15 used RNAse protection to determine expression levels of the three PPAR isoforms in a large variety of organs from adult rats. Using intact tissue (containing muscle cells as well as non-muscle cells) as a source of RNA these investigators showed that in both cardiac and skeletal muscle all three isoforms could be detected. Within both striated muscle types the relative expression levels of the three isoforms were in the following ranking order: $\operatorname{PPAR} \beta / \delta>\operatorname{PPAR} \alpha>\operatorname{PPAR} \gamma$. As mentioned earlier PPAR $\gamma 2$ is considered to be adipocyte specific. Nevertheless, the presence of both the $\gamma 1$ and $\gamma 2$ splice variant in muscle has been reported ${ }^{16}$ and the apparent correlation between the level of PPAR $\gamma$ expression in skeletal muscle and obesity and Type II diabetes ${ }^{17}$ could indicate that part of the PPAR $\gamma$ detected is derived from adipocytes within the muscle. Alternatively, expression of PPAR $\gamma$ within skeletal muscle fibres might be enhanced under certain conditions. In this respect the ability of skeletal muscle cell lines to transdifferentiate into adipocyte-like cells expressing adipocyte-specific genes as the adipocyte-type FABP when cultured under specific conditions is noteworthy ${ }^{18}$. In addition, immunohistochemical analysis also indicated that PPAR $\gamma$ is clearly present in the nuclei of muscle fibres ${ }^{19}$.

Regarding potential differences in PPAR isoform expression between red and white muscle fibres the information available is scanty. Zierath and co-workers ${ }^{19}$ observed no apparent differences in PPAR $\gamma$ immunostaining between red soleus muscle and the white part of gastrocnemius muscle. In contrast PPAR $\alpha$ expression was found to be more prominent in red soleus than in white vastus lateralis muscle as assessed by western blotting ${ }^{20}$. The latter observation is consistent with the notion that red muscle relies more heavily on fatty acids as an energy source. Collectively, the data available suggest that all three PPAR isoforms are present in skeletal and cardiac muscle cells, implying that each isoform could potentially play a role in the regulation of muscle metabolism. 


\subsection{REGULATION OF THE TRANS-ACTIVATING ACTIVITY OF PPARs}

The original concept that ligand availability is the sole and primary factor controlling the activity of PPAR has been replaced in recent years. By now it is being recognized that the activity of each PPAR isoform is controlled at various levels. Not only the availability of activating and inhibitory ligands, but also competition for the mutual dimerisation partner RXR and for PPRE-sites, the recruitment of co-activators and repressors, and the degree of phosphorylation, are factors that ultimately determine the rate of transcription of PPREcontaining genes.

\subsubsection{Natural ligands}

As $\operatorname{PPAR} \alpha$ was initially characterised as a nuclear receptor for fibrate-like drugs ${ }^{1}$, the quest began for the identification of their bona fide ligands. Even now this issue is still not completely settled and several questions remain. Since the pioneering studies of Gottlicher et al. ${ }^{21}$ which showed that long-chain fatty acids trans-activate PPAR $\alpha$, the question whether long-chain fatty acids do function as bona fide ligands has been subject of intensive research. By now a wealth of in vitro studies have demonstrated that a large variety of long-chain fatty acids and fatty acid derivatives, including fatty acid methyl esters, hydroxylated fatty acids, branched-chain fatty acids like phytanic acid, leukotriens and prostaglandins, are able to interact with the PPARs. The broad spectrum of compounds that are able to bind to the PPARs points to a limited ligand specificity of this class of nuclear hormone receptors. Crystallographic studies have resolved the 3-D structure of the ligand binding pocket of each of the PPAR isoforms and confirm that the ligand-binding pockets can accommodate many sorts of lipophilic compounds.

The capacity of individual fatty acid species, differing in chain length and/or degree of saturation, to act as ligands for the three PPAR isoforms has received widespread attention ${ }^{21-26 .}$ Generally speaking these in vitro studies demonstrate that both long-chain saturated, mono- and poly-unsaturated fatty acids bind to $\operatorname{PPAR} \alpha$ and $\operatorname{PPAR} \beta / \delta$ with more or less comparable affinity. In contrast, PPAR $\gamma$ clearly has a very low affinity for saturated fatty acids, making it unlikely that these fatty acid species act as ligands ${ }^{24-26}$. Actually, the prostaglandin J2 
derivative15-deoxy- $\Delta 12,14-\mathrm{PGJ} 2$ has been postulated as the natural ligand of the PPAR $\gamma$ receptor ${ }^{27}$.

Of course, the mere observation that interaction between a certain compound and a receptor protein has been established in vitro, can not be taken as evidence that the compound functions as a natural ligand. In order to act as a bona fide ligand the compound has to be present within the nucleus in sufficient amounts. It is important to realise that in the majority of studies the dissociation constants measured in vitro are in the micromolar rather than nanomolar range ${ }^{23,} 26,28,29$. It is doubtful whether, for instance, local fatty acid concentrations will ever reach such a high level in vivo $0^{30}$. Accordingly, it has been put forward that transfer of fatty acids to PPAR in the nucleus has to be facilitated in some way, possibly by the intracellular fatty acid transporter FABP. In support of this hypothesis is the observation that FABPs are able to translocate to the nucleus ${ }^{31}$ and that FABPs have been shown to physically interact with PPARs $^{31,32}$. Alternatively, it is feasible that fatty acids or prostaglandins are generated locally, due to the action of phospholipases, rather than being derived from exogenous sources. It was shown recently that activation of the $85 \mathrm{kDa}$ cytosolic Phospholipase $A_{2}$ increased PPAR $\alpha$ activity in liver cells ${ }^{33}$. Interestingly, the activity of this phospholipase is subject to tight control by several kinases and the phospholipase is known to translocate from cytosol to nucleus following a rise in intracellular calcium concentration.

It is noteworthy that all of the fatty acids and fatty acid derivatives mentioned earlier function as PPAR agonists. Recent studies ${ }^{34,35}$ indicate that long-chain acyl-CoA esters also interact with PPAR $\alpha$. Interestingly, they were shown to act as inhibitors instead of activators. In vitro studies indicated that the inhibitory effect of acyl-CoA esters on PPAR $\alpha$ activity was due to their ability to promote recruitment of the co-repressor protein $\mathrm{NCoR}^{34}$. It is tempting to speculate that the ratio between fatty acids and fatty acyl-CoA esters, working as agonists and antagonists respectively, may determine the trans-activating activity of PPAR $\alpha$ within the cell.

\subsubsection{Synthetic ligands}

Two classes of PPAR ligands are currently being applied in the treatment of metabolic disorders. The fibrates (e.g. Ciprofibrate), the classical peroxisome proliferators, act as ligands 
for the PPAR $\alpha$ isoform and are being prescribed for the treatment of hyperlipidemia. Their primary target organ is the liver. The thiazolidinediones (TZDs), specific synthetic activators for PPAR $\gamma$, have been shown to have insulin sensitising properties and are successfully being used in the treatment of Type 2 diabetes. First it was believed that TZDs acted primarily on adipose tissue and that the effects on other tissues were secondary to an improved metabolic milieu. By now, it is generally accepted that the beneficial effect of TZDs also includes direct effects on pancreas and skeletal muscle, although the exact mechanism of action has not been completely elucidated.

In preclinical studies the isoform-specific ligands have been proven useful as tools to unravel the biological roles of each of the PPAR isoforms. Several specific synthetic ligands for PPAR $\beta / \delta$ have also been developed recently ${ }^{36}$. Notwithstanding the specificity of the synthetic ligands, it should be realised that at higher concentration (micromolar range) some of the drugs become less selective ${ }^{37}$. Moreover, PPAR-independent effects of the ligands have also been reported. For the TZDs (as well as the presumed natural ligand, prostaglandin J2 derivative15deoxy- $\Delta 12,14-$ PGJ2), a large body of evidence has accumulated that shows that these drugs also modulate the inflammatory response via the NF- $\mathrm{KB}$ pathway. The most convincing evidence illustrating this point is that the anti-inflammatory effect of TZDs can still be demonstrated in PPAR $\gamma$-deficient macrophages ${ }^{38}$. Furthermore, several TZDs were shown to activate MAP kinases independent of PPAR $\gamma^{39}$. These features of the TZDs should be taken into account in studies aimed at assessing the biological significance of PPAR $\gamma$.

\subsubsection{PPAR expression levels}

As discussed earlier PPAR $\alpha, \operatorname{PPAR} \beta / \delta$ as well PPAR $\gamma$ are all present in normal skeletal and cardiac muscle, albeit in different amounts. The tissue contents of these isoforms are likely to vary under physiological and pathological conditions. In rats it was shown that the cardiac PPAR $\alpha$ mRNA level shows diurnal variation, expression levels varying by almost 2 -fold and peaking in the dark phase ${ }^{40}$. The levels of expression of several PPAR-responsive genes varied accordingly, suggesting that this variation is of functional significance in the regulation of cardiac energy metabolism. In the pressure-overloaded hypertrophied heart PPAR $\alpha$ levels are reduced. Interestingly under various pathological conditions the diurnal variation in cardiac 
PPAR $\alpha$ levels was largely abolished ${ }^{40}$. To our knowledge it is unknown whether PPAR $\beta / \delta$ and $\operatorname{PPAR} \gamma$ are also subject to diurnal variation and whether they behave similarly in skeletal muscle.

The truncated PPAR $\alpha$ has been shown to act in a dominant negative fashion, most likely by sequestering co-activators ${ }^{3}$. It is tempting to speculate that the relative amounts of PPAR $\alpha$ splice variants determine the response of PPRE-containing genes and that changes in expression of the two splice variants allow for one level of transcriptional control. Previously we showed the truncated splice variant of PPAR $\alpha$ to be present in human, but not in rat cardiac tissue ${ }^{41}$. By transient transfection of neonatal cardiac myocytes using the PPARresponsive MCPT-1 promoter as read-out, we indeed showed that the stimulatory effect of the full length PPAR $\alpha$ could be diminished by adding increasing amounts of the truncated PPAR $\alpha$ (Fig. 2.2).

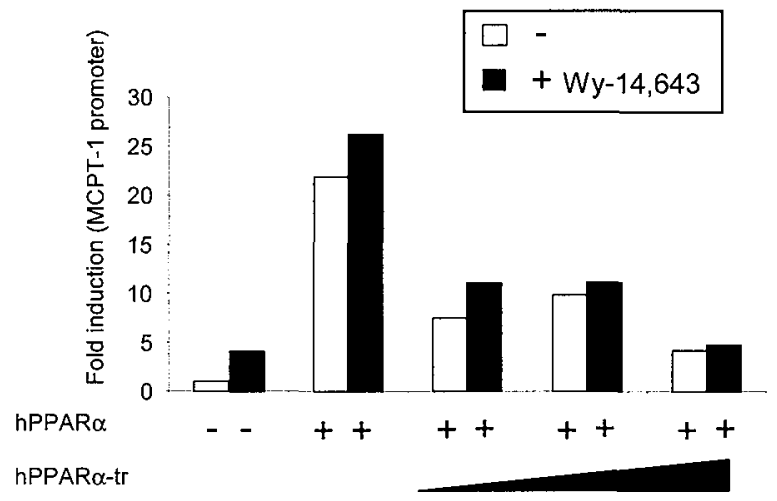

Figure 2.2

The truncated human PPAR $\alpha$ splice variant counteracts the transcriptional activity of the full length human PPAR $\alpha$ on the human muscle-type CPT-1 promoter. Neonatal cardiomyocytes were transiently transfected with MCPT-1/luciferase reporter vector and with a full-length human PPAR $\alpha$ expression vector (hPDAR $\alpha$ ) in the absence or presence of $10 \mu M$ of

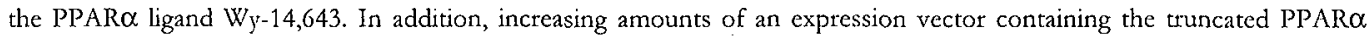
splice variant (hPPAR $\alpha$-tr) were added. The total amount of vector DNA added was kept constant by adding appropriate amounts of empty expression vector.

\subsubsection{Other nuclear hormone receptors}

As several other nuclear hormone receptors also require RXR for dimerisation, it is feasible that the amounts of RXR are limiting under certain conditions. For instance, under 
hypoxic conditions $R X R \alpha$ is rapidly degraded and this mechanism is considered to be involved in reducing the rate of transcription of PPAR responsive genes ${ }^{42}$. Cross-talk between nuclear hormone receptors via RXR was demonstrated by means of transfection studies where PPAR was shown to decrease the activity of thyroid hormone receptor and visa versa ${ }^{43-45}$. In addition to competition for RXR among nuclear receptors, evidence has been provided that some of the nuclear receptors also interact with the PPAR DNA-binding site. The transcription factor COUP-TF (Chicken Ovalbumin Upstream Promoter Transcription Factor) avidly binds to consensus PPRE sequences and thereby represses transcriptional activity ${ }^{46,} 47$. Accordingly, PPARs and COUP-TF have opposing effects on the transcription of PPRE-containing genes. Interestingly, the postnatal rise in cardiac fatty acid oxidation is associated with a decrease in COUP-TF and a rise in PPAR $\alpha$ expression.

\subsubsection{Co-activator and co-repressor proteins}

The PPAR/RXR complex is known to interact with various other proteins, that either stimulate (co-activators) or inhibit (co-repressors) transcriptional activity (for review see ${ }^{48}$ ). These co-factors interact both with nuclear receptors and basal transcription factors, and in this way affect the rate of assembly of the basal transcription initiation complex. Furthermore, some co-factors possess intrinsic histone acetyl-transferase activity and thereby influence the accessibility of PPAR target genes. Co-activators that interact with PPARs include the Steroid Receptor Co-activator SRC-1, the PPAR Binding Protein (PBP), the PPAR $\gamma$ Co-activators PGC-1 and PGC-2, and the integrator protein p30049-52. Co-repressors for PPARs include the Receptor-Interacting Protein-140 (RIP-140), the Silencing Mediator of Retinoid and Thyroid receptors (SMRT), and the Nuclear receptor Co-Repressor $(\mathrm{NCoR})^{53-55}$. There are indications that their interaction with the PPARs is isoform dependent, although literature on this subject is not entirely consistent. For instance, first it was reported that NCoR did not affect PPAR $\gamma$ activity, but repressed PPAR $\alpha$ activity ${ }^{55}$, 56. In a recent study, however, the interaction of NCoR with PPAR $\gamma$ was found to be stronger than with PPAR $\alpha^{57}$. In this study the interaction with $\operatorname{PPAR} \beta / \delta$ turned out to be the strongest.

The recruitment of co-factors can be ligand dependent or in-dependent, depending on co-factor as well as PPAR isoform. In its simplest form a model can be envisioned in which co- 
repressors interact with the PPAR/RXR dimer in its unliganded state, thereby keeping the complex inactive. Ligand binding results in a conformational change, preferring replacement of co-repressor by co-activator proteins. This results in the induction of PPAR-mediated expression. However, there clearly are exceptions to this rule. For instance, the interaction of the co-activator PGC-1 with PPAR $\gamma$ was found to be ligand in-dependent, whereas its interaction with PPAR $\alpha$ was found to be ligand dependent ${ }^{58}$. The role of PGC-1 has received much attention as it is relatively abundant in heart and slow-twitch skeletal muscle 59,60 and interacts with several other nuclear hormone receptors, including the Nuclear Respiratory Factors NRF-1 and NRF-2 that are important for mitochondrial biogenesis. In fact the predominant phenotypic feature of mice with forced overexpression of PGC-1 was an uncontrolled mitochondrial proliferation resulting in cardiomyopathyo ${ }^{61}$ In liver PGC-1 expression has been shown to be strongly stimulated by cAMP62 suggesting that this second messenger affects PPAR transcriptional activity via PGC-1. The question whether similar mechanisms are operative in skeletal or cardiac muscle remains to be answered.

\subsubsection{Phosphorylation}

The activity of PPARs can be modulated by phosphorylation. Phosphorylation affects the trans-activating capacity of PPARs and the process may be influenced by ligand binding 63 , 64. Both PPAR $\gamma$ and PPAR $\alpha$ have been shown to be phosphorylated via Mitogen-Activated Protein Kinases (MAPKs) ${ }^{65}$. The p38-MAPK was shown to phosphorylate serine residues in the $\mathrm{N}$-terminal region of PPAR. This resulted in an enhanced PPAR $\alpha$ activity in cardiac muscle ${ }^{66}$. Paradoxically, the phosphorylation of PPAR $\alpha$ by MAPKs of the ERK family apparently repressed PPAR $\alpha$ activity ${ }^{67}$.

To summarize, the multi-level control of PPAR activity probably ensures fine-tuning and adjustment of lipid metabolism to variations in energy demand. 


\subsection{REGULATION OF SKELETAL AND CARDIAC MUSCLE METABOLISM BY PPARs}

Exercise training increases fatty acid oxidation capacity in skeletal muscle, a response that is associated with an enhanced expression of proteins involved in fatty acid uptake and metabolism ${ }^{20,68}$. An obvious question is whether this response is mediated by PPARs and, if so, by which isoform(s). Treatment of animals with fibrates or TZDs, ligands for PPAR $\alpha$ and PPAR $\gamma$ respectively, has been shown to alter skeletal muscle metabolism and to alter the expression of genes involved in intermediary metabolism metabolism, such as FAT/CD36 and malonyl-CoA decarboxilase ${ }^{10,69}$. As the development of specific PPAR $\beta / \delta$ ligands has lagged behind, it is not yet known whether specific $\beta / \delta$ ligands exert similar effects on skeletal muscle. However, when interpreting these types of studies it is difficult to establish whether these effects represent a direct effect of the drugs on the muscle or whether this represents a secondary effect related to the altered metabolic milieu. In view of the fact that both PPAR $\alpha$, $\operatorname{PPAR} \beta / \delta$ and PPAR $\gamma$ are present in skeletal muscle cells it is likely that direct effects are involved. Circumstantial evidence to support this notion comes from studies reporting a relation between the level of PPAR $\alpha$ and PPAR $\gamma$ expression and the expression of genes involved in fatty acid oxidation ${ }^{20,70}$. More convincingly, the expression of PPAR responsive genes is enhanced when cultured skeletal muscle cells are incubated with fatty acids or specific synthetic ligands for $\operatorname{PPAR} \alpha, \operatorname{PPAR} \beta / \delta$ or $\operatorname{PPAR} \gamma^{71,72}$. Similar observations have been reported with primary cultures of neonatal cardiomyocytes, in which it was shown that fatty acids co-ordinately induce the expression of genes involved in fatty acid transport and metabolism ${ }^{73,74}$. Using transfection assays with CPT-1 promoter/reporter constructs it was subsequently shown that this response required a functional PPRE site ${ }^{75,76}$.

Interestingly, conditions in which plasma fatty acid levels are elevated, e.g. during fasting and in diabetes, are associated with an increased expression of various PPAR responsive genes. Hence, it is tempting to speculate that the increased levels of circulating fatty acids are sensed by PPARs in target tissues and directly responsible for the alterations in gene expression. Studies with PPAR $\alpha$ deficient mice have provided strong evidence for the involvement of PPAR $\alpha$ in cardiac gene expression. Under baseline conditions in the hearts of PPAR $\alpha(-/-)$ 
mice mRNA levels of MCPT-1, Long Chain Acyl-CoA Dehydrogenase (LCAD), Medium Chain Acyl-CoA Dehydrogenase (MCAD) and Acyl-CoA Oxidase (AOX) were found to be lower than in wild-type animals ${ }^{77}$. Furthermore, the fasting-induced rise in cardiac MCPT-1, MCAD, and AOX was nearly absent in PPAR $\alpha(-/-)$ mice $^{78}$. The latter findings provide compelling evidence for the regulatory role of PPAR $\alpha$ in the expression of genes encoding proteins involved in cardiac fatty acid metabolism. Recently, the PPAR $\alpha(-/-)$ mice were also used to investigate the role of this isoform in skeletal muscle metabolism ${ }^{79}$. First of all, it was noted that there were no obvious differences in fatty acid oxidation capacity and in PDK4 and UCP3 expression between skeletal muscle of PPAR $\alpha(-/-)$ and wildtype mice under base-line conditions. Second, the response to exercise and fasting was comparable in PPAR $\alpha(-/-)$ and wild type mice. Together with the observation that $\operatorname{PPAR} \beta / \delta$ is abundantly present is skeletal muscle, this led these investigators to conclude that in skeletal muscle PPAR $\beta / \delta$ largely compensates for the lack of PPAR $\alpha$ in the $-(-/-)$ mice. The notion that PPAR $\alpha$ and PPAR $\beta / \delta$ may have redundant functions is also supported by transient transfection studies with isolated neonatal cardiomyocytes. These studies revealed that PPAR $\alpha$ and PPAR $\beta / \delta$ ligands were both able to activate transcription of the MCPT-1 promoter, whereas PPAR $\gamma$ ligands were not (unpublished observations). Conversely, it has also been reported that in 3T3-L pre-adipocytes $\operatorname{PPAR} \beta / \delta$ acts as a potent repressor of PPAR $\alpha$-mediated transcription. Future studies with $\operatorname{PPAR} \beta / \delta$ deficient mice might be helpful to resolve this issue. As homozygous PPAR $\gamma(-/-)$ mice are not viable and the heterozygous PPAR $(+/-)$ mice have a very complex phenotype, the traditional knockout approach can not be used to fully unravel the role PPAR $\gamma$ in heart and skeletal muscle.

Finally it should be mentioned that fatty acids might affect gene expression independent of PPARs. In neonatal myocytes endogenous heart-type FABP (H-FABP) expression is induced by fatty acids and PPAR $\alpha$ ligands, but in transient transfection studies the H-FABP promoter, containing a potential PPRE consensus sequence, is not activated by any of the PPAR ligands, nor by co-expression of PPAR $\alpha$ (Fig. 2.3). This would imply that another (functional) PPRE must be located outside the promoter region investigated, or that alternative transcriptional mechanisms are involved. In this respect, it is interesting to note that another 
type of fatty acid response element, entirely different from the consensus PPRE sequence, has been identified in FABP genes ${ }^{80}$. This would suggest that fatty acid responsiveness could also be imparted via pathways not involving PPARs.

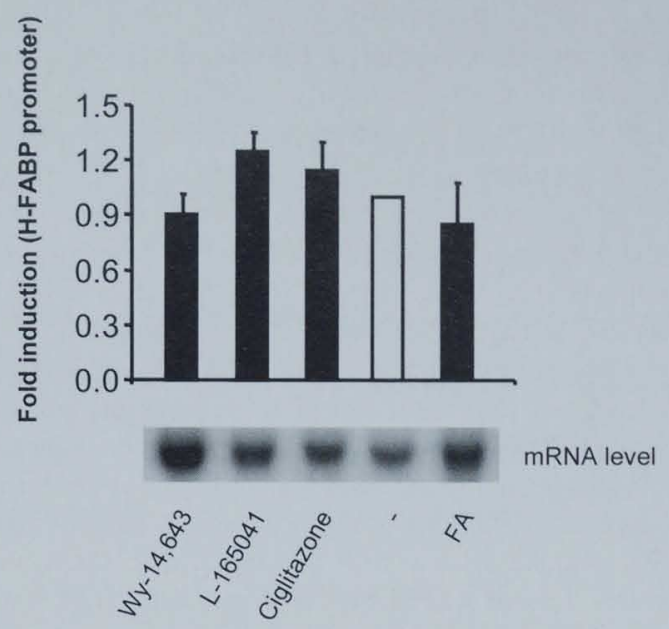

\section{Figure 2.3}

Expression of endogenous heart-type fatty acid binding protein (H-FABP) is increased after treatment of neonatal myocytes with $\mathrm{Wy}_{\mathrm{y}} 14,643$ or fatty acids (FA). Neonatal cardiomyocytes were incubated with fatty acids ( $500 \mu \mathrm{M}$, complexed to BSA) or with $10 \mu \mathrm{M}$ of the PPAR $\alpha$ ligand $W_{y}-14,643$, the PPAR $\beta / \delta$-ligand L-165041 or the PPAR $\gamma$-ligand Ciglitazone, respectively, as described previously ${ }^{74}$. Transient transfection with an $1.5 \mathrm{~kb} \mathrm{H-FABP}$ promoter/Chloramphenicol Acetyl Transferase reporter vector, containing a putative PPRE-site at position -845 , indicates that this promoter region is unresponsive to all interventions. Promoter activity is expressed relative to that of vehicle treated cells $(-)$, the level of which was arbitrarily set at 1.0 .

\section{Acknowledgements}

Supported by grants 97.092 and D98.015 from the Netherlands Heart Foundation. We would like to thank P. Willemsen for his help in preparing the manuscript. 


\section{REFERENCES}

1. Issemann I and Green S. Activation of a member of the steroid hormone receptor superfamily by Peroxisome Proliferators. Nature. 1990;347:645-650.

2. Fajas L, Auboeuf D, Raspe E, Schoonjans K, Lefebvre AM, Saladin R, Najib J, Laville M, Fruchart JC, Deeb S, Vidal Puig A, Flier J, Briggs MR, Staels B, Vidal H and Auwerx J. The organization, promoter analysis, and expression of the human PPAR $\gamma$ gene. J Biol Chem. 1997;272:18779-18789.

3. Gervois P, Torra IP, Chinetti G, Grötzinger T, Dubois G, Fruchart J-C, Fruchart-Najib J, Leitersdorf E and Staels B. A Truncated Human Peroxisome Proliferator-Activated Receptor- $\alpha$ splice variant with dominant negative activity. Mol Endocrinol. 1999;13:1535-1549.

4. Hanselman JC, Vartanian MA, Koester BP, Gray SA, Essenburg AD, Rea TJ, Bisgaier CL and Pape ME. Expression of the mRNA encoding truncated PPAR $\alpha$ does not correlate with hepatic insensitivity to peroxisome proliferators. Mol Cell Biochem. 2001;217:91-97.

5. Jamshidi Y, Montgomery HE, Hense HW, Myerson SG, Torra IP, Staels B, World MJ, Doering A, Erdmann J, Hengstenberg C, Humphries SE, Schunkert $H$ and Flavell DM. Peroxisome Proliferator-Activated Receptor- $\alpha$ gene regulates left ventricular growth in response to exercise and hypertension. Circulation. 2002;105:950-955.

6. Tsai MJ and O'Malley BW. Molecular mechanisms of action of steroid/thyroid receptor superfamily members. Annual Rev Biochem. 1994;63:451-486.

7. Kliewer SA, Umesono K, Noonan DJ, Heyman RA and Evans RM. Convergence of 9-Cis Retinoic Acid and Peroxisome Proliferator signalling pathways through heterodimer formation of their receptors. Nature. 1992;358:771-774.

8. Van der Lee KAJM, Willemsen PHM, van der Vusse GJ and van Bilsen M. Effects of Fatty Acids on uncoupling protein-2 expression in the rat heart. FASEB J. 2000;14:495-502.

9. Wu P, Peters JM and Harris RA. Adaptive increase in pyruvate dehydrogenase kinase 4 during starvation is mediated by Peroxisome Proliferator-Activated Receptor- $\alpha$. Biocbem Biophys Res Commun. 2001;287:391-396.

10. Young ME, Goodwin GW, Ying J, Guthrie P, Wilson CR, Laws FA and Taegtmeyer H. Regulation of cardiac and skeletal muscle Malonyl-CoA Decarboxylase by fatty acids. Am $J$ Physiol. 2001;280:E471-E479.

11. Kliewer SA, Forman BM, Blumberg B, Ong ES, Borgmeyer U, Mangelsdorf DJ, Umesono K and Evans RM. Differential expression and activation of a family of mutine Peroxisome ProliferatorActivated Receptors. Proc Natl Acad Sci USA. 1994;91:7355-7359.

12. Aperlo C, Pognonec P, Saladin R, Auwerx J and Boulukos KE. cDNA Cloning and characterization of the transcriptional activities of the Hamster Peroxisome Proliferator-Activated Receptor- $\gamma$ HaPPAR $\gamma$. Gene. 1995;162:297-302.

13. Braissant O, Foufelle F, Scotto C, Dauça M and Wahli W. Differential expression of Peroxisome Proliferator-Activated Receptors (PPARs): Tissue distribution of PPAR $\alpha, \beta$, and $\gamma$ in the adult rat. Endocrinology. 1996;137:354-366.

14. Takano H, Nagai T, Asakawa M, Toyozaki T, Oka T, Komuro I, Saito T and Masuda Y. Peroxisome Proliferator-Activated Receptor activators inhibit lipopolysaccharide-induced Tumor Necrosis Factor- $\alpha$ expression in neonatal tat cardiac myocytes. Cir Res. 2000;87:596-602.

15. Escher P, Braissant O, Basu-Modak S, Michalik L, Wahli W and Desvergne B. Rat PPARs: Quantitative analysis in adult rat tissues and regulation in fasting and refeeding. Endocrinology. 2001;142:4195-202.

16. Vidal-Puig AJ, Considine RV, Jimenez-Liñan M, Werman A, Pories WJ, Caro JF and Flier JS. Peroxisome Proliferator-Activated receptor gene expression in human tissues. Effects of obesity, weight loss, and regulation by insulin and glucorticoids. J Clin Invest. 1997;99:2416-2422. 
17. Park KS, Ciaraldi TP, Abrams-Carter L, Mudaliar S, Nikoulina SE and Henry RR. PPAR- $\gamma$ gene expression is elevated in skeletal muscle of obese and Type II diabetic subjects. Diabetes. 1997;46:1230-1234.

18. Teboul L, Gaillard D, Staccini L, Inadera H, Amri E-Z and Grimaldi PA. Thiazolidinediones and fatty acids convert myogenic cells into adipose-like cells. J Biol Chem. 1995;270:28183-28187.

19. Zierath JR, Ryder JW, Doebber T, Woods J, Wu M, Ventre J, Li Z, McCrary C, Berger J, Zhang B and Moller DE. Role of skeletal muscle in thiazolidinedione insulin sensitizer (PPAR $\gamma$ Agonist) Action. Endocrinology. 1998;139:5034-5041.

20. Cresci S, Wright LD, Spratt JA, Briggs FN and Kelly DP. Activation of a novel metabolic gene regulatory pathway by chronic stimulation of skeletal muscle. Am J Pbysiol. 1996;270:C1413-C1420.

21. Gottlicher M, Widmark E, Li Q and Gustafsson JA. Fatty acids activate a chimera of the cclofibric acid-activated receptor and the glucocorticoid receptor. Proc Natl Acad Sci. USA. 1992;89:46534657.

22. Issemann I, Prince RA, Tugwood JD and Green S. The Peroxisome Proliferator-Activated Receptor:Retinoid X receptor heterodimer is activated by fatty acids and fibrate hypolipidaemic drugs. J Mol Endocrinol. 1993;11:37-47.

23. Kliewer SA, Sundseth SS, Jones SA, Brown PJ, Wisely GB, Koble CS, Devchand P, Wahli W, Willson TM, Lenhard JM and Lehmann JM. Fatty acids and eicosanoids regulate gene expression through direct interactions with Peroxisome Ptoliferator-Activated Receptors- $\alpha$ and $-\gamma$. Proc Natl Acad Sci USA. 1997;94:4318-4323.

24. Forman BM, Chen J and Evans RM. Hypolipidemic drugs, polyunsaturated fatty acids, and eicosanoids are ligands for Peroxisome Proliferator-Activated Receptors- $\alpha$ and $-\delta$. Proc Natl Acad Sci USA. 1997;94:4312-4317.

25. Johnson TE, Holloway MK, Vogel R, Rutledge SJ, Perkins JJ, Rodan GA and Schmidt A. Structural requirements and cell-type specificity for ligand activation of Peroxisome Proliferator-Activated Receptors. J Steroid Biochem Mol Biol. 1997;63:1-8.

26. Xu HE, Lambert MH, Montana VG, Parks DJ, Blanchard SG, Brown PJ, Sternbach DD, Lehmann JM, Wisely GB, Willson TM, Kliewer SA and Milburn MV. Molecular recognition of fatty acids by Peroxisome Proliferator-Activated Receptors. Molecular Cell. 1999;3:397-403.

27. Forman BM, Tontonoz P, Chen J, Brun RP, Spiegelman BM and Evans RM. 15-Deoxy- $\Delta 12,14-$ Prostaglandin $\mathrm{J}_{2}$ is a ligand for the adipocyte determination factor PPAR $\gamma$. Cell. 1995;83:803-812.

28. Krey G, Braissant O, L-Horset F, Kalkhoven E, Perroud M, Parker MG and Wahli W. Fatty Acids, Eicosanoids, and hypolipidemic agents identified as ligands of Peroxisome Proliferator-Activated Receptors by coactivator-dependent receptor ligand assay. Mol Endocrinol. 1997;11:779-791.

29. Murakami K, Ide T, Suzuki M, Mochizuki $T$ and Kadowaki T. Evidence for direct binding of fatty acids and eicosanoids to human Peroxisome Proliferators-Activated Receptor- $\alpha$. Biochem Biophys Res Commun. 1999;260:609-613.

30. Van der Vusse GJ, Glatz JFC, Stam HCG and Reneman RS. Fatty acid homeostasis in the normoxic and ischemic heart. Pbysiol Rev. 1992;72:881-940.

31. Tan NS, Shaw NS, Vinckenbosch N, Liu P, Yasmin R, Desvergne B, Wahli W and Noy N. Selective cooperation between Fatty Acid Binding Proteins and Peroxisome Proliferator-Activated Receptors in regulating transcription. Mol Cell Biol. 2002;22:5114-5127.

32. Wolfrum $C$, Borrmann $C M$, Borchers $T$ and Spener F. Fatty acids and hypolipidemic drugs regulate Peroxisome Proliferator-Activated Receptors $-\alpha$ and $-\gamma$ mediated gene expression via liver Fatty Acid Binding Protein: a signaling path to the nucleus. Proc Natl Acad Sci USA. 2001;98:2323-2328.

33. Han C, Demetris AJ, Michalopoulos G, Shelhamer JH and Wu T. 85-kDa cPLA(2) plays a critical role in PPAR-mediated gene transcription in human hepatoma Cells. Am J Pbysiol. 2002;282:G586597. 
34. Elholm M, Dam I, Jorgensen C, Krogsdam AM, Holst D, Kratchmarova I, Gottlicher M, Gustafsson JA, Berge R, Flatmark T, Knudsen J, Mandrup S and Kristiansen K. Acyl-Coa esters antagonize the effects of ligands on Peroxisome Proliferator-Activated Receptor- $\alpha$ conformation, DNA binding, and interaction with co-factors. J Biol Chem. 2001;276:21410-21416.

35. Murakami K, Ide T, Nakazawa T, Okazaki T, Mochizuki $T$ and Kadowaki T. Fatty-Acyl-Coa thioesters inhibit recruitment of steroid receptor co-activator 1 to $\alpha$ and $\gamma$ isoforms of Peroxisome-Proliferator-Activated Receptors by competing with agonists. Biochem J. 2001;353:231238.

36. Berger J, Leibowitz MD, Doebber TW, Elbrecht A, Zhang B, Zhou G, Biswas C, Cullinan CA, Hayes NS, Li Y, Tanen M, Ventre J, Wu MS, Berger GD, Mosley R, Marquis R, Santini C, Sahoo SP, Tolman RL, Smith RG and Moller DE. Novel Peroxisome Proliferator-Activated Receptor (PPAR) $-\gamma$ and PPAR ligands produce distinct biological effects. J Biol Chem 1999;274:6718-6725.

37. Wurch T, Junquero D, Delhon A and Pauwels J. Pharmacological analysis of wild-type $\alpha, \gamma$ and $\delta$ subtypes of the human Peroxisome Proliferator-Activated Receptor. Naunyn Schmiedebergs Arch Pharmacol. 2002;365:133-140.

38. Chawla A, Barak Y, Nagy L, Liao D, Tontonoz P and Evans RM. PPAR $\gamma$ dependent and independent effects on macrophage-gene expression in lipid metabolism and inflammation. Nat Med. 2001;7:48-52.

39. Lennon AM, Ramauge M, Dessouroux A and Pierre M. Map Kinase cascades ate activated in astrocytes and preadipocytes by 15 -Deoxy- $\Delta 12-14$-Prostaglandin $\mathrm{J} 2$ and the thiazolidinedione ciglitazone through Peroxisome Proliferator Activator Receptor- $\gamma$-independent mechanisms involving reactive oxygenated species.J Biol Chem. 2002;277:29681-29685.

40. Young ME, Razeghi P, Cedars AM, Guthrie PH and Taegtmeyer H. Intrinsic diurnal variations in cardiac metabolism and contractile function. Circ Res. 2001;89:1199-1208.

41. van Bilsen $M$, van der Vusse GJ, Gilde AJ, Lindhout $M$ and van der Lee KA. Peroxisome Proliferator-Activated Receptors: Lipid binding proteins controlling gene expression. Mol Cell Biocbem. 2002;239:131-138.

42. Huss JM, Levy FH and Kelly DP. Hypoxia inhibits the Peroxisome Proliferator-Activated Receptor- $\alpha$ /Retinoid X Receptor gene regulatory pathway in cardiac myocytes: a mechanism for $\mathrm{O}_{2}$-dependent modulation of mitochondrial fatty acid oxidation. J Biol Chem. 2001;276:2760527612.

43. Juge-Aubry CE, Gorla-Bajszczak A, Pernin A, Lemberger T, Wahli W, Burger AG and Meier CA. Peroxisome Proliferator-Activated Receptor mediates cross-talk with thyroid hormone receptor by competition for Retinoid X Receptor. Possible role of a Leucine Zipper-Like Heptad Repeat. J Biol Chem. 1995;270:18117-18122.

44. Meier-Heusler SC, Zhu X, Juge-Aubry C, Pernin A, Burger AG, Cheng S-y and Meier CA. Modulation of thyroid hormone action by mutant thyroid hormone receptors, c-erbA $\alpha 2$ and Peroxisome Proliferator-Activated Receptor: evidence for different mechanisms of inhibition. Mol Cell Endocrin. 1995;107:55-66.

45. Winrow CJ, Kassam A, Miyata KS, Marcus SL, Hunter J, Capone JP and Rachubinski RA. Interplay of the Peroxisome Proliferator-Activated Receptor and the thyroid hormone receptor-signaling pathways in regulating Peroxisome Proliferator-Responsive genes. Ann New York Acad Sir. 1996;804:214-230.

46. Miyata KS, Zhang B, Marcus SL, Capone JP and Rachubinski RA. Chicken Ovalbumin Upstream Promoter Transcription Factor (COUP-TF) binds to a Peroxisome Proliferator-Responsive Element and antagonizes peroxisome proliferator-mediated sigaling. J Biol Chem. 1993;268:1916919172.

47. Marcus SL, Capone JP and Rachubinski RA. Identification of COUP-TFII as a Peroxisome Proliferator Response Element Binding Factor using genetic selection in yeast: COUP-TFII 
activates transcription in yeast but anatogonizes PPAR signaling in mammalian cells. Mol Cell Endocrin. 1996;120:31-39.

48. McKenna NJ, Lanz RB and O'Malley BW. Nuclear receptor coregulators: cellular and molecular biology. Endocrine Rev. 1999;20:321-344.

49. Zhu Y, Qi C, Calandra C, Rao MS and Reddy JK. Cloning and identification of mouse Steroid Receptor Coactivator-1 (mSRC-1), as a coactivator of Peroxisome Proliferator-Activated Receptor\%. Gene Expression. 1996;6:185-195.

50. Zhu Y, Qi C, Jain S, Rao MS and Reddy JK. Isolation and characterization of PBP, a protein that interacts with Peroxisome Proliferator-Activated Receptor. J Biol Chem. 1997;272:25500-25506.

51. Puigserver P, Wu Z, Park CW, Graves R, Wright M and Spiegelman BM. A cold-inducible coactivator of nuclear receptors linked to adaptive thermogenesis. Cell. 1998;92:829-839.

52. Gelman L, Zhou G, Fajas L, Raspé E, Fruchart J-C and Auwerx J. p300 Interacts with the N- and C-terminal part of PPAR $\gamma 2$ in a ligand-independent and -dependent manner, respectively. $J$ Biol Cbem. 1999;274:7681-7688.

53. Miyata KS, McCaw SE, Meertens LM, Patel HV, Rachubinski RA and Capone JP. ReceptorInteracting Protein 140 interacts with and inhibits transactivation by, Peroxisome ProliferatorActivated Receptor- $\alpha$ and Liver-X-Receptor $\alpha$. Mol Cell Endocrinol. 1998;146:69-76.

54. Robinson CE, Wu X, Nawaz Z, Oñate SA and Gimble JM. A Corepressor and Chicken Ovalbumin Upstream Promoter Transcriptional Factor proteins modulate Peroxisome Proliferator-Activated Receptor- $\gamma_{2} /$ Retinoid X Receptor $\alpha$-activated transcription from the Murine Lipoprotein Lipase Promoter. Endocrinology. 1999;140:1586-1593.

55. Dowell P, Ishmael JE, Avram D, Peterson VJ, Nevrivy DJ and Leid M. Identification of Nuclear Receptor Corepressor as a Peroxisome Proliferator-Activated Receptor- $\alpha$ interacting protein. $J$ Biol Chem. 1999;274:15901-15907.

56. Lavinsky RM, Jepsen K, Heinzel T, Torchia J, Mullen T-M, Schiff R, Del-Rio AL, Ricote M, Ngo S, Gemsch J, Hisenbeck SG, Osborne CK, Glass CK, Rosenfeld MG and Rose DW. Diverse signaling pathways modulate Nuclear Receptor Recruitment of N-CoR and SMRT complexes. Proc Natl Acad Sci USA. 1998;95:2920-2925.

57. Krogsdam AM, Nielsen CA, Neve S, Holst D, Helledie T, Thomsen B, Bendixen C, Mandrup S and Kristiansen K. Nuclear Receptor Corepressor-dependent repression of Peroxisome-ProliferatorActivated Receptor- $\delta$-mediated transactivation. Biochem J. 2002;363:157-165.

58. Vega RB, Huss JM and Kelly DP. The coactivator PGC-1 cooperates with Peroxisome ProliferatorActivated Receptor- $\alpha$ in transcriptional control of nuclear genes Encoding mitochondrial fatty acid oxidation enzymes. Mol Cell Biol. 2000;20:1868-1876.

59. Lin J, Puigserver P, Donovan J, Tarr P and Spiegelman BM. Peroxisome Proliferator-Activated Receptor- $\gamma$ coactivator $1 \beta$ (PGC-1 $\beta$ ), a novel PGC-1-related transcription coactivator associated with host cell factor. J Biol Chem. 2002;277:1645-1648.

60. Lin J, Wu H, Tarr PT, Zhang CY, Wu Z, Boss O, Michael LF, Puigserver P, Isotani E, Olson EN, Lowell BB, Bassel-Duby R and Spiegelman BM. Transcriptional co-activator PGC-1 $\alpha$ drives the formation of slow-twitch muscle fibres. Nature. 2002;418:797-801.

61. Lehman JJ, Barger PM, Kovacs A, Saffitz JE, Medeiros DM and Kelly DP. Peroxisome Proliferator-Activated Receptor- $\gamma$ coactivator- 1 promotes cardiac mitochondrial biogenesis. $J$ C/in Invest. 2000;106:847-856.

62. Yoon JC, Puigserver P, Chen G, Donovan J, Wu Z, Rhee J, Adelmant G, Stafford J, Kahn CR, Granner DK, Newgard CB and Spiegelman BM. Control of hepatic gluconeogenesis through the transcriptional coactivator PGC-1. Nature. 2001;413:131-138.

63. Camp HS and Tafuri SR. Regulation of Peroxisome Proliferator-Activated Receptor- $\gamma$ Activity by Mitogen-Activated Protein Kinase. J Biol Chem 1997;272:10811-10816. 
64. Camp HS, Tafuri SR and Leff T. $c$-Jun N-Terminal Kinase phosphorylates Peroxisome ProliferatorActivated Receptor- $\gamma 1$ and negatively regulates its transcriptional activity. Endocrinology. 1999;140:392-397.

65. Juge-Aubry CE, Hammar E, Siegrist-Kaiser C, Pernin A, Takeshita A, Chin WW, Burger AG and Meier CA. Regulation of the transcriptional activity of the Peroxisome Proliferator-Activated Receptor- $\alpha$ by phosphorylation of a ligand-independent trans-activating domain. $J$ Biol Chem. 1999;274:10505-10510.

66. Barger PM, Browning AC, Garner AN and Kelly DP. p38 Mitogen-Activated Protein Kinase activates Peroxisome Proliferator-Activated Receptor- $\alpha$ : A potential role in the cardiac metabolic stress response. J Biol Chem. 2001;276:44495-44501.

67. Barger PM, Brandt JM, Leone TC, Weinheimer CJ and Kelly DP. Deactivation of Peroxisome Proliferator-Activated Receptor- $\alpha$ during cardiac hypertrophic growth. J Clin Invest. 2000;105:17231730.

68. Tunstall RJ, Mehan KA, Wadley GD, Collier GR, Bonen A, Hargreaves M and Cameron-Smith D. Exercise training increases lipid metabolism gene expression in human skeletal muscle. $A m J$ Pbysiol. 2002;283:E66-72.

69. Cha BS, Ciaraldi TP, Carter L, Nikoulina SE, Mudaliar S, Mukherjee R, Paterniti JR, Jr. and Henry RR. Peroxisome Proliferator-Activated Receptor (PPAR) $\gamma$ and Retinoid X Receptor (RXR) agonists have complementary effects on glucose and lipid metabolism in human skeletal muscle. Diabetologia. 2001;44:444-452.

70. Lapsys NM, Kriketos AD, Lim-Fraser M, Poynten AM, Lowy A, Furler SM, Chisholm DJ and Cooney GJ. Expression of genes involved in lipid metabolism correlate with Peroxisome Proliferator-Activated Receptor- $\gamma$ Expression in human skeletal muscle. $\int$ Clin Endocrinol Metab. 2000;85:4293-4297.

71. Chevillotte E, Rieusset J, Roques M, Desage $M$ and Vidal $H$. The regulation of Uncoupling Protein2 gene expression by omega- 6 polyunsaturated fatty acids in human skeletal muscle cells involves multiple pathways, including the Nuclear Receptor Peroxisome Proliferator-Activated Receptor- $\beta$. J Biol Chem. 2001;276:10853-10860.

72. Muoio DM, Way JM, Tanner CJ, Winegar DA, Kliewer SA, Houmard JA, Kraus WE and Dohm GL. Peroxisome Proliferator-Activated Receptor- $\alpha$ regulates fatty acid utilization in primary human skeletal muscle cells. Diabetes. 2002;51:901-909.

73. Van Bilsen $M$, van der Vusse GJ and Reneman RS. Transcriptional regulation of metabolic processes: implications for cardiac metabolism. Pflïgers Arch. 1998;437:2-14.

74. Van der Lee KAJM, Vork MM, De Vries JE, Willemsen PHM, Glatz JFC, Reneman RS, Van der Vusse GJ and Van Bilsen M. Long-chain ffatty acid-induced changes in gene expression in neonatal cardiac myocytes. J Lipid Res. 2000;41:41-47.

75. Mascaro C, Acosta E, Ortiz JA, Marrero PF, Hegardt FG and Haro D. Control of human muscletype carnitine palmitoyltransferase I gene transcription by Peroxisome Proliferator-Activated Receptor. J Biol Chem. 1998;273:8560-3.

76. Brandt JM, Djouadi F and Kelly DP. Fatty acids activate transcription of the muscle carnitine palmitoyltransferase I Gene in cardiac myocytes via the Peroxisome Proliferator-Activated Receptor- $\alpha$. J Biol Chem. 1998;273:23786-23792.

77. Watanabe K, Fujii H, Takahashi T, Kodama M, Aizawa Y, Ohta Y, Ono T, Hasegawa G, Naito M, Nakajima T, Kamijo Y, Gonzalez FJ and Aoyama T. Constitutive regulation of cardiac fatty acid metabolism through Peroxisome Proliferator-Activated Receptor- $\alpha$ associated with age-dependent cardiac toxicity. J Biol Chem. 2000;275:22293-9.

78. Leone TC, Weinheimer CJ and Kelly DP. A critical role for the Peroxisome Proliferator-Activated Receptor- $\alpha$ (PPAR $\alpha)$ in the cellular fasting response: The PPAR $\alpha-N u l l$ Mouse as a model of fatty acid oxidation disorders. Proc Natl Acad Si USA. 1999;96:7473-7478. 
79. Muoio DM, MacLean PS, Lang DB, Li S, Houmard JA, Way JM, Winegar DA, Corton JC, Dohm GL and Kraus WE. Fatty acid homeostasis and induction of lipid regulatory genes in skeletal muscles of Peroxisome Proliferator-Activated Receptor (PPAR)- $\alpha$ knock-out mice. Evidence for Compensatory Regulation by PPAR $\delta$. J Biol Chem. 2002;277:26089-26097.

80. Wu Q and Haunerland NH. A novel fatty acid response element controls the expression of the flight muscle FABP gene of the desert locust, Schistocerca gregaria. Eur J Biochem. 2001;268:58945900 . 


\section{PPAR-DEPENDENT AND PPAR-INDEPENDENT CHANGES IN CARDIAC GENE EXPRESSION.}

Andries J Gilde, Peter HM Willemsen, Martijn Lindhout, Joris Hoeks ${ }^{2}$, Matthijs KC Hesselink ${ }^{3}$, Patrick Schrauwen ${ }^{2}$, Carley R Benton ${ }^{4}$, Arend Bonen 5 ,

Ger J van der Vusse, and Marc van Bilsen

Submitted for publication 


\subsection{ABSTRACT}

The fatty acid (FA) mediated activation of metabolic gene expression in tissues with high FA oxidation capacity is believed to be due to activation of Peroxisome ProliferatorActivated Receptor- $\alpha$ (PPAR $\alpha$ ) primarily. To investigate the genomic response of the heart to a rise in circulating FA levels rats were subjected to fasting, diabetes, and high-fat diet (longchain or medium-chain FA) or treated with the PPAR $\alpha$ ligand Wy-14,643 or the PPAR $\gamma$ ligand Rosiglitazone. In fasted and diabetic, but not high-fat treated rats, a marked decrease in cardiac expression of GLUT4 and Hexokinase II was observed. The fasting, diabetes and high-fat diet induced rise in plasma FA was consistently associated with enhanced cardiac expression of PPAR-responsive genes. However, administration of $\mathrm{W}_{\mathrm{y}}-14,643$ resulted in a dramatic increase in expression of FA handling genes in liver, but not in heart. Remarkably, Rosiglitazone had limited effects on hepatic gene expression, but gave rise to a substantial reduction of PPARresponsive genes in cardiac muscle. Collectively, the present findings reveal a different response of heart and liver to metabolic interventions, suggesting the involvement of PPAR $\alpha$-dependent and independent processes in the transcriptional control of cardiac as well as hepatic metabolism. 


\subsection{INTRODUCTION}

In the last decade it is being increasingly appreciated that in mammalian tissues the regulation of intermediary metabolism is not only controlled by neurohumoral factors, but also by evolutionary conserved processes allowing the tissue cells to respond directly to alterations in their nutritional environment. In this respect, the discovery of the ligand-activated transcription factors of the nuclear hormone receptor family, the so-called Peroxisome Proliferator-Activated Receptors (PPARs), provided the conceptual framework as to how blood-borne long-chain fatty acids (FA), by acting as ligands for the PPARs, may promote their own metabolic conversion via the up-regulation of genes involved ${ }^{1}$. Interestingly this response is not exclusively restricted to tissues such as adipose tissue and liver, which are intimately involved in whole body lipid homeostasis. More recently, we and others-5 have shown that similar molecular mechanisms are operative in cardiac muscle cells as well.

To sustain its continuous electro-mechanical activity the heart relies on an efficient uptake and metabolism of oxidizable substrates supplied via the coronary circulation. Under normal conditions the oxidation of FA accounts for up to $70 \%$ of the energy need of the beating heart ${ }^{6}$. In cases of increased plasma concentrations of $\mathrm{FA}$, the contribution of FA oxidation to total myocardial energy production may increase even further. Recent studies suggest that this metabolic response cannot be ascribed solely to an enhanced availability of FA, but also involves an adaptive expression of genes involved in cardiac FA utilization ${ }^{7-9}$, possibly involving PPAR-mediated transcriptional processes.

The PPAR family consists of three isoforms, i.e., PPAR $\alpha, \operatorname{PPAR} \beta / \delta$, and PPAR $\gamma$, each with a different expression pattern in the various tissues ${ }^{10}$. In tissues with a high mitochondrial oxidative capacity, like heart and liver, PPAR $\alpha$ is the predominant isoform ${ }^{3,11}$. Assuming that PPAR $\alpha$ is indeed of eminent importance in the regulation of FA metabolism one would expect a comparable genomic response of these tissues when challenged with an increased FA load. However, a systematic comparison of the metabolic response of these tissues at the gene level has to the best of our knowledge not been performed. Accordingly, to obtain more insight into the regulation of metabolic genes in heart and liver in vivo, rats were subjected to different interventions, that all lead to a chronic rise in plasma FA levels. Therefore, rats were either subjected to fasting, or were rendered diabetic by streptozotocin (STZ) treatment. In a separate 
series of experiments the modulating effects of high-fat diets, either composed of long-chain (C16-C18) or medium-chain triacylglycerols (C8-C10), were compared to an isocaloric highcarbohydrate low-fat diet. The latter series of experiments were included to obtain further insight into the role of PPAR $\alpha$ in the metabolic adaptation at the gene level under physiologically relevant conditions since, unlike long-chain FA, medium-chain FA are poor ligands for PPARs ${ }^{12}$. Finally, the involvement of PPAR $\alpha$ in metabolic remodeling was investigated by treating rats with the PPAR $\alpha$ specific ligand $W y-14,643$. As it has been shown that the PPAR $\gamma$ isoform is expressed at very low levels in the cardiac muscle ${ }^{5}$, for comparison rats were also treated with the PPAR $\gamma$ specific ligand Rosiglitazone.

Northern-blot analysis was applied to investigate the expression level of a panel of genes involved in FA uptake and metabolism, the majority of which has been shown to contain functional PPAR-response elements, including Fatty Acid Translocase (FAT/CD36) and Heart- and Liver-type Fatty Acid-Binding Protein (H-FABP, L-FABP), facilitators of uptake and intracellular FA transport, respectively ${ }^{13}$. As markers of FA metabolism mRNA levels of Acyl-CoA Synthetase (ACS), Muscle- and Liver-type Carnitine Palmitoyl Transferase-1 (MCPT1, LCPT-1), Long-Chain Acyl-CoA Dehydrogenase (LCAD) and the peroxisomal enzyme AcylCoA Oxidase $(A O X)$ were measured. In addition, the expression level of the uncoupling proteins UCP2 and UCP3 was determined as both UCPs are targets of PPAR ${ }^{14,15}$ and are likely to be involved in mitochondrial FA handling ${ }^{16}$. To explore the potential relationship between FA and carbohydrate utilization, a number of genes involved in glucose handling were also examined, i.e., the insulin-dependent glucose transporter GLUT4 and Hexokinase II (HKII) that are expressed in cardiac and skeletal muscle but not in liver, and Pyruvate Dehydrogenase Kinase 4 (PDK4) that is expressed both in liver and heart. Finally, Citrate Synthase (CS) expression was assessed as a general marker of mitochondrial capacity.

The present findings demonstrate a pronounced transcriptional response of the cardiac muscle to interventions associated with a rise in plasma FA levels. Moreover, the treatment of rats with isoform specific PPAR $\alpha$ and PPAR $\gamma$ ligands led to markedly divergent responses in liver and heart, suggesting that, in addition to PPAR $\alpha$-mediated mechanisms, other mechanisms are involved in the genomic regulation of lipid metabolism in the heart. 


\subsection{MATERIALS AND METHODS}

\subsubsection{Animal experiments}

Experiments were performed according to the guidelines of the Institutional Animal Care and User Committee at Maastricht University and at the University of Guelph. Rats were kept under a light-dark cycle of 12 hours, were fed ad libitum, and had free access to water, unless indicated otherwise.

Long-chain and medium-chain fat diets: Male Wistar rats, ten weeks old (Charles Rivers), were randomly assigned to three groups receiving a low-fat high-carbohydrate $\operatorname{diet}(2.5 \% \mathrm{FA} \mathrm{w} / \mathrm{w}$, mainly C16:0; low -fat control group), or isocaloric high-fat diets ( $24 \% \mathrm{FA} \mathrm{w} / \mathrm{w})$ containing exclusively medium-chain (MCT: C8:0 and C10:0) or long-chain triacylglycerols (LCT; mainly C16:0) (Hope Farms B.V., Woerden, The Netherlands). Rats were fed the different diets for two weeks, after which the animals were sacrificed.

Streptorotocin-induced diabetes: Male Wistar tats, ten weeks old, were anaesthetized with i.p. ketamine and xylazine (37.5 and $7.5 \mathrm{mg} \cdot \mathrm{kg}^{-1}$, respectively). Subsequently, the animals were treated with $70 \mathrm{mg} \cdot \mathrm{kg}^{-1}$ streptozotocin (STZ) in disodium citrate (100 mM, pH 4.5) via tail vein injection to induce diabetes type 1 . Animals were fed ad libitum on a standard chow (Hope Farms B.V., 5\% FA w/w, consisting mainly of C18:1 and C18:2). STZ-treated animals had free access to tap water containing $5 \%$ glucose $(w / v)$, while untreated control animals had free access to plain tap water. After four weeks the rats were sacrificed.

Fasting: One subgroup of Male Sprague Dawley rats, six weeks old, was fasted for 48 hours, while the other subgroup had free access to the standard chow. During the 48 hour period both subgroups had free access to tap water containing $0.45 \% \mathrm{NaCl}$. Thereafter, the rats were sacrificed.

Wy-14,643 and Rosiglitazone treatment: Male Sprague Dawley rats, ten weeks of age, were treated with either the PPAR $\alpha$ ligand Wy-14,643 (Cedarlane, Hornby, Ontario, Canada) (1 mg/day dissolved in DMSO) or Rosiglitazone (Glaxo Smith Kline, USA) (1 mg/day dissolved in 15\% ethanol) for up to seven days via osmotic mini-pump (ALZET Cupertino, CA, USA) inserted in the scruff of their neck. The animals received a standard chow (5\% FA w/w, Labdiet, PMI Nutrition International, Canada) and had free access to water. 


\subsubsection{Tissue sampling and plasma analysis}

After anesthesia with sodium pentobarbital $(60 \mathrm{mg} / \mathrm{kg}$ body weight), thoracotomy was performed and blood was collected from the left ventricle with a citrate-rinsed syringe. Plasma was obtained after centrifugation of the citrate blood. Plasma glucose concentration was measured on a COBAS BIO (Roche-Diagnostics, Basel, Switserland) and total plasma nonesterified FA by the Wako NEFA C test kit (WAKO Chemicals GmbH, Neuss, Germany). Heart and liver were excised, washed in ice-cold PBS and snap-frozen in liquid nitrogen and stored at $-80^{\circ} \mathrm{C}$ until analysis.

\subsubsection{RNA analysis}

RNA was isolated from liver and cardiac tissue with TriReagent (Sigma-Aldrich, St. Louis, MO, USA) after homogenizing the tissues in a pre-cooled mortar. RNA was size-fractionated, transferred to nylon membranes, and hybridized with ${ }^{32} \mathrm{P}-\mathrm{dCTP}$ labeled cDNA fragments of AOX, L-FABP (a gift of Dr. J. Gordon, Washington University, St. Louis, USA), PDK4 (a gift of Dr. P. Wu, Indiana University School of Medicine, USA), MCPT-1, LCPT-1 (a gift of Dr. F. van der Leij, University of Groningen, The Netherlands), ACS, LCAD, H-FABP, FAT, UCP2 and UCP3 as described previously,7. Labeling of CDNA and Northern-blot detection were performed as described earlier by Gilde et al. 5 .

\subsubsection{Statistics}

Results were obtained from at least five animals in one group and presented as sample means \pm SD. A two-tailed Student's t-test for unpaired data was carried out for each group except for the high-fat diet groups on which a one-way analysis of variance (ANOVA) was performed applying Bonferroni's adjustment for multiple comparison ${ }^{17}$. Differences were considered significant at $\mathrm{p}<0.05$. 


\subsection{RESULTS}

\subsubsection{Plasma glucose and $F A$ levels}

As anticipated four weeks after STZ treatment plasma glucose levels had increased dramatically reflecting the diabetic state. In addition, plasma FA levels had increased approximately 2 -fold in the diabetic rats (Table 3.1). Two days of fasting, however, was associated with a decline in glucose level in combination with a sharp rise in plasma FA. After two weeks of dietary interventions plasma FA levels tended to be increased in the high-fat longchain triacylglycerol group (1.6 fold; $\mathrm{p}=0.07$ ). Plasma FA and glucose levels were not affected by feeding the rats a diet enriched in medium-chain triacylglycerols. The administration of the PPAR $\alpha$ ligand $W_{y}-14,643$ or the PPAR $\gamma$ ligand Rosiglitazone for seven days influenced neither plasma FA nor glucose levels.

\begin{tabular}{|c|c|c|c|c|c|}
\hline Group & & Glucose $[\mathrm{mM}]$ & P-value & NEFA [mM] & p-value \\
\hline \multirow[t]{2}{*}{ Diabetes } & sham & $7.0 \pm 0.7$ & & $0.13 \pm 0.06$ & \\
\hline & treated & $22.0 \pm 3.0$ & 0.01 & $0.27 \pm 0.09$ & $<0.001$ \\
\hline \multirow[t]{2}{*}{ Fasting } & sham & $8.2 \pm 0.2$ & & $0.45 \pm 0.13$ & \\
\hline & treated & $5.9 \pm 0.7$ & 0.02 & $1.33 \pm 0.25$ & $<0.001$ \\
\hline \multirow[t]{3}{*}{ High Fat } & sham & $14.2 \pm 3.3$ & & $0.20 \pm 0.06$ & \\
\hline & $\mathrm{MCT}$ & $15.3 \pm 2.5$ & 0.75 & $0.29 \pm 0.07$ & 0.23 \\
\hline & LCT & $17.7 \pm 1.3$ & 0.02 & $0.32 \pm 0.04$ & 0.07 \\
\hline \multirow[t]{2}{*}{$W y-14,643$} & sham & $10.6 \pm 2.2$ & & $0.27 \pm 0.05$ & \\
\hline & treated & $11.9 \pm 2.6$ & 0.45 & $0.23 \pm 0.04$ & 0.21 \\
\hline \multirow[t]{2}{*}{ Rosiglitazone } & sham & $10.4 \pm 2.3$ & & $0.25 \pm 0.01$ & \\
\hline & treated & $10.4 \pm 1.3$ & 0.89 & $0.26 \pm 0.05$ & 0.69 \\
\hline
\end{tabular}

Table 3.1

Plasma concentrations of glucose and non-esterified long-chain fatty acids (F $\Lambda$ ) of diabetic rats, fasted rats, rats fed a highfat medium-chain triacylglycerols (MCT) or long-chain triacylglycerols (LCT) diet, and rats treated with the PPAR $\alpha$ ligand Wy-14,643 or PPAR $\gamma$ ligand Rosiglitazone, respectively. Data expressed as means \pm SD ( $n=7)$, p-values refer to differences versus corresponding sham-groups. 


\subsubsection{Expression of metabolic genes: fasting and diabetes}

In the hearts of fasted animals there was a significant increase in the expression of genes involved in the FA uptake (FAT/CD36), intracellular transport (H-FABP) and metabolism (LCPT-1 and MCPT-1, LCAD, AOX, UCP3), the only exception being ACS and UCP2 the expression of which was not affected or slightly diminished, respectively (Fig. 3.1A). Overall, the direction of changes in expression in the hearts of diabetic animals was similar, but from a quantitative point of view the changes were less outspoken than in fasted animals and did not reach the level of statistical significance.

The expression of genes involved in cardiac glucose metabolism changed substantially both in fasted and diabetic rats, with an over 5-fold increase in PDK4 expression and a marked reduction in GLUT4 and HKII expression (Fig. 3.1A). The expression of the mitochondrial citric acid cycle enzyme CS was not affected, neither in hearts of fasted nor diabetic rats.

For the liver as well, the changes in gene expression in response to both interventions revealed a similar pattern, albeit that in general the response to fasting appeared to be more pronounced than the response to diabetes (Fig. 3.1B).

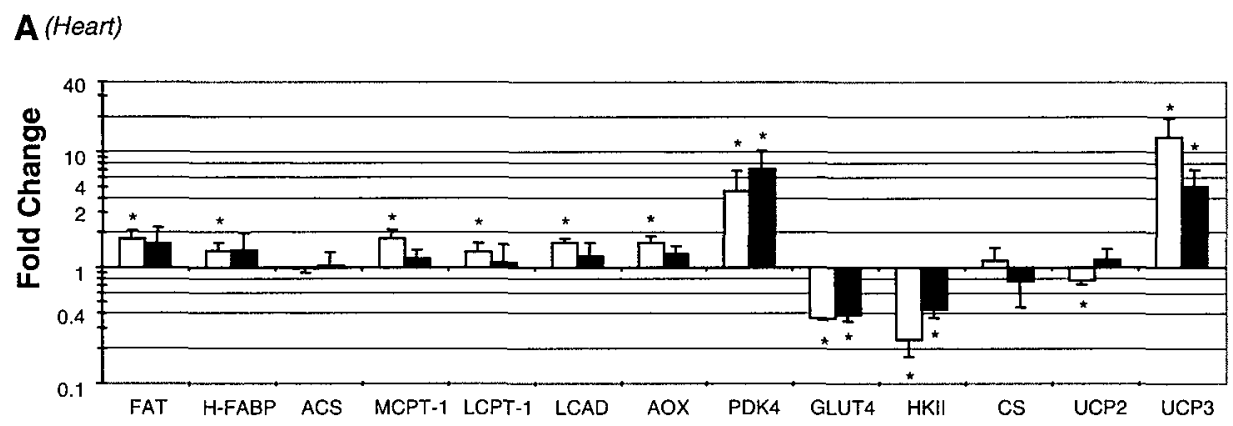

B (Liver)

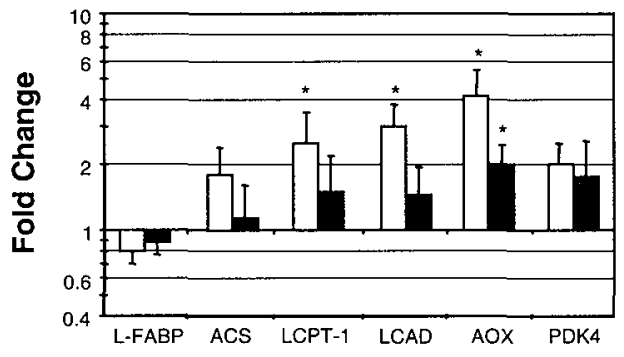

Figure 3.1

Expression of metabolic genes in the heart (panel A) and liver (panel B) of rats that were fasted (open bars) or rendered diabetic via streptozotocin injection (black bars). Tissue mRNA levels of FAT/CD36, H-FABP, L-FABP, ACS, MCPT-1, LCPT-1, LCAD, AOX, PDK4, GLUT4, HKII, CS, UCP2, and UCP3 were assessed. Results are expressed as fold changes relative to the corresponding sham groups (rats fed ad libitum or injected with vchicle, respectively), the mean level of expression of which was arbitrarily set at 1.0. Data are presented as means $\pm S D(n=5)$. * Indicates significantly different $(p<0.05)$ from corresponding control groups. 


\subsubsection{Expression of metabolic genes: dietary interventions}

In the hearts of animals receiving a high-fat diet composed of long-chain triacylglycerols (LCT) the expression of several genes involved in fatty acid uptake (FAT/CD36, H-FABP) and metabolism (ACS, CPT-1, LCAD, AOX, UCP3) was increased (Fig. 3.2A). The effect of the isocaloric medium-chain triacylglycerol (MCT) high-fat diet on the expression of PPARresponsive genes turned out to be less marked, reaching the level of significance for a limited number of genes only, i.e., FAT/CD36, H-FABP, PDK4 and UCP3. Interestingly, unlike the fasted and diabetic rats, feeding a high-fat diet did not lead to a reciprocal adjustment of the cardiac expression of genes involved in glucose uptake and metabolism, as the mRNA levels of GLUT4 and HKII were unaltered.

In hepatic tissue the response to the high-fat diets on the expression of PPARresponsive genes was more complex (Fig. 3.2B). In general, both MCT and LCT treatment resulted in the same response in case of ACS and PDK4 (no change), and LCAD and AOX (increased expression). L-FABP and LCPT-1 expression was unchanged in the MCT group, while the LCT diet resulted in a reduced L-FABP and an increased LCPT-1 expression.

\section{A (Heart)}

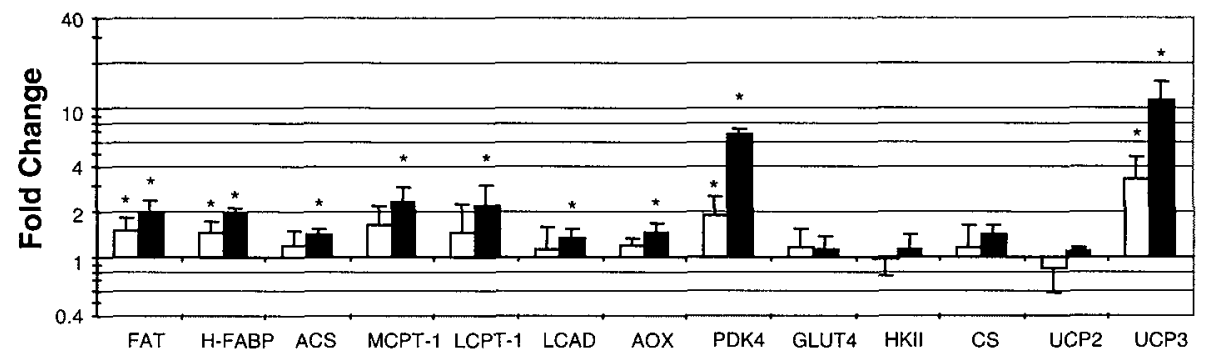

$\mathbf{B}($ Liver)

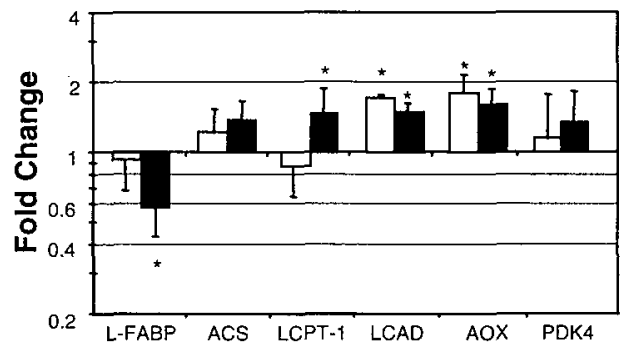

Figure 3.2

Expression of metabolic genes in the heart (panel A) and liver (panel B) of rats that where fed a highfat diet. The tissue mRNA levels as a result of a high-fat diet with medium-chain triacylglycerols (open bars) and long-chain triacylglycerols (black bars) of FAT/CD36, H-FABP, L-FABP, ACS, MCPT-1, ICPT-1, LCAD, AOX, PDK4, GLUT4, HKII, CS, UCP2, and UCP3 are depicted. Results are expressed as fold change relative to the control group (low fat, high carbohydrate diet), the level of expression of which was arbitrarily set at 1.0. Data are presented as means $\pm S D(n=5)$. * Indicates significantly different $(p<0.05)$ from the control group. 


\subsubsection{Expression of metabolic genes: PPAR ligands}

In the hearts of rats treated with the potent PPAR $\alpha$-specific ligand $W y-14,643$ for 1,3 , 5 , or 7 days no changes were observed in the expression of any of the metabolic genes examined. To illustrate this lack of effect, representative northern blot data are provided of several PPAR-responsive genes in the hearts from rats treated with vehicle or $\mathrm{W}_{\mathrm{y}}-14,643$ for 7

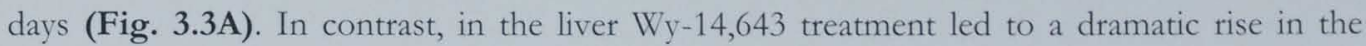
mRNA level of all of the PPAR-responsive genes examined, which was already evident at day 1 of treatment (data not shown) and was maintained thereafter (Fig. 3.3B). Conversely, administration of the PPAR $\gamma$ ligand Rosiglitazone for up to 7 days did not have obvious effects on hepatic expression of PPAR-responsive genes (Fig. 3.3B), but appeared to reduce the expression of these genes in the cardiac muscle (Fig. 3.3A). This intriguing finding prompted us to investigate the effects of Rosiglitazone on cardiac and hepatic gene expression in more detail.
A (Heart)
Figure 3.3
Representative Northern blots displaying the effect of PPAR $\alpha$ and PPAR $\gamma$ specific ligands on gene expression in heart (panel A) and liver (panel B). RNA levels of H-FABP, L-FABP, LCAD, AOX, and PDK4 are shown. The $18 \mathrm{~S}$ signal is shown to demonstrate comparable RNA loading. Animals were exposed to the PPAR $\alpha$ ligand $W_{y}-14,643\left(W_{y}\right)$ or the PPAR $\gamma$ ligand Rosiglitazone (Rosi) for 7 days. (-) refers to vehicle- treated control rats.

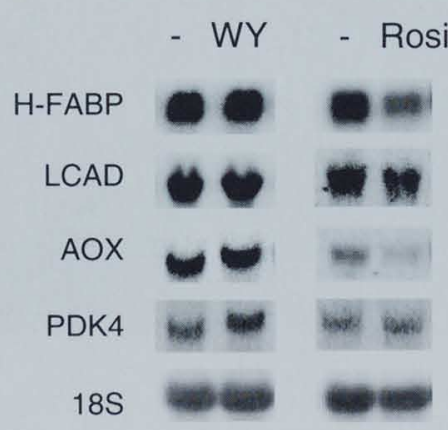

B (Liver)

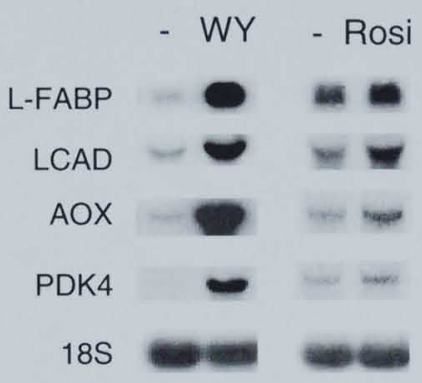


Remarkably, the administration of the PPAR $\gamma$ ligand Rosiglitazone led to timedependent changes in cardiac gene expression (Fig. 3.4A). Generally speaking, the expression level of most genes investigated tended to rise during the first three days. Conversely, after 7 days of treatment a pronounced reduction in the expression of most genes became apparent, including all of the genes the expression of which is considered to be PPAR-dependent. In the livers of Rosiglitazone-treated rats no such changes were observed at any of the time points examined (Fig. 3.4B). If anything, the hepatic expression of several genes tended to increase, rather than decrease, although the level of significance was not reached.

A (Heart)

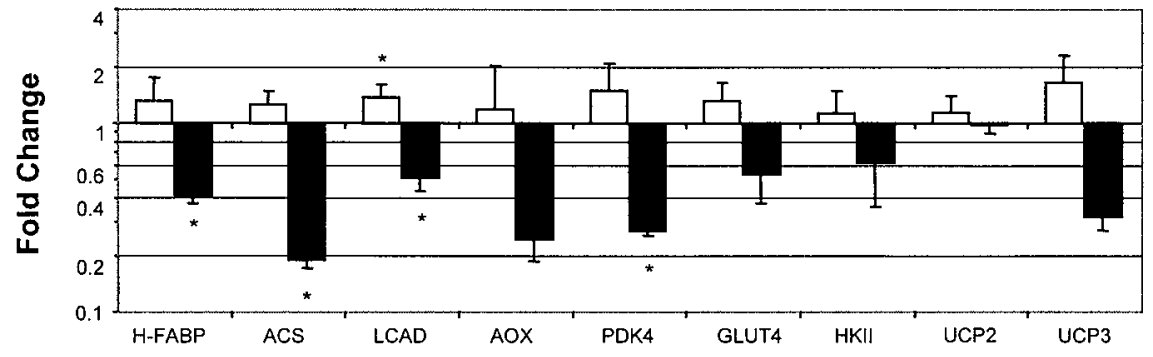

B (Liver)

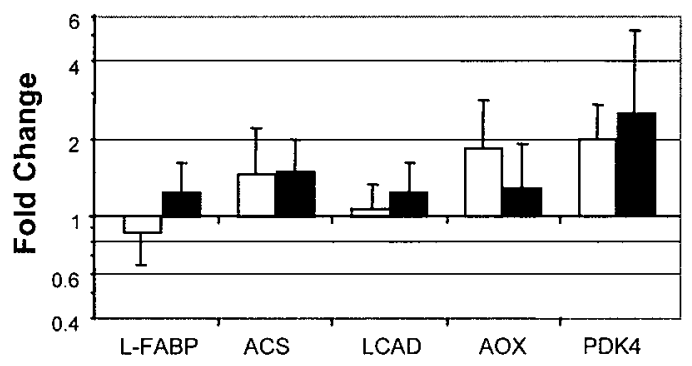

Figure 3.4

Expression of metabolic genes in the heart (panel A) and liver (panel B) of rats that where exposed to the PPAR $\gamma$ ligand Rosiglitazone. The tissue mRNA levels of H-FABP, L-FABP, ACS, LCAD, AOX, PDK4, GLUT4, HKII, UCP2, and UCP 3 after 3 days (open bars) and 7 days (black bars) of Rosiglitazone treatment are depicted. Results are expressed as fold change compared to the control group, the level of expression of which was arbitrarily set at 1.0 . Data are presented as means $\pm S D(n=5)$. * Indicates significantly different $(p<0.05)$ of the vehicle treated rats. 


\subsection{DISCUSSION}

In the present study the genomic response of cardiac tissue to three (patho-) physiological interventions, i.e., fasting, diabetes and high-fat diet, was investigated, and compared to that of hepatic tissue. However diverse, these interventions have in common that they are all characterized by a chronic increase in plasma FA availability of the tissues investigated. As PPARs have been implicated as key regulators of cellular lipid metabolism, by acting as "transcriptional FA sensors", special attention was paid to potential changes in the expression of established PPAR-responsive genes. In this regard, the direct effect of administration of the potent PPAR $\alpha$ ligand $\mathrm{W}_{\mathrm{y}}-14,643$ and the PPAR $\gamma$ ligand Rosiglitazone to rats was also explored. The collective findings strongly suggest that factors in addition to PPAR $\alpha$ modulate the cardiac expression of metabolic genes under conditions in which the FA load is enhanced.

\subsubsection{Fasting and diabetes.}

Both fasting and STZ treatment result in an increase of plasma FA levels, but the effects on blood glucose concentrations are divergent (see table 1). Interestingly, the direction of changes in cardiac gene expression under these two experimental conditions are strikingly similar, as reflected by the modest increase in expression of various FA handling genes and the prominent rise in PDK4 expression, which will lead to phosphorylation of and, hence, inhibition of the activity of the Pyruvate Dehydrogenase complex. In combination with the marked reduction of the expression of GLUT4 and HKII, the pattern of changes in gene expression, indicate an enhanced capacity of the myocardium to utilize FA, as evidenced by the increased expression of genes involved in FA uptake and subsequent intracellular conversion, and a diminished capacity to utilize glucose during prolonged fasting and diabetes. Accordingly, the changes reflect an adequate response to the altered nutritional environment of the cardiac muscle cells.

From a mechanistic point of view, the changes in expression of established PPARresponsive genes involved in FA handling (FAT/CD36, ACS, CPT-1, LCAD, AOX, UCP3) and regulation of glucose metabolism (PDK4), are consistent with the notion that the increased FA supply to the myocardium will lead to activation of PPARs. Both in vitro ${ }^{5}, 18$ and in vivo 
studies $^{8,19}$ indicated that of all PPAR responsive genes PDK4 and UCP3 are among the cardiac genes that respond very forcefully to enhanced exposure to natural (long-chain FA) or synthetic (e.g. Wy-14,643) PPAR $\alpha$ ligands. Previous studies demonstrated altered expression of FA handling genes in the heart as well as in liver in fasted animals $7,20,21$. Furthermore, studies with PPAR $\alpha$ null mice revealed a blunted response to fasting 22 , underscoring the importance of PPAR $\alpha$ in the transcriptional control of cardiac lipid metabolism.

However, the substantial reduction in the cardiac expression of GLUT4 and HKII cannot be explained in terms of a PPAR-mediated process, as these genes do not contain PPRE sites in their promoter regions. Furthermore, a prominent role for glucose metabolites in the transcriptional regulation of these genes is also less likely as the plasma glucose levels show opposite changes in response to fasting and diabetes, but as discussed below a modulating effect of insulin is worth considering.

\subsubsection{Fatty acid-enriched diets.}

Replacement of long-chain triacylglycerols (LCT) by medium-chain triacylglycerols (MCT) has been advocated in view of their rapid intra-hepatic metabolism, bypassing the mitochondrial carnitine shuttle, resulting in a reduced body weight gain secondary to an increased energy expenditure $23-25$. The putatively increased energy utilization of MCT-fed animals is not reflected by a systematic increase in the expression of genes involved in longchain FA conversion. The most marked changes were a 1.8 fold increase in the expression of AOX in the liver and a 3.3 fold increase in the expression of UCP3 in the heart. Relative to the high-fat MCT diet, in the cardiac muscle the high-fat LCT diet gave rise to a more pronounced increase in the expression of FA handling genes. It is of note that, in contrast to fasting and diabetes, the high-fat LCT diet did not influence the expression of any of the genes involved in cardiac glucose handling, i.e., genes that are unresponsive to PPAR like GLUT4 and HKII'. This is consistent with the involvement of insulin as modulator of GLUT4 and HKII expression signaling as these genes do contain insulin sensitive regions in their promoters ${ }^{26,27}$ and plasma insulin levels are decreased in diabetes and fasting 28,29 in contrast to high-fat feeding 30,31 .

Whereas long-chain FA are considered bona fide PPAR ligands, medium-chain FA are poor activators of PPAR 12,32 . Consistent with this, Han and coworkers ${ }^{25}$ showed that, relative 
to LCT-feeding, MCT-feeding for nearly 2 months was associated with a lower level of expression of the PPAR-responsive genes ACS and aP2 in white adipose tissue. Likewise, the present results with the high-fat diet groups reveal that in the hearts of LCT-fed animals the increase in the expression of PPAR-responsive genes is more outspoken than in animals fed an isocaloric MCT diet.

\subsubsection{Synthetic $P P A R \alpha$ ligands}

To directly test the involvement of PPAR $\alpha$ in the metabolic adaptation of heart and liver towards an increase in FA load, rats were treated with the potent ligand Wy-14,643. Administration of this ligand led to massive induction of PPAR-responsive genes in liver, implying that the dose administered to the rats is sufficient to evoke a functional response. Nevertheless, despite the fact that both heart and liver are considered organs in which PPAR $\alpha$ plays a prominent role in the transcriptional regulation of lipid metabolism, in the cardiac muscle $W_{y-14,643}$ administration failed to elicit any effects. To the best of our knowledge only one research group was able to show that the administration of $\mathrm{Wy}_{\mathrm{y}-14,643 \text { resulted in an }}$ increased expression of PPAR-responsive genes involved in the cardiac FA metabolic pathway, albeit that the effects were very modest (in the order $+30 \%$ for MCPT- 1 and MCAD) and did not give rise to an enhanced FA oxidation rate ${ }^{8}$. However, most studies are in line with the current findings in that the administration of Wy-14,643 or other PPAR $\alpha$ ligands (fibrates) to rodents was not associated with significant alterations in the expression of lipid handling genes in the heart ${ }^{33-37}$. It has been suggested that the absence of effects on cardiac gene expression was due to limited bioavailability of the compounds, with most of the drug being removed by the liver (so-called first-pass effects) consequent to oral administration of the drug. The latter notion is consistent with the observation that direct exposure of rat neonatal cardiomyocytes to Wy-14,643 leads to a marked increase in the expression of the same genes ${ }^{5}, 7$. It should be emphasized, however, that in the present study the PPAR ligand was administered subcutaneously via implanted osmotic minipumps. This way of administration results in a continuous release of the drug into the systemic circulation and avoids potential problems related to first-pass effects, making it less likely that the absence of effects of PPAR $\alpha$ agonists on cardiac gene expression in vivo is due to an impaired bio-availability. The corollary of the 
latter notion is that the difference in response of cardiac and hepatic tissue to PPAR $\alpha$ ligands is most likely based on intrinsic differences in the contribution of PPAR $\alpha$ in the regulation of metabolic gene expression between these tissues in vivo. In this respect a number of studies also alluded to the contribution of PPAR $\alpha$-independent mechanisms in cardiac and skeletal muscle. For instance, in the PPAR $\alpha$-null mouse the cardiac response of PDK4 to fasting is completely intact ${ }^{38}$. Likewise, in gastrocnemius muscle UCP3 expression was increased after fasting in both wild type and PPAR $\alpha$ null mice ${ }^{8}$. Furthermore, an entirely distinct FA-responsive DNA sequence has been identified in the promoter of the H-FABP gene ${ }^{39}$. Along with the current findings the latter observations provide strong evidence for an additional role of PPAR $\alpha$ independent transcriptional mechanisms in the control of FA-mediated transcriptional effects in cardiac muscle. For the liver the significance of other transcription factors that respond directly (SREBPs) or indirectly (LXR) to long-chain FA has already been established ${ }^{40,}{ }^{41}$. However, as far as the cardiac muscle is concerned the nature of such additional transcriptional regulators awaits further investigation.

In this respect the current observation that the prolonged administration of a PPAR $\gamma$ ligand gave rise to a marked reduction in the expression of nearly all FA handling genes involved is very intriguing in view of the fact that PPAR $\gamma$ is expressed at very low levels in the cardiac myocyte ${ }^{5,10}$. Previous studies showed that exposure of isolated neonatal cardiomyocytes to Rosiglitazone did not affect transcription of PPAR-responsive genes at all. Furthermore, the forced expression of PPAR $\gamma$ in these cells resulted in a Rosiglitazone-mediated increase, rather than decrease, in the expression of PPAR-responsive genes ${ }^{5}$. Therefore, the observed decline in gene expression cardiac muscle in tesponse to Rosiglitazone most likely is secondary to PPAR $\gamma$-mediated effects in other peripheral tissues, such as the adipose tissue. This notion is supported by the findings of Hevener and co-workers ${ }^{42}$ in the muscle-specific PPAR $\gamma$ knockout mouse, showing a decreased expression of UCP3 and PDK4 in skeletal muscle after Rosiglitazone treatment of both wild-type and knockout animals. It is noteworthy that administration of Rosiglitazone for seven days was not associated with a decline in the plasma FA concentration, which is in line with other studies demonstrating that Rosiglitazone-induced changes in circulating FA and glucose levels are apparent in obese, but not in lean rodent models ${ }^{43}, 44$. The latter observation excludes the possibility that the diminished expression of 
metabolic genes in the cardiac muscle is secondary to a reduced availability of exogenous FA. Consistent with the present findings the treatment of mice with the PPAR $\gamma$ agonist Troglitazone also led to a time-dependent decrease in the expression of acyl-CoA oxidase in the murine heart ${ }^{45}$. In the latter study evidence was provided that this response coincided with an increased expression of COUP-TFII, a transcription factor that has been previously shown to compete with PPARs for binding to the PPRE 46,47 .

The present findings indicate that, irrespective of the type of metabolic intervention (fasting, diabetes, high-fat diet), the cardiac muscle responds to an enhanced FA supply by adjusting metabolic gene expression, indicating that the cardiac muscle is endowed with the capacity to respond avidly to altered nutritional conditions. From a teleological point of view one may argue that this metabolic plasticity at the genome level enables this vital organ to maintain the required high level of energy production in the face of alterations in substrate supply.

Remarkably, unlike the liver, the cardiac muscle seems to be resistant to treatment with PPAR $\alpha$ ligands. The observation that systemic administration of the PPAR $\gamma$ ligand Rosiglitazone has a repressive effect on the expression of FA metabolizing enzymes in the heart is intriguing and may have far-reaching implications. As diabetic patients receive thiazolinediones as drug therapy on a regular basis and are already at risk of developing diabetic cardiomyopathy, this raises the question whether this by-effect will compromise cardiac energy production and, hence, cardiac performance in the long term.

\section{Acknowledgements}

$\mathrm{MvB}$ is an established investigator of the Netherlands Heart Foundation (1998T015).

$\mathrm{JH}$ was supported by a grant from the Netherlands Organization for Scientific Research (NWO). PS was supported by a fellowship of the Royal Netherlands Academy of Arts and Sciences. AB is Canada Research Chair in Metabolism and Health, Supported by the Canadian Institutes of Health Research and the Heart and Stroke Foundation of Ontario. 


\section{REFERENCES}

1. Desvergne B and Wahli W. Peroxisome Proliferator-Activated Receptors: Nuclear Control of Metabolism. Endocrine Rev. 1999;20:649-688.

2. Brandt JM, Djouadi F and Kelly DP. Fatty acids activate transcription of the Muscle Carnitine Palmitoyltransferase I gene in cardiac myocytes via the Peroxisome Proliferator-Activated Receptor-a. J Biol Chem. 1998;273:23786-23792.

3. Djouadi F, Brandt JM, Weinheimer CJ, Leone TC, Gonzalez FJ and Kelly DP. The role of the Peroxisome Proliferator-Activated Receptor- $\alpha(\operatorname{PPAR} \alpha)$ in the control of cardiac lipid metabolism. Prostaglandins Leukot Essent Fatty Acids. 1999;60:339-343.

4. Van der Lee KAJM, Vork MM, De Vries JE, Willemsen PHM, Glatz JFC, Reneman RS, Van der Vusse GJ and Van Bilsen M. Long-chain fatty acid-induced changes in gene expression in neonatal cardiac myocytes. J Lipid Res. 2000;41:41-47.

5. Gilde AJ, van der Lee KA, Willemsen PH, Chinetti G, van der Leij FR, van der Vusse GJ, Staels B and van Bilsen M. Peroxisome Proliferator-Activated Receptor (PPAR)- $\alpha$ and PPAR $\beta / \delta$, but not PPAR $\gamma$, modulate the expression of genes involved in cardiac lipid metabolism. Circ Res. 2003;92:518-524.

6. Van der Vusse GJ, Glatz JFC, Stam HCG and Reneman RS. Fatty acid homeostasis in the normoxic and ischemic heart Pbysiol Rev. 1992;72:881-940.

7. Van der Lee KAJM, Willemsen PHM, Samec S, Seydoux J, Dulloo AG, Pelsers MMAL, Glatz JFC, van der Vusse GJ and van Bilsen M. Fasting-induced changes in the expression of genes controlling substrate metabolism in the tat heart. J Lipid Res 2001;42:1752-1758.

8. Young ME, Patil S, Ying J, Depre C, Ahuja HS, Shipley GL, Stepkowski SM, Davies PJ and Taegtmeyer H. Uncoupling Protein 3 transcription is regulated by Peroxisome ProliferatorActivated Receptor- $\alpha$ in the adult rodent heart. FASEB J. 2001;15:833-845.

9. Young ME, Goodwin GW, Ying J, Guthrie P, Wilson CR, Laws FA and Taegtmeyer H. Regulation of cardiac and skeletal muscle Malonyl-CoA Decarboxylase by fatty acids. Am J Pbysiol. 2001;280:E471-E479.

10. Escher P, Braissant O, Basu-Modak S, Michalik L, Wahli W and Desvergne B. Rat PPARs: Quantitative analysis in adult rat tissues and regulation in fasting and refeeding. Endocrinology. 2001;142:4195-4202.

11. Sugden MC, Bulmer K, Gibbons GF, Knight BL and Holness MJ. Peroxisome-ProliferatorActivated Receptor- $\alpha$ (PPAR $\alpha$ ) deficiency leads to dysregulation of hepatic lipid and carbohydrate metabolism by fatty acids and insulin. Biochem J. 2002;364:361-368.

12. Xu HE, Lambert MH, Montana VG, Parks DJ, Blanchard SG, Brown PJ, Sternbach DD, Lehmann JM, Wisely GB, Willson TM, Kliewer SA and Milburn MV. Molecular recognition of fatty acids by Peroxisome Proliferator-Activated Receptors. Molecular Cell. 1999;3:397-403.

13. Van der Vusse GJ, van Bilsen M and Glatz JFC. Cardiac fatty acid uptake and transport in health and disease. Cardionasc Res. 2000;45:279-293.

14. Van der Lee KAJM, Willemsen PHM, van der Vusse GJ and van Bilsen M. Effects of fatty acids on Uncoupling Protein-2 expression in the rat heart. FASEB J. 2000;14:495-502.

15. Brun S, Carmona MC, Mampel T, Viñas O, Giralt M, Iglesias R and Villarroya F. Activators of Peroxisome Proliferator-Activated Receptor- $\alpha$ induce the expression of the Uncoupling Protein- 3 gene in skeletal muscle. A potential mechanism for the lipid intake-dependent activation of Uncoupling Protein-3 gene expression at birth. Diabetes. 1999;48:1217-1222.

16. Schrauwen P, Hoeks J, Schaart G, Kornips E, Binas B, Van Der Vusse GJ, Van Bilsen M, Luiken JJ, Coort SL, Glatz JF, Saris WH and Hesselink MK. Uncoupling Protein 3 as a mitochondrial fatty acid anion exporter. FASEB J. 2003;17:2272-2274. 
17. Wallenstein S, Zucker CL and Fleiss JL. Some statistical methods useful in Circulation Research. Circ Res. 1980;47:1-9.

18. Motojima $\mathrm{K}$ and Seto $\mathrm{K}$. Fibrates and statins rapidly and synergistically induce Pyruvate Dehydrogenase Kinase $4 \mathrm{mRNA}$ in the liver and muscles of mice. Biol Pharm Bull. 2003;26:954-958.

19. Huang $B$, Wu P, Bowker-Kinley $M M$ and Harris RA. Regulation of Pyruvate Dehydrogenase Kinase expression by Peroxisome Proliferator-Activated Receptor- $\alpha$ ligands, glucocorticoids, and insulin. Diabetes. 2002;51:276-283.

20. Le May C, Pineau T, Bigot K, Kohl C, Girard J and Pegorier JP. Reduced hepatic fatty acid oxidation in fasting PPAR $\alpha$ null mice is due to impaired mitochondrial HydroxymethylglutarylCoA Synthase gene expression. FEBS Lett. 2000;475:163-166.

21. Kok T, Wolters H, Bloks VW, Havinga R, Jansen PL, Staels B and Kuipers F. Induction of hepatic $A B C$ transporter expression is part of the PPAR $\alpha$-mediated fasting response in the mouse. Gastroenterology. 2003;124:160-171.

22. Leone TC, Weinheimer CJ and Kelly DP. A critical role for the Peroxisome Proliferator-Activated Receptor- $\alpha$ (PPAR $\alpha$ ) in the cellular fasting response: The PPAR $\alpha$-null mouse as a model of fatty acid oxidation disorders. Proc Natl Acad Sci USA. 1999;96:7473-7478.

23. St-Onge MP and Jones PJ. Physiological effects of medium-chain triglycerides: Potential agents in the prevention of obesity. J Nutr. 2002;132:329-332.

24. Hoeks J, Hesselink MK, van Bilsen M, Schaart G, van der Vusse GJ, Saris WH and Schrauwen P. Differential response of UCP3 to medium versus long chain triacylglycerols; Manifestation of a functional adaptation. FEBS Lett. 2003;555:631-637.

25. Han J, Hamilton JA, Kirkland JL, Corkey BE and Guo W. Medium-chain oil reduces fat mass and down-regulates expression of adipogenic genes in rats. Obes Res. 2003;11:734-744.

26. Osawa $\mathrm{H}$, Sutherland C, Robey RB, Printz RL and Granner DK. Analysis of the signaling pathway involved in the regulation of Hexokinase II gene transcription by insulin. $J$ Biol Chem. 1996;271:16690-16694.

27. Hernandez R, Teruel $\mathrm{T}$ and Lorenzo M. Insulin and dexamethasone induce GLUT4 gene expression in foetal brown adipocytes: Synergistic effect through CCAAT/Enhancer-Binding Protein $\alpha$. Biochem J. 2003;372:617-624.

28. Camps M, Castello A, Munoz P, Monfar M, Testar X, Palacin M and Zorzano A. Effect of diabetes and fasting on GLUT-4 (Muscle/Fat) glucose-transporter expression in insulin-sensitive tissues. Heterogeneous response in heart, red and white muscle. Biochem. J. 1992;282:765-772.

29. Yechoor VK, Patti ME, Saccone R and Kahn CR. Coordinated patterns of gene expression for substrate and energy metabolism in skeletal muscle of diabetic mice. Proc Natl Acad Sci USA. 2002;99:10587-10592.

30. Kim CH, Kim MS, Youn JY, Park HS, Song HS, Song KH, Park JY and Lee KU. Lipolysis in skeletal muscle is decreased in high-fat-fed rats. Metabolism. 2003;52:1586-1592.

31. Iossa S, Lionetti L, Mollica MP, Crescenzo R, Botta M, Barletta A and Liverini G. Effect of high-fat feeding on metabolic efficiency and mitochondrial oxidative capacity in adult rats. $\mathrm{Br} J \mathrm{Nutr}$. 2003;90:953-960.

32. Van Bilsen $M$, van der Vusse GJ, Gilde AJ, Lindhout $M$ and van der Lee KA. Peroxisome Proliferator-Activated Receptors: Lipid binding proteins controling gene expression. Mol Cell Biochem. 2002;239:131-138.

33. Schoonjans K, Peinado-Onsurbe J, Lefebvre A-M, Heyman RA, Briggs M, Deeb S, Staels B and Auwerx J. PPAR $\alpha$ and PPAR $\gamma$ activators direct a distinct tissue-specific transcriptional response via a PPRE in the Lipoprotein Lipase gene. EMBO J. 1996;15:5336-5348.

34. Schoonjans K, Staels B and Auwerx J. Role of the Peroxisome Proliferator-Activated Receptor (PPAR) in mediating the effects of fibrates and fatty acids on gene expression. I Iipid Res. 1996;37:907-925. 
35. Martin G, Schoonjans K, Lefebvre AM, Staels B and Auwerx J. Coordinate regulation of the expression of the Fatty Acid Transport Protein and Acyl-CoA Synthetase genes by PPAR $\alpha$ and PPAR $\gamma$ activators. J Biol Chem. 1997;272:28210-28217.

36. Cook WS, Yeldandi AV, Rao MS, Hashimoto $T$ and Reddy JK. Less. Extrahepatic induction of fatty acid $\beta$-oxidation enzymes by PPAR $\alpha$. Biochem Biopbys Res Commun. 2000;278:250-257.

37. Holness MJ, Smith ND, Bulmer K, Hopkins T, Gibbons GF and Sugden MC. Evaluation of the role of Peroxisome-Proliferator-Activated Receptor- $\alpha$ in the regulation of cardiac Pyruvate Dehydrogenase Kinase 4 protein expression in response to starvation, high-fat feeding and hyperthyroidism. Biochem J. 2002;364:687-694.

38. Holness MJ, Bulmer K, Gibbons GF and Sugden MC. Up-regulation of Pyruvate Dehydrogenase Kinase Isoform 4 (PDK4) protein expression in oxidative skeletal muscle does not require the obligatory participation of Peroxisome-Proliferator-Activated Receptor $\alpha$ (PPAR $\alpha$ ). Biochem J. 2002;366:839-846.

39. Wu Q and Haunerland NH. A novel Fatty Acid Response Element controls the expression of the Flight Muscle FABP gene of the desert locust, Schistocerca Gregaria. Eur J Biochem. 2001;268:58945900.

40. Jump DB. Dietary polyunsaturated fatty acids and regulation of gene transcription. Curr Opin Lipidol. 2002;13:155-164.

41. Sekiya M, Yahagi N, Matsuzaka T, Najima Y, Nakakuki M, Nagai R, Ishibashi S, Osuga J, Yamada $\mathrm{N}$ and Shimano $\mathrm{H}$. Polyunsaturated fatty acids ameliorate hepatic steatosis in obese mice by SREBP-1 suppression. Hepatology. 2003;38:1529-1539.

42. Hevener AL, He W, Barak Y, Le J, Bandyopadhyay G, Olson P, Wilkes J, Evans RM and Olefsky J. Muscle-specific PPAR $\gamma$ deletion causes insulin resistance. Nat Med. 2003;9:1491-1497.

43. Edvardsson U, Bergstrom M, Alexandersson M, Bamberg K, Ljung B and Dahllof B. Rosiglitazone (BRL49653), a PPAR $\gamma$-Selective agonist, causes Peroxisome Proliferator-like liver effects in obese mice. J Lipid Res. 1999;40:1177-1184.

44. Sidell RJ, Cole MA, Draper NJ, Desrois M, Buckingham RE and Clarke K. Thiazolidinedione treatment normalizes insulin resistance and ischemic injury in the Zucker fatty rat heart. Diabetes. 2002;51:1110-1117.

45. Cabrero A, Jove M, Planavila A, Merlos M, Laguna JC and Vazquez-Carrera M. Down-regulation of Acyl-CoA Oxidase gene expression in heart of Troglitazone-treated mice through a mechanism involving Chicken Ovalbumin Upstream Promoter Transcription Factor II. Mol Pharmacol. 2003;64:764-772.

46. Carter ME, Gulick T, Moore DD and Kelly DP. A Pleiotropic Element in the Medium-Chain Acyl Coenzyme A Dehydrogenase gene promoter mediates transcriptional regulation by multiple nuclear receptor transcription factors and defines novel receptor-DNA binding motifs. Mol Cell Biol. $1994 ; 14: 4360-4372$.

47. Sack MN, Disch DL, Rockman HA and Kelly DP. A role for Sp and nuclear receptor transcription factors in a cardiac hypertrophic growth program. Proc Natl Acad Sci US A. 1997;94:6438-6443. 
$\alpha_{1}$-ADRENERGIC AND THYROID HORMONE-INDUCED PHENOTYPIC AND METABOLIC ALTERATIONS IN NEONATAL CARDIOMYOCYTES

Andries J Gilde, Peter HM Willemsen, Martijn Lindhout, Pascal Smeets, Ger J van der Vusse and Marc van Bilsen

Manuscript in preparation 


\subsection{ABSTRACT}

The current paradigm reads that fatty acid (FA) metabolism is attenuated in the hypertrophied and failing heart, due to decreased expression of genes involved in FA uptake en metabolism, secondary to a decline in Peroxisome Proliferator-Activated Receptor $\alpha$ (PPAR $\alpha$ ) activity, key regulator of the expression of FA handling proteins. The aim of the present study was to investigate the relation between the expression of FA handling genes and FA oxidation rate during cardiac hypertrophy using neonatal tat cardiomyocytes (NCM) as model system.

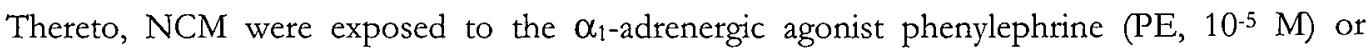
thyroid hormone $\left(\mathrm{T} 3,10^{-8} \mathrm{M}\right)$ in the absence or presence of natural $(\mathrm{FA})$ or synthetic (Wy14,643) PPAR $\alpha$ ligands for 48 hours. PE and T3 stimuli induced distinct cellular phenotypes as evidenced by cell morphology and the differential expression of the hypertrophic marker gene Atrial Natriuretic Factor and Sarcoplasmic Reticulum $\mathrm{Ca}^{2+}$-ATPase 2a. PE and T3 neither affected the basal expression nor PPAR-mediated induction of a panel of lipid metabolising genes. In transient transfection studies the basal activity of the human Muscle-type Carnitine Palmitoyl Transferase-I promoter was not affected by PE or T3. However, the PPAR-mediated enhancement of MCPT-1 promoter activity was reduced in PE- and T3-treated NCM. Functionally, PE but not T3 markedly increased the oxidation of $\left[{ }^{14} \mathrm{C}\right]$-palmitate (3-fold), whereas the oxidation rates of glucose and pyruvate remained constant. The PPAR-mediated increase in $\left[{ }^{14} \mathrm{C}\right]$-palmitate oxidation rate was not affected by PE or T3. The present findings point to a selective increase of FA oxidation capacity in PE-stimulated hypertrophied cardiomyocytes independent of changes in the expression of FA handling genes, thereby challenging the concept that cardiac hypertrophy is associated with a decline in PPAR $\alpha$ activity and, consequently, reduced expression of lipid metabolising genes and reduced FA oxidation rate. 


\subsection{INTRODUCTION}

Cardiac hypertrophy and failure are associated with multiple changes in cardiac energy metabolism, one of the most characteristic features being a shift away from long-chain fatty acids (FA) towards glucose as the primary energy source ${ }^{1}$. Both in vivo and in vitro studies provided indications that this metabolic shift can be attributed to a diminished expression of genes encoding for proteins involved in myocardial FA oxidation ${ }^{2-4}$. It is commonly acknowledged that transcription factors of the ligand-activated nuclear hormone receptor family, i.e., the Peroxisome Proliferator-Activated Receptors (PPARs) play a pivotal role in the transcriptional regulation of lipid metabolism ${ }^{5,6}$. As for now three PPAR isoforms (PPAR $\alpha$, $\operatorname{PPAR} \beta / \delta$ and PPAR $\gamma$, each encoded by a different gene, have been identified. Long-chain FA are considered to act as natural ligands for the PPARs. The PPARs interact with the RetinoidX-Receptor (RXR) and the PPAR/RXR heterodimer binds to the consensus DNA-binding sequence AGGTCAnAGGTCA, referred to as Peroxisome Proliferator Response Element (PPRE). Many genes responsible for the uptake and intracellular metabolism of FA contain a functional PPRE ${ }^{7}$, making PPAR a feasible candidate for the orchestration of the observed metabolic changes associated with cardiac hypertrophy and failure. Indeed, several studies showed that during cardiac hypertrophy PPAR $\alpha$ and $\operatorname{RXR} \alpha$ content are reduced ${ }^{8}$, ?. The latter observations provide a mechanistic explanation for the decline in expression of FA metabolising genes and, hence, for the diminished utilization of FA in the setting of cardiac hypertrophy. Furthermore, in humans certain polymorphisms in the PPAR $\alpha$ gene influence the degree of left ventricular hypertrophy as induced by exercise or hypertension ${ }^{10}$. Collectively, these findings suggest that, on the one hand, cardiac hypertrophy is associated with changes in PPAR $\alpha$ activity and, on the other hand, intrinsic changes in PPAR $\alpha$ activity may influence the hypertrophic response. Consistent with this cardiomyocyte hypertrophy, as induced by the

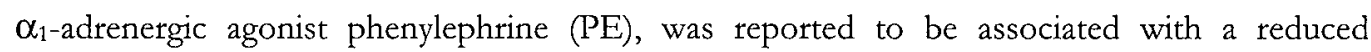
expression of the PPAR-responsive Muscle-type Carnitine-Palmitoyl Transferase-1 (MCPT-1) gene and a reduction in FA oxidation rate ${ }^{8}$. Furthermore, exposure of neonatal rat cardiomyocytes to the long-chain FA oleate was found to potentiate norepinephrine-induced hypertrophy ${ }^{11}$. On the other hand, the potent synthetic PPAR $\alpha$ ligand $W y-14,643$ was found to 
attenuate the endothelin-induced hypertrophy in neonatal cardiomyocytes ${ }^{12}$. Accordingly, the exact nature of the link between PPAR $\alpha$, cardiac FA metabolism, and cardiomyocyte hypertrophy still remains to be established.

To investigate the relationship between cardiomyocyte hypertrophy and the transcriptional regulation of cardiac FA metabolism in more detail, primary cultures of neonatal rat cardiomyocytes were exposed to the $\alpha_{1}$-adrenergic agonist PE or to thyroid hormone (T3). T3 was included, as this hormone has been reported to induce a distinct cell phenotype, which in some ways resembles a more physiological (e.g. exercise-induced) instead of pathological type of cardiac hypertrophy ${ }^{13}$. PE- and T3-treated cardiomyocytes were co-incubated with FA or Wy-14,643, representing natural and synthetic PPAR $\alpha$ ligands, respectively, in order to evaluate whether PPAR-mediated expression of genes involved in FA uptake and metabolism was mitigated in hypertrophic cardiomyocytes. To this end, the effect of these interventions on the expression of hypertrophic marker genes (ANF, SERCA2a) was monitored. To investigate the effects on metabolic remodeling, the mRNA and protein levels of a panel of (PPARresponsive) genes involved in FA metabolism were assessed. Besides, transient transfection was applied to evaluate the effects of the hypertrophic stimuli on the transcriptional activity of the human MCPT-1 promoter. Finally, oxidation rates of various energy providing substrates (FA, glucose, pyruvate) were determined in an attempt to link changes in gene expression, if any, to functional effects.

Collectively, the present findings do not support the contention that PPAR-mediated expression is affected in cardiac hypertrophy. In contrast, we observed a selective increase in FA oxidation capacity in PE-stimulated hypertrophic cardiomyocytes, which may be accounted for by post-translational, rather than transcriptional mechanisms. 


\subsection{MATERIALS AND METHODS}

\subsubsection{Cell culture}

Experiments were approved according to the guidelines of the Institutional Animal Care and User Committee of the Maastricht University. Neonatal rat ventricular cardiomyocytes were prepared as described previously ${ }^{14}$. Cells were plated at a density of 250 cells $/ \mathrm{mm}^{2}$. Chemicals were obtained from Sigma (Sigma, St. Louis MO, USA) unless mentioned otherwise. At the start of the experiments, cardiomyocytes were incubated in serum-free medium consisting of a 4:1 mixture of DMEM/M199, gentamicin (50 mg/L) and glucose (10 mM) as the sole substrate, for $24 \mathrm{~h}$. Subsequently, the cells were rinsed once with serum-free medium, whereupon experimental medium was applied to the cells. The experimental medium consisted of serum-free medium enriched with $0.25 \mathrm{mM} \mathrm{L}$-carnitine, $0.25 \mathrm{mU} / \mathrm{ml}$ insulin and $0.15 \mathrm{mM}$ bovine serum albumin. Cardiomyocytes were treated with $10 \mu \mathrm{M}$ phenylephrine (PE) or 10 $\mathrm{nM}$ triiodothyrodine (T3), added to the experimental-medium. Long-chain fatty acids (FA) palmitic and oleic acid $(0.25 \mathrm{mM})$ each complexed to $0.15 \mathrm{mM} \mathrm{BSA}$, as described elsewhere ${ }^{14}$ or the PPAR $\alpha$-specific ligand Wy-14,643 (10 $\mu \mathrm{M}$ ) (Biomol, Plymouth Meeting, PA, USA) were used as PPAR ligands. Wy-14,643 was dissolved in DMSO, which was also added as vehicle $(0.1 \% \mathrm{v} / \mathrm{v})$ to control cells.

\subsubsection{Cytocbemistry}

Cardiomyocytes were cultured on coated glass coverslips (fibronectin $12.5 \mu \mathrm{g} / \mathrm{ml}$ in $0.02 \%$ gelatin) in 6-well plates and exposed to PE or T3. Unexposed cells served as control. After $48 \mathrm{~h}$ treatment, the plates were washed with ice-cold PBS and fixed with $3.7 \%$ formaline in PBS. Cells were permeabilized for 10 min using 0.1\% Triton X-100 in PBS and subsequently stained with Phalloidin-TRITC (200 nM in 0.1\% Triton X-100 in PBS) and Hoechst-33258 $(2.5 \mu \mathrm{g} / \mathrm{ml}$ in $0.1 \%$ Triton $\mathrm{X}-100$ in PBS) for $30 \mathrm{~min}$. Thereafter, cells were washed with PBS and analysed using a fluorescence microscope (Nikon Eclipse E800). 


\subsubsection{RNA analysis}

After $48 \mathrm{~h}$ of incubation RNA was isolated from culture plates $(10 \mathrm{~cm} \varnothing)$, with Tri Reagent. Total RNA was size-fractionated, transferred to nylon membranes, and probed with cDNA fragments of Fatty Acid Translocase (FAT/CD36), Heart-type Fatty Acid-Binding Protein (HFABP), Acyl-CoA Synthetase (ACS), Muscle-Carnitine Palmitoyl Transferase-1 (MCPT-1), Long-Chain Acyl-CoA Dehydrogenase (LCAD), and Uncoupling Protein 2 (UCP-2) as described previously5, 15, 16. Probes for the hypertrophic markers Atrial Natriuratic Factor (ANF) and Sarcoplasmic Reticulum $\mathrm{Ca}^{2+}$-ATPase 2a (SERCA2a) were generated according to Degens et al. ${ }^{17}$. The cDNA probes were labeled with ${ }^{32} \mathrm{P}$-dCTP $(3000 \mathrm{Ci} / \mathrm{mmol}$; Amersham Pharmacia Biotech UK Limited, Buckinghamshire, UK) by random-priming (Radprime, Life Technologies) to a specific activity of $>0.5 \times 10^{9} \mathrm{cpm} / \mu \mathrm{g}$ DNA. To correct for possible differences in transfer and loading the membranes were also hybridised with a 32P-labeled ribosomal 18S RNA probe. Following hybridisation, membranes were washed at the appropriate stringency to remove non-specific binding. The membranes were exposed to imaging screens and subsequently scanned on a Personal FX Imager (Bio-Rad Laboratories, Hercules, CA, USA). Signals were quantified using Quantity One software (Bio-Rad).

\subsubsection{Transient transfection}

Transient transfection of cardiomyocytes was performed as described before ${ }^{6}$. In short, cells seeded on 6-well plates, were transfected with $0.5 \mu \mathrm{g}$ of the pGL3 luciferase vector containing a $1.3 \mathrm{~kb}$ fragment of the human MCPT-1 promoter (MCPT-1-luc) using the transfection reagent FuGENE 6 (Roche, Indianapolis, IN, USA). Transfection efficiency was checked with the CMV- $\beta$-galactosidase containing vector pON249 $(0.25 \mu \mathrm{g})$. The total amount of plasmid DNA per well and the ratio of plasmid DNA $(\mu \mathrm{g})$ over FUGENE $(\mu \mathrm{l})$ was kept constant by adding empty pSG5 vector (Promega, Madison, WI, USA), according to the manufacturers instructions. Luciferase activity was determined using a commercial firefly luciferase assay according to the supplier's instructions (Steady Glo, Promega) in white 96-well plates (Nunc International, Maperville, IL, USA) and FluorS Imager (Bio-Rad) for measuring luminescence. $\beta$-Galactosidase activity was determined spectrophotometrically. 


\subsubsection{Western-Blotting}

Cardiomyocytes were cultured on $10 \mathrm{~cm}$ plates. After $48 \mathrm{~h}$ cells were rinsed three times with ice-cold PBS and subsequently lysed in sample buffer consisting of $69 \mathrm{mM}$ Tris- $\mathrm{HCl} \mathrm{pH} 6.8$, $5 \%$ glycerol, $2 \%$ SDS, and $5 \% \beta$-mercapto-ethanol. Protein concentration was determined using RC-DC Protein Assay (Bio-Rad), according to the manufacturers instructions. The protein samples $(15 \mu \mathrm{g})$ were separated on a 10\% acrylamide-gel and blotted on a nitrocellulose membrane (Bio-Rad) using standard techniques. Antibodies for H-FABP ${ }^{18}$ and FAT/CD36 (Dr. N. Tandon, Otsuka Pharmaceuticals, Bethesda, MD, U.S.A.) were diluted in TBS-T 1:3000, and TBS-T containing 5\% non-fat dry milk 1:20,000, respectively ${ }^{19}$. Membranes were blocked by $5 \% \mathrm{BSA}$ or $7.5 \% \mathrm{BSA}$ in TBS-T for $\mathrm{H}-\mathrm{FABP}$ or FAT detection, respectively. Subsequently, the membranes were incubated with a secondary antibody, rabbit anti-mouse conjugated with Peroxidase, diluted 1:2500 in TBS-T for both H-FABP and FAT.

To correct for possible differences in transfer and loading, the membranes were also incubated with a GAPDH antibody (RDI, Flanders, NJ, U.S.A.). Membranes were blocked by $5 \%$ non-fat dry milk in TBST-T. The GAPDH antibody was diluted 1:5000 in TBS-T. Subsequently, the membranes were incubated with a secondary antibody, rabbit anti-mouse conjugated with Peroxidase, diluted 1:2500 in TBS-T.

Detection of the signal was established by using the ECLTM Western Blotting Analysis System (Amersham Biosciences) in combination with Hyperfilm (Amersham Biosciences) and quantified using a FluorS Imager (Bio-Rad).

\subsubsection{Oxidation of substrates}

After incubating cardiomyocytes with experimental medium for the indicated time, the palmitate, glucose and pyruvate oxidation rates were determined using radioactively labelled substrates (Amersham Pharmacia Biotech, s'-Hertogenbosch, The Netherlands). The palmitate oxidation protocol was adapted from Van der Lee et al.5. In short, the experimental medium was aspirated and the cells were washed with oxidation buffer, containing $\mathrm{NaCl}(120 \mathrm{mM})$, HEPES $(20 \mathrm{mM}), \mathrm{NaH}_{2} \mathrm{PO}_{4}(1 \mathrm{mM}), \mathrm{KCl}(5 \mathrm{mM}), \mathrm{MgSO}_{4}(0.4 \mathrm{mM}), \mathrm{CaCl}_{2}(1 \mathrm{mM}), \mathrm{L}-$ carnitine $(0.25 \mathrm{mM})$, insulin $(0.25 \mathrm{U} / \mathrm{l})$, and $\mathrm{BSA}(0.3 \mathrm{mM})$ at $\mathrm{pH} 7.4$. For the determination of palmitate oxidation rate, the oxidation buffer was supplemented with a combination of palmitate $(0.05 \mathrm{mM})$ and oleate $(0.05 \mathrm{mM})$ complexed to $\mathrm{BSA}$ and added to the cells. 
Alternatively, to determine glucose or pyruvate oxidation rate, the oxidation buffer was supplemented with glucose $(5 \mathrm{mM})$ or pyruvate $(1 \mathrm{mM})$, respectively. Cells were pre-incubated in these buffers for $30 \mathrm{~min}$ at $37^{\circ} \mathrm{C}$, after which tracer was added (either $3 \cdot 10^{5} \mathrm{cpm}$ of $[1-14 \mathrm{C}]$ palmitate bound to BSA, $6 \cdot 10^{5} \mathrm{cpm}$ of D-[U-1 $\left.{ }^{14} \mathrm{C}\right]$-glucose, or $3 \cdot 10^{5} \mathrm{cpm}$ of $\left[1-{ }^{14} \mathrm{C}\right]$-pyruvate per dish). After $30 \mathrm{~min}$ of incubation in the presence of tracer, a well containing $1 \mathrm{M} \mathrm{NaOH}$ as $\mathrm{CO}_{2}$-trapping agent was inserted and the Petri-dish was sealed air tight with Parafilm (American National Can, Chicago, IL, USA). $\mathrm{CO}_{2}$ production was stopped after $30 \mathrm{~min}$ by injection $0.5 \mathrm{ml}$ of $5 \mathrm{M} \mathrm{HClO}_{4}$ through the silicone septum into the oxidation buffer. $\left[{ }^{14} \mathrm{C}\right]-\mathrm{CO}_{2}$ was allowed to accumulate overnight in the trapping agent and was counted thereafter by means of liquid scintillation.

\subsubsection{Statistics}

Results are obtained from triplicate incubations in at least three independent cardiomyocyte isolations and presented as sample means $\pm \mathrm{SD}$. Comparison between groups was performed with one-way analysis of variance (ANOVA). In case the F-ratio obtained indicated that significant differences between groups were present, a two-tailed Student's t-test for unpaired data was carried out, applying Bonferroni's adjustment for a multiple comparison ${ }^{20}$. Differences were considered significant at $\mathrm{p}<0.05$.
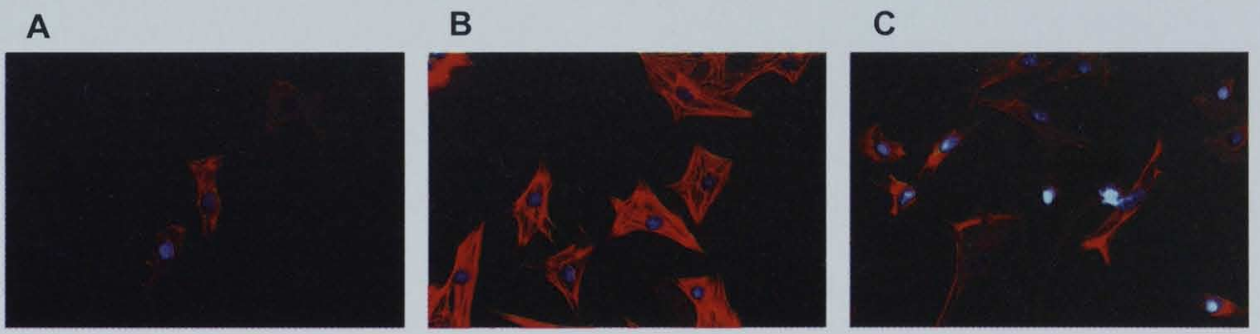

Figure 4.1

Morphological changes in neonatal cardiomyocytes stimulated with PE $(1 \mu \mathrm{M})$ or T3 $(1 \mathrm{nM})$ for $48 \mathrm{~h}$. Phalloidine-TRITC and Hoechst 33258 staining was applied to visualise F-actin and nuclei, respectively, in unstimulated (A) and PE (B)- and T3 (C)-stimulated cardiomyocytes. 


\subsection{RESULTS}

\subsubsection{Cardiomyocyte Phenotype}

To investigate the effect of PE $(10 \mu \mathrm{M})$ and $\mathrm{T} 3(10 \mathrm{nM})$ on neonatal cardiomyocytes phenotype, cellular morphology, cellular protein content, and the expression of marker genes were monitored after $48 \mathrm{~h}$ of stimulation.

PE stimulation resulted in enlargement of cells with a typical triangular appearance and sarcomere organisation (Fig. 4.1) along with a 50\% increase in cell protein content (Fig. 4.2A). In contrast, T3 treatment resulted in elongation of the cells without a significant change in cell protein content (Fig. 4.1 and 4.2A).

The mRNA level of the hypertrophy marker ANF was markedly increased ( $>20$ fold) in PE-stimulated cells compared to unstimulated cells. T3 did not affect ANF expression (Fig. 4.2B). The expression of SERCA2a was not changed in the PE group, whilst T3 increased the expression of SERCA2a over 2 fold (Fig. 4.2C).

Co-incubation with long-chain fatty acids (FA) affected neither the morphological appearance of PE- and T3-stimulated cells (data not shown), nor the protein content, nor the mRNA levels of ANF and SERCA2a (Fig. 4.2), demonstrating that FA did not modify the hypertrophic response of cardiomyocytes.

A
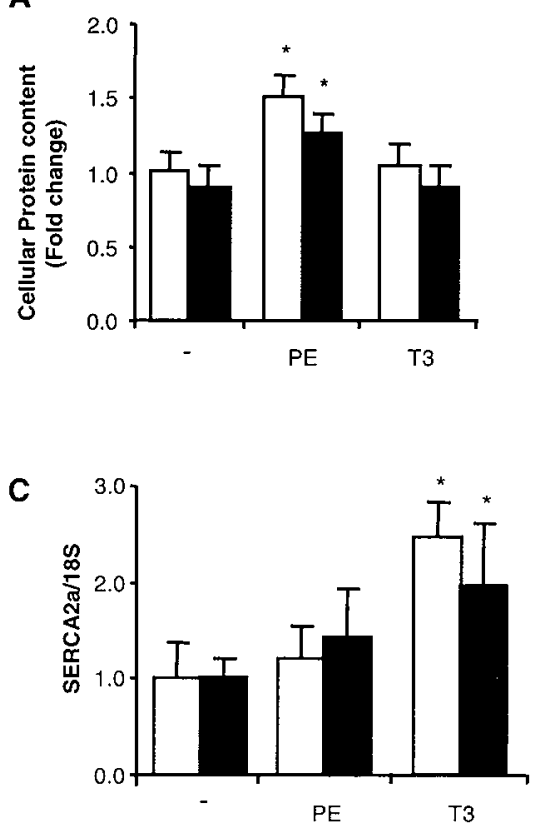

B

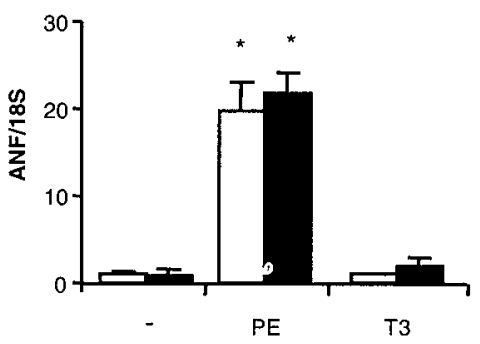

Figure 4.2

Effect of $P E$ and $T 3$ on protein content (panel $A$ ), and mRNA levels of ANF (panel B) and SERCA2a (panel C) of cardionyocytes cultured in the absence (open bars) or presence (black bars) of FA. Results are expressed as fold change compared to unstimulated cells cultured in the absence of $F A$, the average value of which was set 1.0 . Data are presented as means \pm SD. * Indicates significantly different $(p<0.05)$ from unstimulated cells cultured in the absence of $F A$. 


\subsubsection{Expression of $F A$ bandling genes}

As hypertrophy has been reported to be associated with a reduction in the expression of FA-metabolising genes ${ }^{2}$ and FA co-ordinately induce the expression of these genes in a PPARdependent manner ${ }^{5}$ the interaction between hypertrophic stimuli and FA was investigated. Remarkably, stimulation of cardiomyocytes with either PE or T3 did not affect the expression of any of the PPAR-dependent genes examined, i.e. FAT/CD36, H-FABP, ACS, MCPT-1, LCAD, and UCP-2 (Fig. 4.3). As reported earlier ${ }^{5}$ exposure of unstimulated cardiomyocytes to FA resulted in significantly increase in the mRNA level of genes involved in trans-sarcolemmal FA uptake and intracellular transport (FAT/CD36, H-FABP), and FA metabolism (ACS, MCPT-1, LCAD, UCP-2). Neither PE nor T3 affected the FA-mediated induction of these PPAR-dependent genes, the only exception being H-FABP. The FA-induced expression of $\mathrm{H}-$ FABP was mitigated in PE-treated cells, and potentiated in T3-treated cells.
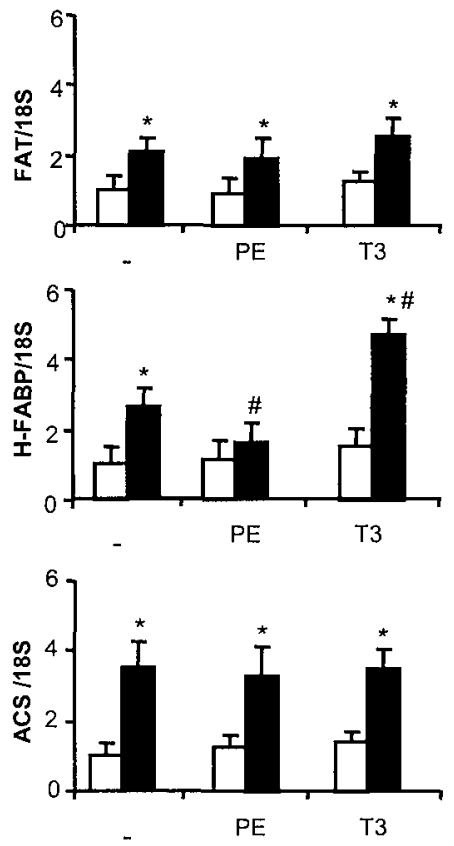
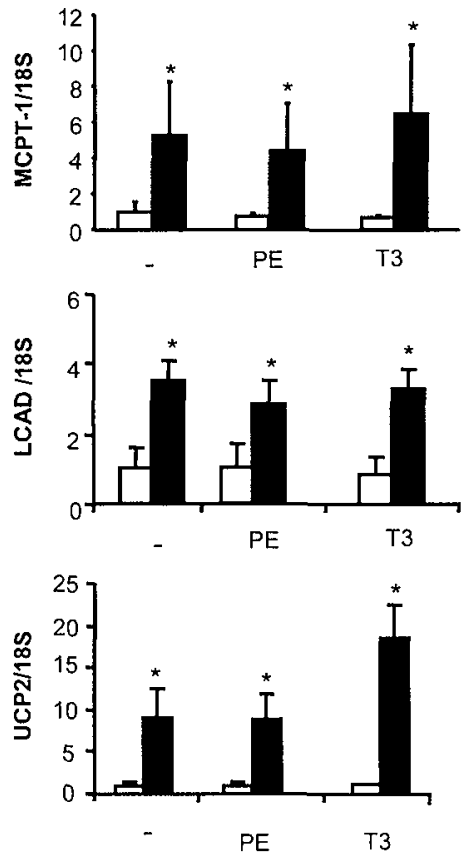

Figure 4.3

Effect of PE and T3 stimulation on mRNA levels of FAT/CD36, H-FABP, ACS, MCPT-1, LCAD, and UCP-2 in cardiomyocytes cultured in the absence (open bars) or presence (black bars) of FA. Results are expressed as fold change compared to unstimulated cells cultured in the absence of FA, the average value of which was set 1.0. Data are presented as means $\pm S D$. * Indicates significantly different $(p<0.05)$ from the unstimulated cells cultured in the absence of FA.

\# Indicates significantly different $(\mathrm{p}<0.05)$ from unstimulated cells cultured in the presence of FA. 


\subsubsection{MCPT-1 promoter activity}

Next, the interaction between hypertrophic stimuli and FA was investigated at the transcriptional level using the PPAR-responsive MCPT-1 promoter as read-out (Fig. 4.4). Stimulation of cardiomyocytes with PE or T3 did not influence MCPT-1 promoter activity.

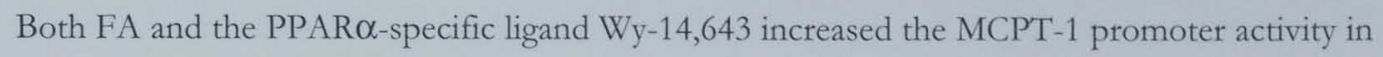

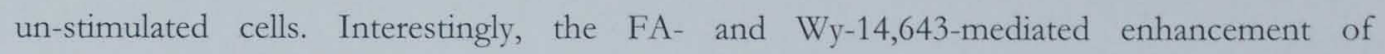
transcriptional activity was significantly attenuated by PE as well as T3.
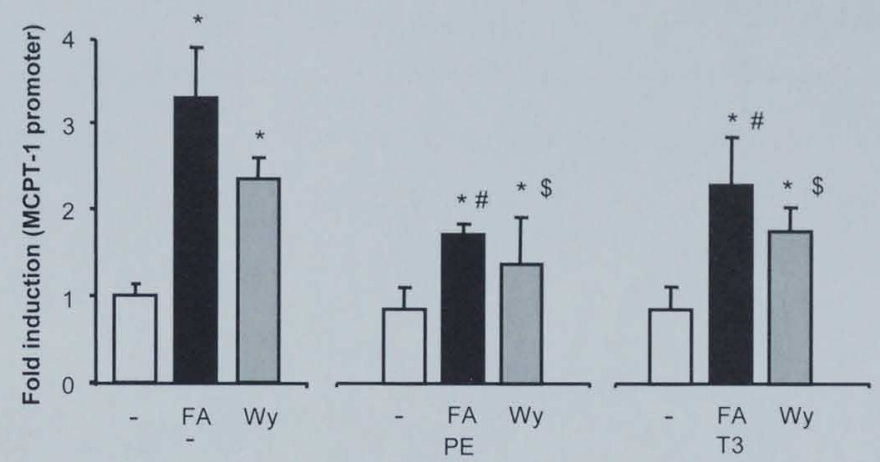

\section{Figure 4.4}

The effect of PE and T3 on MCPT-1 promoter activity in transiently transfected cardiomyocytes cultured in the absence (open bars) or presence of FA (black bars) or Wy-14,643 (grey bars). Results are expressed as fold induction compared to unstimulated cells, the average value of which was set $1.0 . *$ Indicates significantly different $(p<0.05)$ from unstimulated cells. \# Indicates significantly different $(\mathrm{p}<0.05)$ from corresponding unstimulated cells exposed to FA. $\$$ Indicates significantly different $(\mathrm{p}<0.05)$ from corresponding unstimulated cells exposed to $\mathrm{W} y-14,643$.

\subsubsection{Protein levels of metabolic genes.}

To evaluate whether the changes at the promoter and mRNA level also led to comparable changes in protein content, Western-blot analysis was performed on a selection of genes (Fig. 4.5). Consistent with the mRNA data, stimulation of the cells with PE or T3 for 48h was not associated with changes in the cellular protein level of FAT/CD36 (Fig. 4.5A). Likewise, when un-stimulated cells are exposed to FA or Wy-14,643 an increase in FAT/CD36 protein content is observed, reaching the level of significance for FA, but not for Wy-14,643.

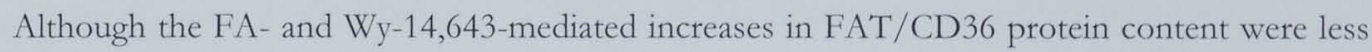
pronounced in PE- and T3 treated cells, these changes did not reach the level of significance. 
The H-FABP content was not altered to a significant extent in cardiomyocytes in response to $\mathrm{PE}$ or T3 stimulation, regardless whether or not the cells were co-incubated with FA or Wy14,643 (Fig. 4.5B).

A
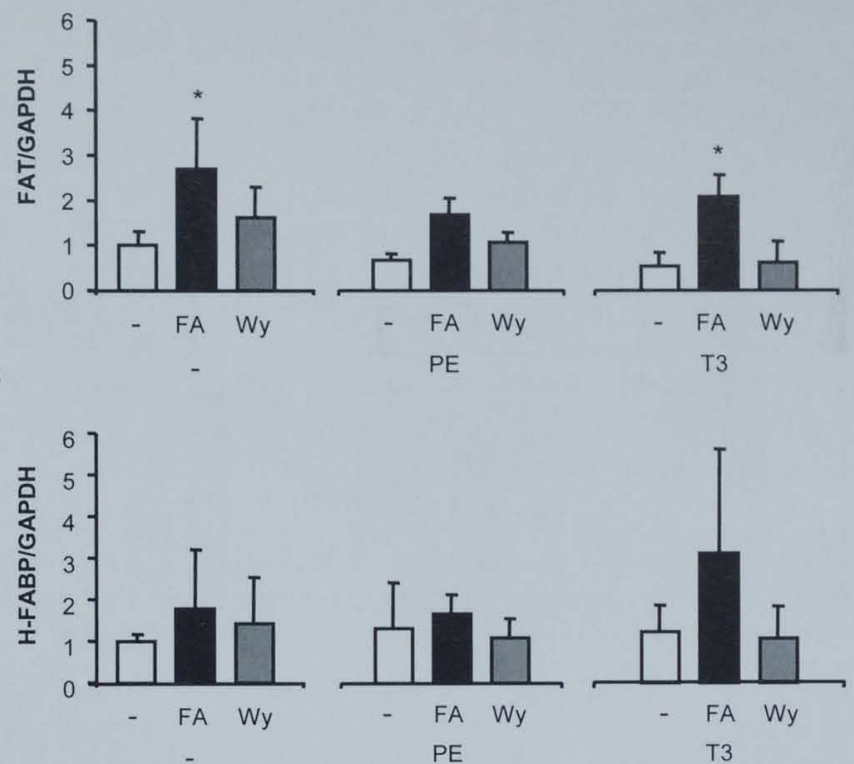

Figure 4.5

The effect of PE and T3 on cellular FAT/CD36 (panel A) and H-FABP (panel B) protein content of cardiomyocytes cultured in the absence (open bars) or presence of FA (black bars) or Wy-14,643- (grey bars). Results are expressed as fold change compared to unstimulated cells, the average value of which was arbitrarily set $1.0 . *$ Indicates significantly different $(p<0.05)$ from untreated control.

\subsubsection{Fatty acid oxidation}

To investigate the functional consequences of $\mathrm{PE}$ and $\mathrm{T} 3$ stimulation on cardiac FA metabolism, the oxidation rate of palmitate was determined. In contradiction to the generally held view that cardiac hypertrophy is associated with a reduction in FA oxidation a nearly 3fold increase in palmitate oxidation was observed in PE-induced hypertrophic cardiomyocytes (Fig. 4.6A). This effect was specific for PE as palmitate oxidation was not altered in T3stimulated cells.

To examine the possibility that the PE-induced rise in FA oxidation reflected an overall increase in oxidative metabolism, glucose (Fig. 4.6B) and pyruvate (Fig. 4.6C) oxidation were 
determined as well. However, the oxidation rate of these substrates was not enhanced in response to stimulation with hypertrophic factors, indicating that PE-stimulation was associated with a selective increase in FA oxidation.

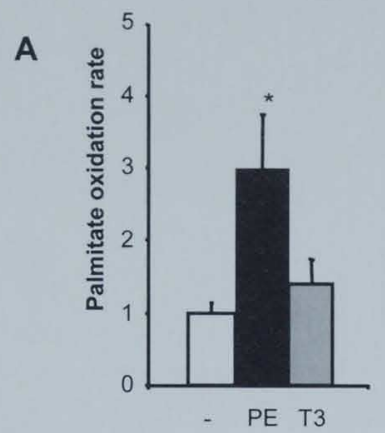

B

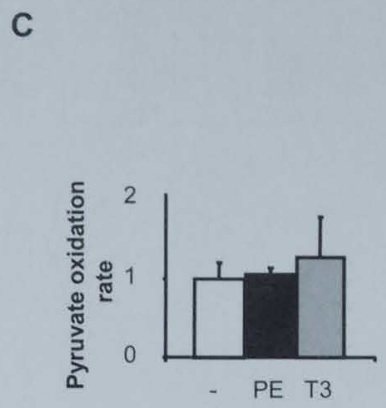

Figure 4.6

The effect of PE and T3 on substrate oxidation rates in cardiomyocytes. The oxidation of palmitate (panel A), glucose (panel B) and pyruvate (panel C) was assessed in unstimulated (open bars) and PE- (black bars) and T3-stimulated (grey bars) cardiomyocytes. In unstimulated cardiomyocytes the substrate oxidation rates amounted to $0.15 \pm 0.04 \mathrm{nmol}$ palmitate $\cdot \mathrm{min}^{-1}$ per $\mathrm{mg}, 0.70 \pm 0.09 \mathrm{nmol}$ glucose $\cdot \mathrm{min}^{-1}$ per $\mathrm{mg}$, and $0.50 \pm 0.10 \mathrm{nmol}$ pyruvate $\cdot \mathrm{min}^{-1}$ per mg of cell protein. Results are expressed as fold change compared to unstimulated cells, the average value of which was arbitrarily set $1.0 . *$ Indicates significantly different $(p<0.05)$ from unstimulated cells.

To further probe the nature of the PE-induced rise in FA metabolism, palmitate oxidation rates were determined in cells exposed to the PPAR $\alpha$-specific ligand Wy-14,643. Exposure of un-stimulated cells with $\mathrm{W}_{\mathrm{y}}-14,643$ resulted in a $46 \% \quad(\mathrm{p}<0.05)$ increase in palmitate oxidation rate (Fig. 4.7A). In PE-stimulated hypertrophic cardiomyocytes co-

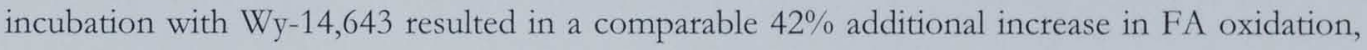
although this incremental change did not reach the level of significance due to larger intergroup differences.

In an attempt to discriminate between early and late effects of PE on palmitate oxidation rate, cardiomyocytes were exposed to PE either for $15 \mathrm{~min}, 24 \mathrm{~h}$, or $48 \mathrm{~h}$. As compared to unstimulated cells already within $15 \mathrm{~min}$ of PE exposure a 1.4 fold increase in the palmitate oxidation rate was observed (Fig. 4.7B). Extending the duration of exposure to PE to 24 or 48 h significantly increased the rate of palmitate oxidation 2.2 and 3.0 fold, respectively. 
A

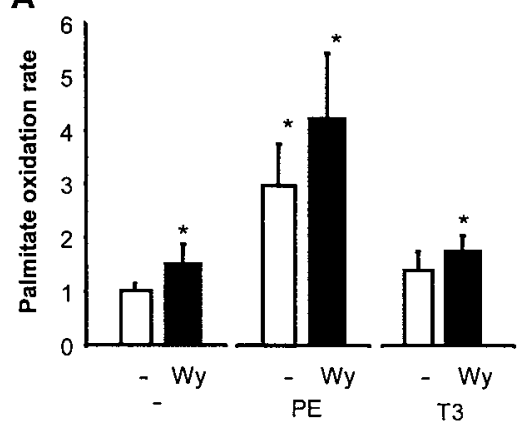

B

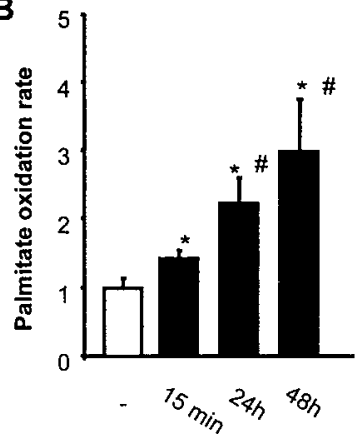

Figure 4.7

Panel A: Effect of the PPAR $\alpha$ ligand $\mathrm{W}_{\mathrm{y}}-14,643$ on palmitate oxidation rate of unstimulated and PE-and T3-stimulated cardiomyocytes. Open bars and black bars refer to vehicle- and $W_{y}-14,643$-treated cells, respectively. Results are expressed as fold change compared to unstimulated, vehicle-treated cells, the average value of which was arbitrarily set $1.0 .{ }^{*}$ Indicates significantly different $(p<0.05)$ from unstimulated cells.

Panel B: Time-dependent effects of PE exposure on palmitate oxidation rate in cardiomyocytes. Cells were exposed to PE for the indicated times. Results are expressed as fold change compared to unstimulated cells (open bar), the average value of which was arbitrarily set 1.0 . * Indicates significantly different $(p<0.05)$ from untreated control. " Indicates significantly different $(\mathrm{p}<0.05)$ from $15 \mathrm{~min}$ PE-treated cardiomyocytes.

\subsection{DISCUSSION}

Hypertrophic stimuli have been reported to influence cardiac metabolism, whilst vice versa recent findings suggest that lipid metabolism modulates the hypertrophic growth of cardiomyocytes ${ }^{11}$. Accordingly, the main objective of the present study was to elucidate the mutual interaction between hypertrophic growth and the genomic regulation of cardiac fatty acid metabolism. Thereto, neonatal rat cardiomyocytes were stimulated with either the $\alpha_{1}$ adrenergic agonist phenylephrine (PE) or thyroid hormone (T3), which gave rise to discrete hypertrophic phenotypes, as far as cell shape and the expression of hypertrophic marker genes are concerned. Co-incubation with long-chain FA, which act both as a prime substrate for energy metabolism and as ligands for the PPARs, revealed that FA markedly induced the expression of PPAR-responsive genes involved in cardiomyocyte FA uptake and metabolism, but had no effect at all on the hypertrophic response as induced by PE or T3. In addition, although it is generally assumed that FA metabolism is attenuated in cardiac hypertrophy in 
favour of glucose metabolism, we observed a nearly 3-fold increase in FA oxidation rate in PEstimulated, but not in T3-stimulated cardiomyocytes. Interestingly, the rise in metabolic oxidative capacity in PE-stimulated hypertrophic cells was specific for FA since the oxidation of alternative substrates, such as glucose and pyruvate, remained unaffected. Moreover, the enhanced FA oxidation rate could not be explained in terms of PPAR-dependent changes in the expression of FA handling genes, but rather suggested that post-translational mechanisms are involved.

\subsubsection{Cardiomyocyte bypertropby and substrate utilization}

Cardiac hypertrophy is associated with alterations in cardiac metabolism. Indeed, various studies on ex vivo -perfused or the in situ hypertrophied hearts reported that cardiac hypertrophy goes along with a switch from fatty acids to glucose as primary substrate ${ }^{21,22}$. Presumably, the decline in cardiac FA utilization is caused by a reduction in the expression of genes involved in FA oxidation ${ }^{23}$ which, in turn, has been linked to a diminished activity of PPAR $\alpha$ in the hypertrophied myocardium 8,9 .

In the present study this hypothesis was further explored using PE- and T3-stimulated neonatal cardiac myocytes as a model system. The activation of the G-protein coupled $\alpha_{1-}$ adrenergic receptor and thyroid hormone receptor results in distinct phenotypes. Whereas PEstimulation is associated with an increase in cell width, T3 leads to an elongated appearance of the cardiomyocytes as has been noted earlier ${ }^{24}$. Along with the activation of distinct sets of hypertrophic marker genes, i.e. the induction of ANF and $\beta M H C$ by PE and of SERCA2a and $\alpha \mathrm{MHC}$ by T3, respectively, it is believed that the stimulation of G-protein coupled receptors gives rise to a phenotype resembling pathological hypertrophy ${ }^{25,26}$, whereas T3-stimulation mimics physiological hypertrophy in various aspects ${ }^{13,24}$

Remarkably, in PE-stimulated hypertrophied cardiomyocytes we observed a pronounced increase rather than decrease in FA oxidation rate, whereas in T3-stimulated cells FA oxidation rate remained unchanged. The present findings are at variance with the study of Barger and coworkers $^{8}$ who reported that PE-induced hypertrophy led to an approximately $40 \%$ reduction of FA oxidation in neonatal cardiomyocytes. The discrepancy between both observations remains elusive, although a number of differences in cell culture conditions (dose of PE, cell density, 
incubation time) have to be appreciated. Perhaps the most marked difference relates to the FA oxidation assay itself, as in the former study oxidation was measured over a long period of time after addition of a trace amount of an ethanolic palmitate solution, whereas in the present study FA oxidation was measured subsequent to the incubation in the presence of physiological levels of palmitate/oleate complexed to BSA.

To evaluate whether the observed rise in FA oxidation rate reflected a general increase in metabolic flux in PE-stimulated hypertrophic cardiomyocytes, the rate of oxidation of alternative substrates was also determined. Remarkably, the rise in oxidation rate of PE-stimulated cells turned out to be selective for FA, as the oxidation rates of both glucose and pyruvate were unchanged. Whether the specific rise in FA utilization in the hypertrophic cardiomyocytes reflects an overall increase in metabolic demand, due to, for instance, an increased protein synthesis rate, metabolic uncoupling, or spontaneous beating activity, remains to be established. The latter option seems unlikely since PE-stimulation is associated with the appearance of spontaneous contractions in a minority of cells only (personal observation). In this respect, it is noteworthy that electrical stimulation of isolated adult cardiomyocytes at high frequency $(4 \mathrm{~Hz})$ led to a $50 \%$ increase in $\mathrm{FA}$ oxidation rate ${ }^{27}$, a relatively modest change compared to the 3-fold increase in the PE-stimulated cells.

Intriguingly, prior stimulation of the cells with PE for only 15 min was already sufficient to increase FA oxidation rate by $45 \%$, suggesting that post-translational changes play a role in the increase in FA oxidation rate following $\alpha_{1}$-adrenergic stimulation. It is feasible that the post-translational effect involves an augmentation of FAT/CD36-mediated cellular FA uptake, as the rate of palmitate uptake by adult cardiomyocytes was strongly increased following 15 minutes of PE exposure (personal communication D.P.Y. Koonen).

\subsubsection{FA utilization and gene expression}

Although it has often been argued that changes in FA oxidation by the hypertrophic heart can be attributed to changes in the level of expression of relevant genes ${ }^{23,} 28-30$, the present findings show a complete dissociation between alterations in the expression of genes involved in FA metabolism and the rate of cardiac FA oxidation under various conditions. To illustrate, the relative mRNA level of MCPT'-1, which behaves as a prototypic PPAR-responsive gene and plays a central role in the regulation of FA oxidation ${ }^{31}$, is plotted against the palmitate oxidation 
rate as measured in unstimulated and PE and T3-stimulated cardiomyocytes, incubated in the absence or presence of the PPAR $\alpha$ ligand Wy-14,643 (Fig.4.8). It shows that the oxidation rate can vary approximately 3-fold, irrespective of the MCPT-1 mRNA level. Comparable patterns were obtained in scatter plots constructed for other genes involved in FA metabolism (data not shown).

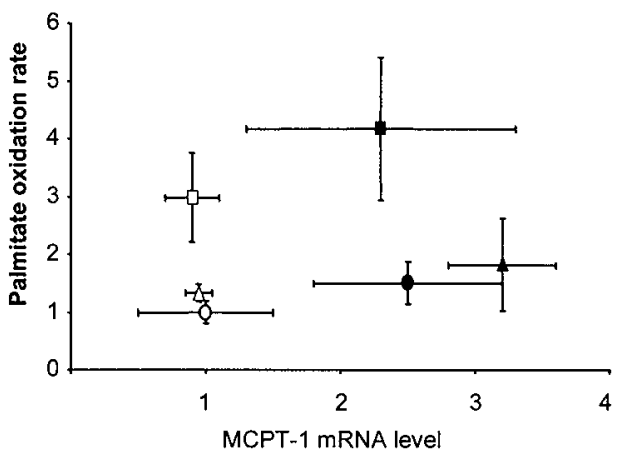

\begin{abstract}
Figure 4.8
Relation between MCPT-1 mRNA expression and palmitate oxidation rate in unstimulated cells (circles) and $\mathrm{PE}$ (squares) or T3 (triangles) treated cells incubated in the absence (open symbols) or presence of the PPAR $\alpha$ ligand Wy-14,643 (closed symbols). Results are expressed as fold change compared to unstimulated cells (open circle), the average value of which was arbitrarily set 1.0 .
\end{abstract}

Interestingly, the H-FABP gene responded differently from the other PPAR-responsive genes studied, as its expression was blunted following PE treatment and enhanced following T3 treatment. The mechanism responsible for the unique behaviour of the H-FABP gene remains elusive. It is of note, that an alternative FA-responsive cis-regulatory DNA element, unrelated to the PPRE sequence, has been identified in the H-FABP promoter ${ }^{32}$, 33. Furthermore, it should be realized that for this gene the direction of changes (diminished H-FABP expression in the face of an enhanced FA oxidation in PE-stimulated cells) points to an even greater dissociation between changes at the genomic level and functional level.

It has been reported that the trans-activating capacity of PPAR $\alpha$ is diminished in the hypertrophied myocardium as a result of a reduced expression level of PPAR $\alpha{ }^{8}$ and/or its dimerization partner $\operatorname{RXR}^{9}, 34$, or alterations in phosphorylation status of PPAR $\alpha^{8}$, 35. The present findings clearly show that the activity of the MCPT-1 promoter was not affected in PEstimulated hypertrophic cardiomyocytes, cultured in the absence of FA. However, the FA- and Wy-14,643-mediated induction of MCPT-1 promoter activity was attenuated under these conditions. Similar changes were observed in cells exposed to T3. The promoter data could be interpreted as such that indeed the sensitivity of endogenous PPAR towards their natural (FA) 
or artificial (Wy-14,643) ligands is diminished in PE- and T3-stimulated cardiomyocytes. Notably, in a previous study PE was found to reduce MCPT-1 promoter activity, both in the absence and presence of oleate ${ }^{8}$. In the present study the decline in MCPT-1 promoter activity in PE- and T3-stimullated cells was not paralleled by a reduction in the mRNA level of MCPT1. The observed difference in the response of the $1.2 \mathrm{~kb}$ promoter fragment and the mRNA level of MCPT-1 might be related to the involvement of cis-regulatory elements outside the promoter region investigated. Furthermore, transcription factors other than PPAR have been shown to regulate MCPT-1 promoter activity, including MEF2 and GATA4, the transactivating capacity of which increases during cardiomyocyte hypertrophy ${ }^{36}$. Accordingly, the ultimate level of expression of genes like MCPT-1 during hypertrophy will be determined by multiple transcription factors that do not necessarily work in concert. Generally speaking exposure of the cells to long-chain FA, being bona fide PPAR ligands, was found to induce expression of 5 out of 6 of the PPAR-responsive genes examined (the exception being $\mathrm{H}$ FABP, as discussed above) to the same extent in non-hypertrophic and hypertrophic cardiomyocytes. Furthermore, when cells were treated with the PPAR $\alpha$ ligand Wy-14,643, the percentage increase in FA oxidation was comparable, i.e. approximately $40 \%$, in both control and hypertrophic cardiomyocytes. Therefore, the combined observations strongly suggest that impairment of PPAR $\alpha$ activity, if any, is not a hallmark of the hypertrophic growth response.

\subsubsection{Fatty acids and cardiomyocyte pbenotype}

Long-chain FA have been shown to modulate cell function and phenotype. We and others demonstrated that saturated, but not unsaturated, FA induce cardiomyocyte apoptosis ${ }^{37,38}$. More recently, it was reported that administration of long-chain FA modulated cardiomyocyte hypertrophy ${ }^{11}$. FA enhanced de novo protein synthesis rate and ANF expression in unstimulated cells and further potentiated the hypertrophic response as induced by norepinephrine (NE), the stimulatory effect being more pronounced for palmitate than for oleate. In that study the mechanism underlying the pro-hypertrophic effect was not addressed. Accordingly, it remains to be established whether the pro-hypertrophic effect is related to FAmediated activation of PPARs or to other factors. In this context, synthetic PPAR $\gamma$ and $\alpha$ ligands were found to exert an inhibitory instead of stimulatory effect on endothelin and stretch-induced cardiomyocyte hypertrophy ${ }^{12,39}$. In the present study it is shown that co- 
incubation with FA led to marked upregulation of the expression of metabolic genes, which points to the activation of endogenous PPARs, but did not affect cardiomyocyte phenotype, irrespective of the type of hypertrophic stimulus applied. Similar results were obtained when PE-stimulated cells were co-incubated with the PPAR $\alpha$-specific ligand Wy-13,643 (unpublished observations). Collectively, the current findings argue against a direct modulatory effect of natural and synthetic PPAR $\alpha$ ligands on cardiomyocyte hypertrophy.

In summary, the present findings demonstrate that PE-induced cardiomyocyte hypertrophy does not lead to an impairment of PPAR $\alpha$-mediated expression and, in fact, is associated with a marked increase, rather than decrease, in cardiac FA oxidation rate. Most likely, the latter change is related to non-genomic alterations of factors modulating FA metabolism, as it is convincingly shown that the rise cannot be explained in terms of alterations in the expression of the genes encoding for components of the metabolic pathway. The observed complete dissociation between gene expression and FA metabolism demonstrates that the extrapolation of changes in the expression of metabolic genes to alterations in metabolic flux should be done with care, irrespective of whether the observations are made in in vitro or in vivo models of cardiac hypertrophy.

\section{Acknowledgements:}

The work and expertise of E. van Rooij MSc and W. Engels $\mathrm{PhD}$, regarding the culture and immuni-cytochemisty of cardiomyocytes, is gratefully acknowledged.

MvB is an established investigator of the Netherlands Heart Foundation, Grant Number $1998 \mathrm{~T} 015$. 


\section{REFERENCES}

1. Allard MF, Schonekess BO, Henning SL, English DR and Lopaschuk GD. Contribution of oxidative metabolism and glycolysis to ATP production in hypertrophied hearts. Am J Pbysiol. 1994;267:H742-H750.

2. Sack MN, Rader TA, Park S, Bastin J, McCune SA and Kelly DP. Fatty acid oxidation enzyme gene expression is downregulated in the failing heart. Circulation. 1996;94:2837-2842.

3. Brandt JM, Djouadi F and Kelly DP. Fatty acids activate transcription of the Muscle Carnitine Palmitoyltransferase I gene in cardiac myocytes via the Peroxisome Proliferator-Activated Receptor- $\alpha . J$ Biol Cbem. 1998;273:23786-23792.

4. Recchia FA, McConnell PI, Bernstein RD, Vogel TR, Xu X and Hintze TH. Reduced Nitric Oxide production and altered myocardial metabolism during the decompensation of pacing-induced heart failure in the conscious dog. Circ Res. 1998;83:969-979.

5. Van der Lee KAJM, Vork MM, De Vries JE, Willemsen PHM, Glatz JFC, Reneman RS, Van der Vusse GJ and Van Bilsen M. Long-chain fatty acid-induced changes in gene expression in neonatal cardiac myocytes. J Lipid Res. 2000;41:41-47.

6. Gilde AJ, van der Lee KA, Willemsen PH, Chinetti G, van der Leij FR, van der Vusse GJ, Staels B and van Bilsen M. Peroxisome Proliferator-Activated Receptor (PPAR)- $\alpha$ and PPAR $\beta / \delta$, but not PPAR $\gamma$ modulate the expression of genes involved in cardiac lipid metabolism. Circ Res. 2003;92:518-524.

7. Schoonjans K, Staels B and Auwerx J. Role of the Peroxisome Proliferator-Activated Receptor (PPAR) in mediating the effects of fibrates and fatty acids on gene expression. J. Lipid Res. 1996;37:907-925.

8. Barger PM, Brandt JM, Leone TC, Weinheimer CJ and Kelly DP. Deactivation of Peroxisome Proliferator-Activated Receptor- $\alpha$ during cardiac hypertrophic growth. J Clin Invest. 2000;105:17231730.

9. Osorio JC, Stanley WC, Linke A, Castellari M, Diep QN, Panchal AR, Hintze TH, Lopaschuk GD and Recchia FA. Impaired myocardial fatty acid oxidation and reduced protein expression of Retinoid X Receptor- $\alpha$ in pacing-induced heart failure. Circulation. 2002;106:606-612.

10. Jamshidi Y, Montgomery HE, Hense HW, Myerson SG, Torra IP, Staels B, World MJ, Doering A, Erdmann J, Hengstenberg C, Humphries SE, Schunkert $\mathrm{H}$ and Flavell DM. Peroxisome Proliferator--Activated Receptor- $\alpha$ gene regulates left ventricular growth in response to exercise and hypertension. Circulation. 2002;105:950-955.

11. Zahabi $A$ and Deschepper CF. Long-chain fatty acids modify hypertrophic responses of cultured primary neonatal cardiomyocytes. J Lipid Res. 2001;42:1325-1330.

12. Liang F, Wang F, Zhang S and Gardner DG. Peroxisome Proliferator Activated Receptor (PPAR)$\alpha$ agonists inhibit hypertrophy of neonatal rat cardiac myocytes. Endocrinology. 2003;144:4187-4194.

13. Kinugawa K, Yonekura K, Ribeiro RC, Eto Y, Aoyagi T, Baxter JD, Camacho SA, Bristow MR, Long CS and Simpson PC. Regulation of Thyroid Hormone Receptor isoforms in physiological and pathological cardiac hypertrophy. Circ Res. 2001;89:591-598.

14. De Vries JE, Vork MM, Roemen THM, De Jong YF, Cleutjens JP, Van der Vusse GJ and Van Bilsen M. Saturated, but not mono-unsaturated, fatty acids induce apoptotic cell death in neonatal rat ventricular myocytes. J Lipid Res. 1997;38:1384-1394.

15. Van der Lee KAJM, Willemsen PHM, van der Vusse GJ and van Bilsen M. Effects of fatty acids on Uncoupling Protein-2 expression in the rat heart. FASEB J. 2000;14:495-502.

16. Van der Lee KAJM, Willemsen PHM, Samec S, Seydoux J, Dulloo AG, Pelsers MMAL, Glatz JFC, van der Vusse GJ and van Bilsen M. Fasting-induced changes in the expression of genes controlling substrate metabolism in the rat heart. J Lipid Res. 2001;42:1752-1758. 
17. Degens H, Gilde AJ, Lindhout M, Willemsen PH, Van der Vusse GJ and Van Bilsen M. Functional and metabolic adaptation of the heart to prolonged thyroid hormone treatment. Am J Physiol. 2003;284:H108-H115.

18. Vork MM, Glatz JFC, Surtel DAM, Knubben HJM and Van der Vusse GJ. A sandwich Enzyme Linked Immuno-Sorbent Assay for the determination of rat Heart Fatty Acid-Binding Protein using the Streptavidin-Biotin system. Application to tissue and effluent samples from normoxic rat heart perfusion. Biochim Biopbys Acta. 1991;1075:199-205.

19. Koonen DP, Coumans WA, Arumugam Y, Bonen A, Glatz JF and Luiken JJ. Giant membrane vesicles as a model to study cellular substrate uptake dissected from metabolism. Mol Cell Biochem. 2002;239:121-130.

20. Wallenstein S, Zucker CL and Fleiss JL. Some statistical methods useful in Circulation Research. Circ Res. 1980;47:1-9.

21. El Alaoui-Talibi Z, Landormy S, Loireau A and Moravec J. Fatty acid oxidation and mechanical performance of volume-overloaded rat hearts. Am J Pbysiol. 1992;262:H1068-H1074.

22. Allard MF, Schonekess BO, Henning SL, English DR and Lopaschuk GD. Contribution of oxidative metabolism and glycolysis to ATP production in hypertrophied hearts. Am J Pbysiol. 1994;267:H742-H750.

23. Sack MN, Rader TA, Park S, Bastin J, McCune SA and Kelly DP. Fatty acid oxidation enzyme gene expression is downregulated in the failing heart. Circulation. 1996;94:2837-2842.

24. Liang F, Webb P, Marimuthu A, Zhang $S$ and Gardner DG. Triiodothyronine increases Brain Natriuretic Peptide (BNP) gene transcription and amplifies Endothelin-dependent BNP gene transcription and hypertrophy in neonatal rat ventricular myocytes. J Biol Chem. 2003;278:1507315083.

25. Seccia TM, Belloni AS, Kreutz R, Paul M, Nussdorfer GG, Pessina AC and Rossi GP. Cardiac fibrosis occurs early and involves Endothelin and AT-1 receptors in hypertension due to endogenous Angiotensin II. J Am Coll Cardiol. 2003;41:666-673.

26. Yoshida J, Yamamoto K, Mano T, Sakata X, Nishikawa N, Nishio M, Ohtani T, Miwa T, Hori M and Masuyama T. AT-1 receptor blocker added to ACE inhibitor provides benefits at advanced stage of hypertensive diastolic heart failure. Hypertension. 2004;43:686-691.

27. Luiken JJ, Willems J, van der Vusse GJ and Glatz JF. Electrostimulation enhances FAT/CD36mediated long-chain fatty acid uptake by isolated rat cardiac myocytes. Am J Physiol. 2001;281:E704E712.

28. Recchia FA, Osorio JC, Chandler MP, Xu X, Panchal AR, Lopaschuk GD, Hintze TH and Stanley WC. Reduced synthesis of NO causes marked alterations in myocardial substrate metabolism in conscious dogs. Am J Physiol. 2002;282:E197-E206.

29. Razeghi P, Young ME, Ying J, Depre C, Uray IP, Kolesar J, Shipley GL, Moravec CS, Davies PJ, Frazier $\mathrm{OH}$ and Taegtmeyer $\mathrm{H}$. Downregulation of metabolic gene expression in failing human heart before and after mechanical unloading. Cardiology. 2002;97:203-209.

30. Van Bilsen M, Smeets PJ, Gilde AJ and van der Vusse GJ. Metabolic Remodelling of the Failing Heart: The Cardiac Burn-out Syndrome? Cardiovasc Res. 2004;61:218-226.

31. Eaton S, Bartlett K and Quant PA. Carnitine Palmitoyl Transferase I and the control of $\beta$-oxidation in heart mitochondria. Biocbem Biophys Res Commun. 2001;285:537-539.

32. Wu Q, Andolfatto P and Haunerland NH. Cloning and sequence of the gene encoding the Muscle Fatty Acid Binding Protein from the desert locust, Schistocerca Gregaria. Insect Biochem Mol Biol. 2001;31:553-562.

33. Wu Q, Chang W, Rickers-Haunerland J, Higo $\mathrm{T}$ and Haunerland NH. Characterization of a new Fatty Acid Response Element that Controls the expression of the locust Muscle FABP gene. Mol Cell Biochem. 2002;239:173-180. 
34. Huss JM, Levy FH and Kelly DP. Hypoxia inhibits the Peroxisome Proliferator-Activated Receptor- $\alpha /$ Retinoid X Receptor gene regulatory pathway in cardiac myocytes: A mechanism for $\mathrm{O}_{2}$-dependent modulation of mitochondrial fatty acid oxidation. J Biol Chem. 2001;276:27605-27612.

35. Han J, Hajjar DP, Tauras JM, Feng J, Gotto AM, Jr. and Nicholson AC. Transforming Growth Factor- $\beta 1$ (TGF- $\beta 1$ ) and TGF- $\beta 2$ decrease expression of CD36, the Type B Scavenger Receptor, through Mitogen-Activated Protein Kinase Phosphorylation of Peroxisome Proliferator-Activated Receptor- $\gamma$. J Biol Chem. 2000;275:1241-1246.

36. Moore ML, Wang GL, Belaguli NS, Schwartz RJ and McMillin JB. GATA-4 and Serum Response Factor regulate transcription of the Muscle-Specific Carnitine Palmitoyltransferase I $\beta$ in rat heart. $J$ Biol Chem. 2001;276:1026-1033.

37. De Vries JE, Vork MM, Roemen THM, de Jong YF, Cleutjens JPM, van der Vusse GJ and van Bilsen $M$. Saturated but not mono-unsaturated fatty acids induce apoptotic cell death in neonatal rat ventricular myocytes. J Lipid Res. 1997;38:1384-1394.

38. Chiu HC, Kovacs A, Ford DA, Hsu FF, Garcia R, Herrero P, Saffitz JE and Schaffer JE. A Novel mouse model of lipotoxic cardiomyopathy. J Clin Invest. 2001;107:813-822.

39. Yamamoto K, Ohki R, Lee RT, Ikeda U and Shimada K. Peroxisome Proliferator-Activated Receptor- $\gamma$ Activators inhibit cardiac hypertrophy in cardiac myocytes. Circulation. 2001;104:16701675. 
PPAR $\alpha$ AND PPAR $\beta / \delta$, BUT NOT PPAR $\gamma$, MODULATE THE EXPRESSION OF GENES INVOLVED IN CARDIAC LIPID METABOLISM.

Andries J Gilde*, Karin AJM van der Lee*, Peter HM Willemsen, Giulia Chinetti ${ }^{6}$,

Feike R van der Leij ${ }^{7}$, Ger J van der Vusse, Bart Staels ${ }^{6}$, and Marc van Bilsen

*These authors contributed equally to the work

Circulation Research 2003;92:518-524 


\subsection{ABSTRACT}

Long-chain fatty acids (FA) coordinately induce the expression of a panel of genes involved in cellular FA metabolism in cardiac muscle cells, thereby promoting their own metabolism. These effects are likely to be mediated by peroxisome proliferator-activated receptors (PPARs). Whereas the significance of PPAR $\alpha$ in FA-mediated expression has been demonstrated, the role of the PPAR $\beta / \delta$ - and PPAR $\gamma$-isoforms in cardiac lipid metabolism is unknown.

To explore the involvement of each of the PPAR isoforms, neonatal tat cardiomyocytes were exposed to FA, or ligands specific for either PPAR $\alpha$ (Wy-14,643), PPAR $\beta / \delta$ (L-165041, GW501516) or PPAR $\gamma$ (Ciglitazone, Rosiglitazone). Their effect on FA oxidation rate, expression of metabolic genes, and muscle-type carnitine palmitoyltransferase-1 (MCPT-1) promoter activity was determined.

Consistent with the PPAR isoform expression pattern, the FA oxidation rate increased in cardiomyocytes exposed to PPAR $\alpha$ and PPAR $\beta / \delta$ ligands, but not to PPAR $\gamma$ ligands. Likewise, the FA-mediated expression of FA-handling proteins was mimicked by PPAR $\alpha$ and $\operatorname{PPAR} \beta / \delta$, but not by PPAR $\gamma$ ligands. As expected, in embryonic rat heart-derived H9c2 cells, that only express PPAR $\beta / \delta$, the FA-induced expression of genes was mimicked by the PPAR $\beta / \delta$ ligand only, indicating that FA also act as ligands for the $\operatorname{PPAR} \beta / \delta$ isoform. In cardiomyocytes MCPT-1 promoter activity was unresponsive to PPAR $\gamma$ ligands. However, addition of PPAR $\alpha$ and $\operatorname{PPAR} \beta / \delta$ ligands dose-dependently induced promoter activity. Collectively, the present findings demonstrate that, next to $\operatorname{PPAR} \alpha, \operatorname{PPAR} \beta / \delta$, but not PPAR $\gamma$, plays a prominent role in the regulation of cardiac lipid metabolism, thereby warranting further research into the role of $\operatorname{PPAR} \beta / \delta$ in cardiac disease. 


\subsection{INTRODUCTION}

It is generally acknowledged that dietary factors, among which major energy-providing substrates as fatty acids (FA), act as signaling molecules that modulate gene expression in a variety of tissues, including the heart (for review see ${ }^{1,2}$ ). Using primary cultures of neonatal rat cardiomyocytes, it was recently demonstrated that exposure of these cells to long-chain FA markedly enhances the expression of genes encoding proteins involved in FA transport and metabolism ${ }^{3,4}$. In addition, evidence was provided that the modulating effect of FA is mediated by peroxisome proliferator-activated receptors (PPARs) ${ }^{3,4}$. Of the three PPAR isoforms known to date, the significance of PPAR $\alpha$ and PPAR $\gamma$ in the regulation of whole-body and cellular lipid metabolism has been firmly established (reviewed in ${ }^{5}$ ). The function of the ubiquitously expressed PPAR $\beta / \delta$ isoform, however, temains largely elusive.

Through the development of specific synthetic ligands for PPAR $\alpha^{6}$, PPAR $\gamma^{7}$ and, more recently, for $\operatorname{PPAR} \beta / \delta^{8,9}$, powerful tools have become available to delineate the biological roles of each of the PPAR isoforms in more detail. This prompted us to investigate the specific roles of PPAR $\alpha, \operatorname{PPAR} \beta / \delta$ and PPAR $\gamma$ in the cardiac muscle cell with respect to the regulation of genes encoding proteins involved in energy metabolism. Thereto neonatal rat cardiomyocytes as well as the embryonic rat heart-derived $\mathrm{H} 9 \mathrm{c} 2$ cells were cultured in defined medium in the absence or presence of FA. To fully appreciate the role of each of the three PPAR isoforms, their expression pattern was assessed in cardiac cells and $\mathrm{H} 9 \mathrm{c} 2$ myoblasts and myotubes. Next, it was examined whether specific ligands for $\operatorname{PPAR} \alpha(\mathrm{W} y-14,643), \operatorname{PPAR} \beta / \delta$ (L-165041, GW501516) and PPAR $\gamma$ (Ciglitazone, Rosiglitazone) were able to mimic the modulating effect of FA on metabolic gene expression in these cell models. Accordingly, their effects on the expression of various proteins involved in cardiac FA metabolism, such as Acyl-CoA Synthetase (ACS), Muscle-type Carnitine Palmitoyl Transferase-1 (MCPT-1), Long-chain AcylCoA Dehydrogenase (LCAD) and the Uncoupling Proteins 2 and 3 (UCP2/3) were determined at the mRNA level. To assess the functional consequences of PPAR-mediated transcription on cellular lipid metabolism FA oxidation rates were measured. For comparison, mRNA levels of proteins involved in glucose transport (GLUT4) and metabolism Hexokinase II (HKII) were 
determined. Finally, the effect of the isoform-specific PPAR ligands was explored further in transient transfection studies using the PPAR responsive human MCPT-1 promoter ${ }^{3}$.

The collective data indicate that, besides PPAR $\alpha$, the PPAR $\beta / \delta$ isoform is involved in regulation of cardiac lipid metabolism. In contrast the role of PPAR $\gamma$ in this process appears to be insignificant.

\subsection{MATERIALS AND METHODS}

\subsubsection{Cell culture}

Neonatal rat ventricular cardiomyocytes were prepared as described previously ${ }^{10}$. Experiments were approved by the Institutional Animal Care and User Committee of the Maastricht University.

H9c2 cells (ATCC CRL-1446; Rockville MD, USA; passage numbers 18-22) were maintained in growth medium composed of DMEM supplemented with $10 \%$ fetal bovine serum (Life Technologies). H9c2 cells were plated at a density of $2000 \mathrm{cells} / \mathrm{cm}^{2}$ and allowed to proliferate in growth medium. Medium was changed twice a week. To induce differentiation of H9c2 myoblasts into myotubes growth medium was replaced with differentiation medium (DMEM containing $2 \%$ horse serum) when cells had reached near confluence. The extent of differentiation of the $\mathrm{H} 9 \mathrm{c} 2$ cells was evaluated on the basis of morphological criteria and by measuring cellular creatine kinase (CK) activity. Cells were considered differentiated after formation of multi-nucleated myotubes and an $>10$-fold increase in CK activity.

At the start of the experiments, H9c2 myoblasts (at near confluence), H9c2 myotubes and neonatal cardiomyocytes were incubated in serum-free medium consisting of a 4:1 mixture of DMEM/M199, gentamicin (50mg/L) and glucose $(10 \mathrm{mM})$ as the sole substrate, for $24 \mathrm{~h}$. Subsequently, the cells were rinsed once with serum-free medium, whereupon experimental medium was applied to the cells. The experimental medium consisted of serum-free medium enriched with $0.25 \mathrm{mM} \mathrm{L}$-carnitine, $0.25 \mathrm{mU} / \mathrm{ml}$ insulin and $0.15 \mathrm{mM}$ bovine serum albumin (BSA; A-7906, Sigma, St. Louis MO, USA). When indicated the medium was further supplemented with FA (palmitic and oleic acid $0.25 \mathrm{mM}$ each complexed to $0.15 \mathrm{mM} \mathrm{BSA}$, described elsewhere ${ }^{10}$ ). To test the effects of PPAR-specific ligands, cells receiving glucose as 
the only substrate were incubated with the PPAR $\alpha$-ligand Wy-14,643 (reported $\mathrm{EC}_{50}=0.63$ $\mu \mathrm{M}^{\top}$; Biomol, Plymouth Meeting, PA, USA), the PPAR $\beta / \delta$ ligands L-165041 (a gift from Dr. J. Berger, Merck, Rahway, NJ, USA) and GW501516 (EC50 $=3.8$ and $0.024 \mu \mathrm{M}$, respectively $\left.{ }^{7,9}\right)$, or the PPAR -ligands Ciglitazone (Biomol), and Rosiglitazone (BRL49653, kindly provided by GlaxoSmithKline, Worthington, $\mathrm{UK})\left(\mathrm{EC}_{50}=3.0\right.$ and $0.076 \mu \mathrm{M}$, respectively $\left.{ }^{7}\right)$, at the indicated concentrations (see results). For detailed information regarding the potency and selectivity of the various ligands for the three PPAR isoforms we refer to reference ${ }^{7}$ and $^{9}$. PPAR ligands were dissolved in DMSO, which was also added as vehicle $(0.1 \% \mathrm{v} / \mathrm{v})$ to control cells.

\subsubsection{Tissues and cells}

Hearts and epididymal white adipose tissue were dissected from neonatal and adult Lewis rats. To determine the presence of PPAR isoforms in cardiac myocytes, the myocyte fraction was isolated from neonatal and adult hearts following Collagenase treatment by Percoll-gradient centrifugation ${ }^{10}$ and sedimentation ${ }^{11}$, respectively. Tissues and cell fractions were immediately frozen in liquid nitrogen and stored at $-80^{\circ} \mathrm{C}$ until analysis.

\subsubsection{RNA analysis}

After $48 \mathrm{~h}$ of incubation RNA was isolated with TRIzol reagent (Life Technologies). Ten $\mu \mathrm{g}$ of total RNA was size-fractionated, transferred to nylon membranes, and probed with cDNA fragments of GLUT4, HKII, ACS, LCAD, MCPT-1, UCP-2, and UCP-3 as described previously ${ }^{4,12,13}$. An $0.9 \mathrm{~kb}$ PstI fragment of mouse PPAR $\alpha$, a $1.5 \mathrm{~kb}$ BamHI fragment of tat $\operatorname{PPAR} \beta / \delta$ (a gift of Dr. P.A. Grimaldi, University of Nice, France), and a $0.6 \mathrm{~kb}$ BglII fragment of hamster PPAR $\gamma$, were also used for hybridization. The cDNA probes were labeled with ${ }^{32 \mathrm{P}-}$ dCTP (3000 Ci/mmol; Amersham Pharmacia Biotech UK Limited, Buckinghamshire, UK) by tandom-priming (Radprime, Life Technologies) to a specific activity of $>0.5 \times 10^{9} \mathrm{cpm} / \mu \mathrm{g}$ DNA. To correct for possible differences in transfer and loading the membranes were also hybridized with a ${ }^{32} \mathrm{P}-l a b e l e d$ ribosomal $18 \mathrm{~S}$ probe. Following hybridization, membranes were washed at the appropriate stringency to remove non-specific binding. The membranes were exposed to imaging screens and subsequently scanned on the Personal FX Imager (Bio-Rad 
Laboratories, Hercules CA, USA). Signals were quantified using Quantity One software (Bio$\mathrm{Rad})$.

\subsubsection{Protein extraction and Western blot}

Tissues and cells were homogenized in lysis buffer $(10 \mathrm{mmol} / \mathrm{L}$ Tris-HCl, $150 \mathrm{mM} \mathrm{NaCl}, 1$ mM EDTA, $0.1 \%$ NP-40, 0.5\% Na-Deoxycholate, 1\% SDS and a protease inhibitor cocktail) and proteins were collected by centrifugation at $4^{\circ} \mathrm{C}$. Proteins $(100 \mu \mathrm{g})$ were loaded onto $10 \%$ SDS-PAGE gels. Ponceau's red staining was performed to verify equal loading. Western blot analysis was performed using a monoclonal antibody against PPAR $\gamma$ (Santa Cruz Biotechnology Inc., Santa Cruz, CA, USA) or against $\alpha$-actinin (Sigma). Specific signals were visualized using the chemiluminescence system (ECL, Amersham).

\subsubsection{Transient transfection}

For transient transfection neonatal cardiomyocytes were seeded on 6-well plates at a density of $2.5 \times 10^{5}$ cells in $2 \mathrm{ml}$ of medium per well. Cells were transfected $16 \mathrm{~h}$ before addition of experimental medium using the transfection reagent FuGENE 6 (Roche, Indianapolis IN, USA). Cells were transfected with $0.5 \mu \mathrm{g}$ of promoter/reporter vector, i.e. a $1.3 \mathrm{~kb}$ fragment of the human MCPT-1 promoter generated by high fidelity PCR (Expand, Roche) of genomic DNA (corresponding to pos. 61203 - 62543, Genbank Accession Number U62317) ${ }^{14}$ and cloned into the pGL3 luciferase vector (MCPT-1-luc), or a construct containing three copies of the PPRE-site of the human Apo A-II promoter (PPRE3-TK-luc) ${ }^{15}$. The CMV- $\beta$-galactosidase containing vector pON249 $(0.25 \mu \mathrm{g})$ was co-transfected to control for transfection efficiency ${ }^{16}$. In a sub-series of experiments $0.5 \mu \mathrm{g}$ of the pSG5 expression vector containing the cDNA of PPAR $\gamma^{17}$ was co-transfected. The total amount of plasmid DNA per well was always kept constant by adding empty pSG5 vector (Promega, Madison, WI, USA).

Cells were harvested $24 \mathrm{~h}$ after addition of experimental medium (see above) and immediately processed for the determination of reporter activity. Luciferase activity was determined using a commercial firefly luciferase assay according to the suppliers instructions (Steady Glo, Promega) in white 96-well plates (Nalge Nunc International, Maperville, IL, USA) and FluorS imager (Bio-Rad) for measuring luminescence. $\beta$-Galactosidase activity was determined 
spectrophotometrically (Titertek Multiskan Plus MKII, Thermo LabSystems, Helsinki, Finland) as described previously ${ }^{16}$.

\subsubsection{Fatty acid oxidation}

Experiments to determine the oxidation capacity of $\left[1-{ }^{14} \mathrm{C}\right]$ palmitic acid (Amersham) in neonatal rat ventricular cardiomyocytes were performed according to Van der Lee et al. ${ }^{4}$.

\subsubsection{Statistics}

Results are obtained from at least three independent experiments and presented as sample means $\pm \mathrm{SD}$. Comparison between groups was performed with one-way analysis of variance (ANOVA). In case the F-ratio obtained indicated that significant differences between groups were present, a two-tailed Student's t-test for unpaired data was carried out, applying Bonferroni's adjustment for multiple comparison ${ }^{18}$. Differences were considered significant at $\mathrm{p}<0.05$. 


\subsection{RESULTS}

\subsubsection{Fatty acid supplementation and gene expression}

To assess the effects of FA on gene expression neonatal rat cardiomyocytes and myoblasts and myotubes of the embryonic rat heart-derived $\mathrm{H} 9 \mathrm{c} 2$ cell line were cultured in the presence of either glucose or a combination of glucose and FA (palmitic and oleic acid) as substrates.

Cardiomyocytes: Consistent with previous studies $4,48 \mathrm{~h}$ after exposure to FA, mRNA levels of the glucose transporter GLUT4 and the glycolytic enzyme HKII were lower (Fig. 5.1A). In contrast, the mRNA levels of ACS, LCAD and the uncoupling protein UCP-2 were markedly increased.

H9c2 cells: The differentiation of $\mathrm{H} 9 \mathrm{c} 2$ myoblasts into myotubes was associated with a rise in the mRNA levels of proteins involved in both glucose (GLUT4, HKII) and FA metabolism (ACS, LCAD), but still the mRNA levels were substantially lower than those in cardiomyocytes exposed to identical conditions (data not shown). Likewise, the FA-induced changes in gene expression were less pronounced in the H9c2 cells, reaching statistical significance for HKII, LCAD and UCP-2 in the myoblasts (Fig. 5.1B), and for GLUT4, HKII, ACS, LCAD as well as UCP2 in the myotubes, respectively (Fig. 5.1C).

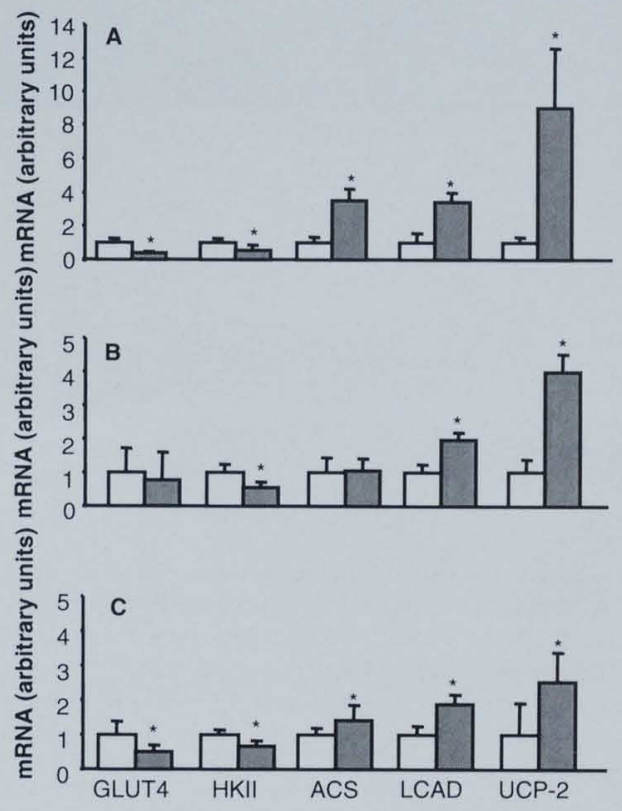

\section{Figure 5.1}

Effects of FA on mRNA levels of genes involved in glucose and FA uptake and metabolism in neonatal rat cardiomyocytes (panel A), H9c2 myoblasts (panel B) and H9c2 myotubes (panel C). Cells were exposed to either $10 \mathrm{mM}$ glucose (open bars) or a combination of glucose and 0.5 $\mathrm{mM}$ FA (hatched bars) for $48 \mathrm{~h}$. The expression levels of the insulin-dependent Glucose Transporter (GLUT4), Hexokinase II (HKII), Acyl-CoA Synthetase (ACS), Long-Chain Acyl-CoA Dehydrogenase (LCAD) and Uncoupling Protein-2 (UCP2), relative to levels after exposure to glucose only (arbitrarily set at 1.0 ) are shown. Data are presented as means $\pm S D(n=5-7)$. * Indicates significantly different $(\mathrm{p}<0.05)$ from glucose group. 


\subsubsection{PPAR-isoform expression}

As shown in Figure 1 the effects of FA on gene expression are more pronounced in cardiac myocytes than in $\mathrm{H} 9 \mathrm{c} 2$ cells. As the effects of FA on cardiac myocytes are considered to be PPAR-mediated ${ }^{3,4}$, we first looked for possible differences in PPAR isoform expression or abundance. Thereto, mRNA levels of the PPAR-isoforms were determined in the different cell types and in ventricular tissue of neonatal and adult rats (Fig. 5.2). In $\mathrm{H} 9 \mathrm{c} 2$ myoblasts and myotubes as well as in cardiac myocytes and ventricular tissue PPAR $\beta / \delta$ was abundantly expressed. Interestingly, PPAR $\alpha$ mRNA was not detectable in $\mathrm{H} 9 \mathrm{c} 2$ cells, but was clearly present in isolated cardiomyocytes and cardiac tissue. In contrast to its preponderance in white adipose tissue a clear PPAR $\gamma$ mRNA signal was not detected, neither in $\mathrm{H} 9 \mathrm{c} 2$ cells, nor in isolated cardiomyocytes, nor in intact ventricular tissue. As the presence of PPAR $\gamma$ in cardiac myocytes is controversial ${ }^{19,20}$, we also applied western blotting to further check for the possible presence of this isoform in neonatal and adult cardiac myocytes. PPAR $\gamma$ immunoreactivity was readily observed in white adipose tissue, whereas substantially longer exposure times were required to detect signals in cardiac tissue and cardiomyocytes (Fig. 5.3). Collectively these findings demonstrate that the PPAR-isoforms are all present in cardiac muscle cells, albeit that $\gamma$-isoform is expressed at relatively low levels.

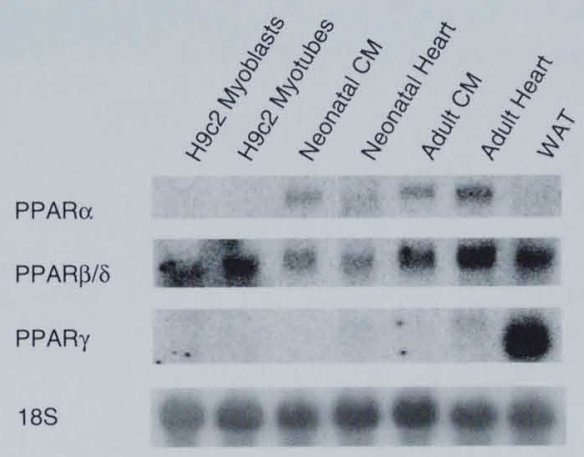

Figure 5.2

Northern blots showing the distribution of $\operatorname{PPAR} \alpha$, $\operatorname{PPAR} \beta / \delta$ and PPAR $\gamma$ mRNA in isolated, H9c2 myoblasts, H9c2 myotubes, neonatal and adult rat cardiomyocytes and in neonatal and adult rat heart tissue (representative of 3 experiments). White adipose tissue (WAT) is included as a positive control for PPAR $\gamma$. The $18 \mathrm{~S}$ rRNA signal demonstrates equal loading of the gel.

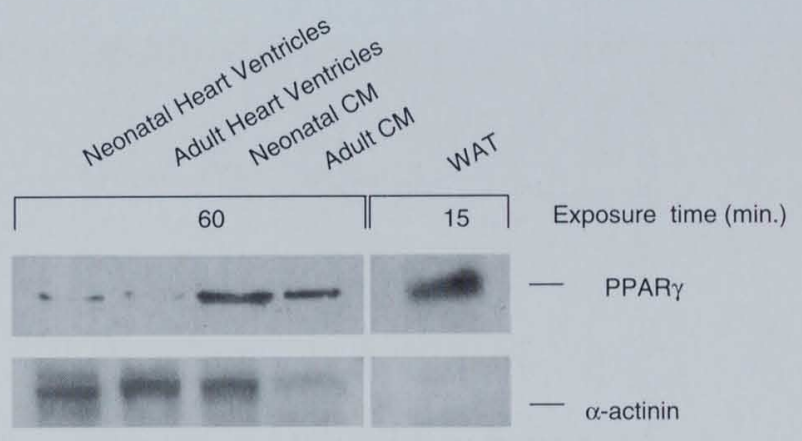

Figure 5.3

Western blot showing PPAR $\gamma$ expression in neonatal and adult rat ventricular tissue and freshly isolated cardiomyocytes (CM) and white adipose tissue (representative of 2 isolations). Note that for the detection of PPAR $\gamma$ immunoreactivity in cardiac fractions substantially longer exposure times $(60 \mathrm{~min}$ instead of $15 \mathrm{~min})$ were required. Sarcomeric $\alpha$-actinin immunoreactivity is included as control. 


\subsubsection{Effects of isoform-specific PPAR agonists}

Next the involvement of each of the PPAR-isoforms to the FA-mediated changes in gene expression was assessed functionally. Thereto cardiomyocytes and $\mathrm{H} 9 \mathrm{c} 2$ cells were treated with Wy-14,643, L-165041 and Ciglitazone, specific agonists for PPAR $\alpha, \operatorname{PPAR} \beta / \delta$ and PPAR $\gamma$, respectively. At concentrations of $10 \mu \mathrm{M}$ these PPAR agonists were previously shown to be effective and isoform-specific in other cell types ${ }^{6-8}$.

Cardiomyogytes: As shown in Figure 5.4, none of the PPAR ligands significantly affected the expression of genes involved in glucose uptake (GLUT4) and metabolism (HKII). In contrast the PPAR $\alpha$ specific ligand $\mathrm{Wy}_{\mathrm{y}}-14,643$ was as effective as FA in inducing the expression of the FA-handling proteins ACS, MCPT-1, LCAD and UCP-2 in cardiomyocytes. The addition of the PPAR $\beta / \delta$ agonist L-165041 also led to an increase, albeit less pronounced, in the mRNA levels of ACS, MCPT-1, and UCP-2.

H9c2 cells: In accordance with the expression pattern of the PPAR isoforms in H9c2 myoblasts and myotubes the PPAR $\alpha$ and PPAR $\gamma$ specific ligands were ineffective (Fig. 5.5). In contrast, the PPAR $\beta / \delta$ ligand L-165041 increased mRNA levels of both ACS and LCAD in H9c2 cells to the same degree as FA. Likewise, UCP-2 mRNA levels were clearly upregulated by both FA and L-165041 in H9c2 myoblasts. Conversely, while mRNA of UCP-3 could not be detected in $\mathrm{H} 9 \mathrm{c} 2$ myoblasts, in $\mathrm{H} 9 \mathrm{c} 2$ myotubes UCP-3 expression was markedly induced by both FA and the PPAR $\beta / \delta$ agonist. Interestingly, the PPAR ligands did not affect GLUT4 and HKII mRNA levels in myotubes, but exposure to FA was associated with a decline suggesting that FA also exert PPAR-independent effects.
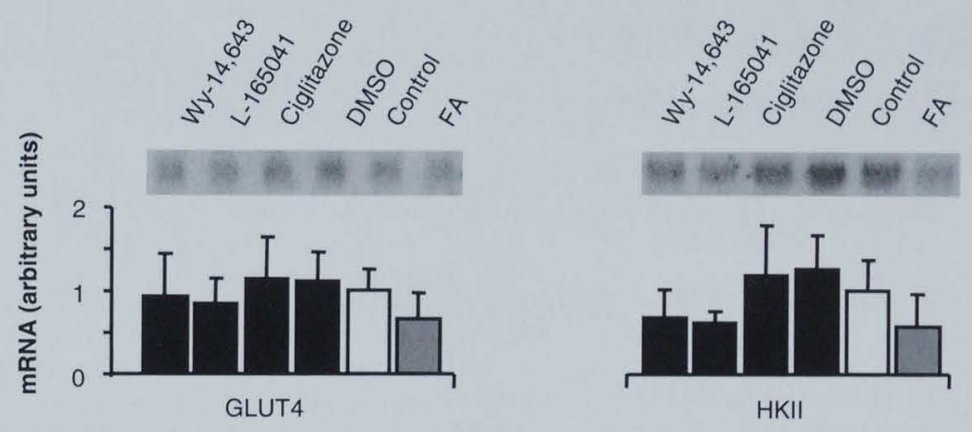

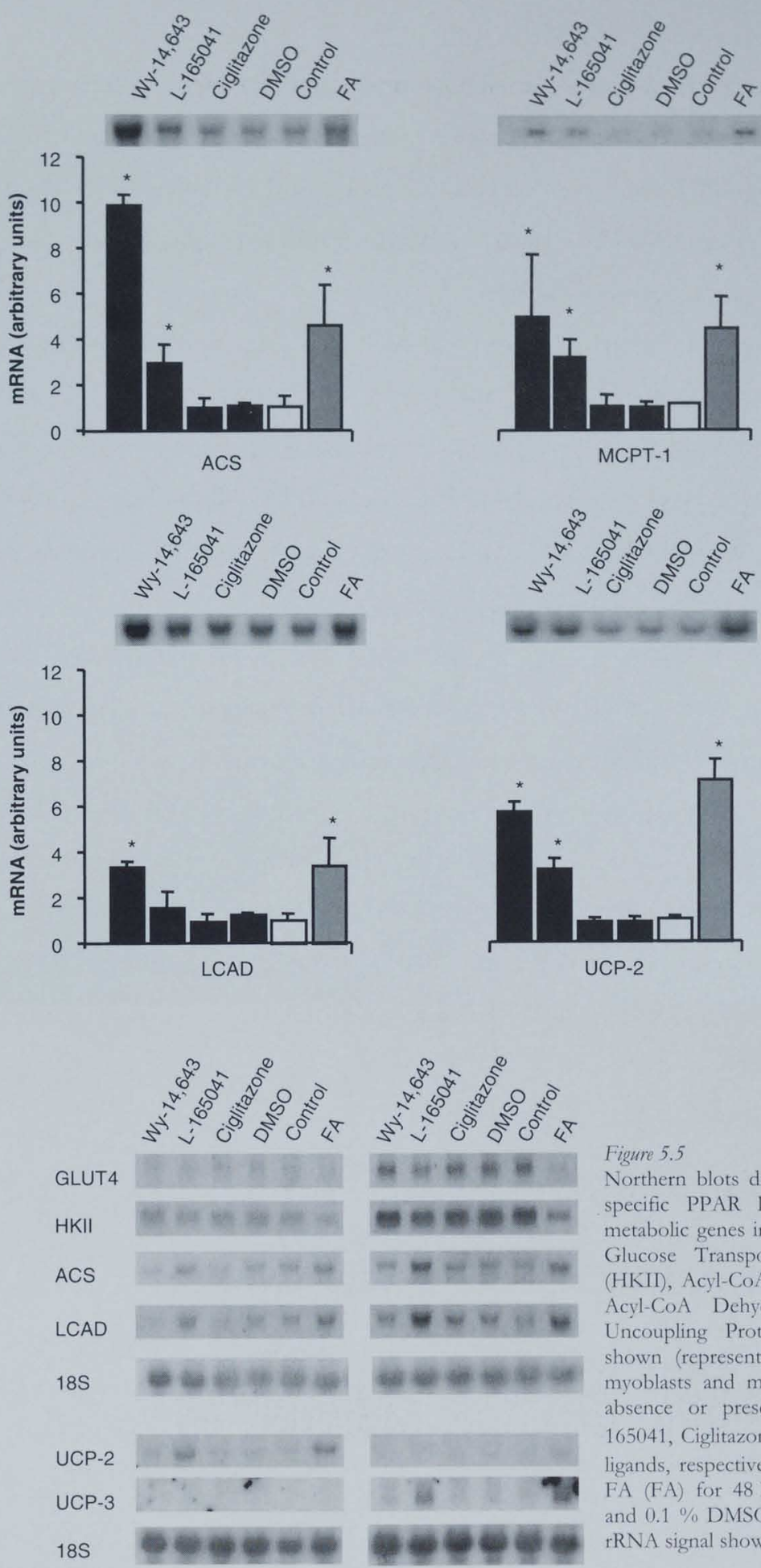

UCP-2
Figure 5.4

Effects of FA and isoform-specific PPAR ligands $(10 \mu \mathrm{M})$ on cardiomyocyte gene expression. The level of expression of the insulin dependent Glucose Transporter (GLUT4), Hexokinase II (HKII), Acyl-CoA Synthetase (ACS), Muscle-type Carnitine Palmitoyltransferase-1 (MCPT-1), Long-Chain Acyl-CoA

Dehydrogenase (LCAD), and the Uncoupling Protein 2 (UCP-2) are compared to the control group (glucose as sole substrate). Cells were exposed to glucose (open bars), either in combination of FA (FA, hatched bars), or one of the isoform-specific PPAR ligands (10 $\mu \mathrm{M}$ ) using $0.1 \% \mathrm{DMSO}$ as vehicle (black bars) for 48 h. Representative northern blot signals of the mRNAs investigated are included. Data are presented as means $\pm \mathrm{SD}(\mathrm{n}=5-7)$. * Indicates significantly different $\quad(\mathrm{p}<0.05)$ from control group.

\section{Figure 5.5}

Northern blots displaying the effects of isoform specific PPAR ligands on the expression of metabolic genes in $\mathrm{H} 9 \mathrm{c} 2$ cells. RNA levels of the Glucose Transporter GLUT4, Hexokinase II (HKII), Acyl-CoA Synthetase (ACS), Long-chain Acyl-CoA Dehydrogenase (LCAD), and the Uncoupling Proteins UCP-2 and UCP-3 are shown (representative of 3 experiments). $\mathrm{H} 9 \mathrm{c} 2$ myoblasts and myotubes were incubated in the absence or presence of either $W_{y}-14,643$, L165041, Ciglitazone (PPAR $\alpha, \beta / \delta$ and $\gamma$-specific ligands, respectively, at $10 \mu \mathrm{M})$, or with $0.5 \mathrm{mM}$ FA (FA) for $48 \mathrm{~h}$. Medium containing glucose and $0.1 \%$ DMSO served as vehicle control. $18 \mathrm{~S}$ rRNA signal shows equal loading. 


\subsubsection{PPAR-isoform specific transcriptional activation}

To demonstrate the PPAR-isoform specific response of neonatal cardiomyocytes, transient transfection was applied. Thereto the dose response to the various isoform-specific ligands was investigated using the human muscle-type CPT-1 promoter, containing a functional PPAR-responsive element ${ }^{3}$ (Fig. 5.6). The PPAR $\alpha$ ligand $W y-14,643$ as well as the PPAR $\beta / \delta$ ligands L-165041 and GW501516 dose-dependently induced promoter activity. For each ligand at approximately $5 \mu \mathrm{M}$ the response reached maximal values, but the level of induction was still lower than that with FA (3.5 +/- 1.0 fold). The PPAR $\beta / \delta$ ligand GW501516 proved to be the most potent ligand used and significantly increased MCPT-1 promoter activity at $10 \mathrm{nM}$ already. The specific PPAR $\gamma$ ligands Ciglitazone and Rosiglitazone, however, were unable to induce MCPT-1 promoter activity, irrespective of the dose applied. The forced overexpression of PPAR $\gamma$ substantially increased basal and rosiglitazone-activated transcription activity of both the MCPT-1 promoter (Fig. 5.7A) and a minimal promoter construct containing 3 copies of the Apo A-II PPRE (PPRE3-TK-Luc) (Fig. 5.7B), thereby demonstrating the potential of PPAR $y$ to regulate transcription in the cardiomyocyte context, provided that PPAR $\gamma$ is expressed at high levels.

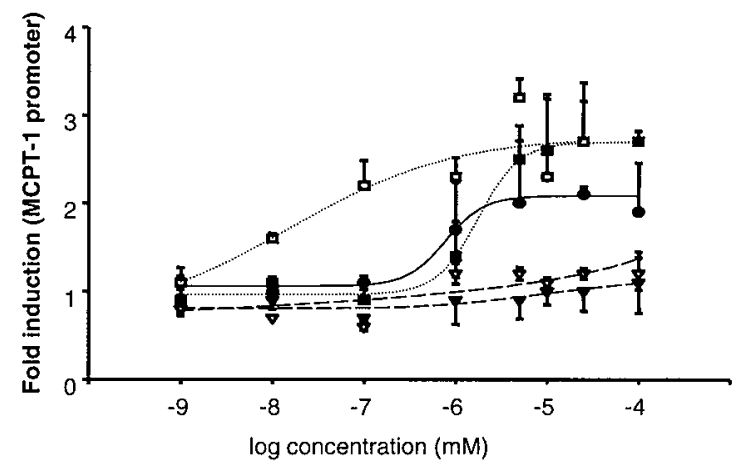

Figure 5.6

Dose response of the human muscle-type carnitine palmitoyl transferase-1 (MCPT-1) promoter in neonatal cardiomyocytes exposed to the PPAR $\alpha$ ligand $W y-14,643(\bullet), P P A R \beta / \delta$ ligands $L_{-}-165041$ ( $)$ and GW501516 ( $\square$ )and PPAR $\gamma$ ligands Ciglitazone $(\boldsymbol{\nabla})$ and Rosiglitazone $(\vee)$, respectively. Cells were transiently transfected with the MCPT-1 promoter/luciferase reporter vector, and subsequently treated with the different ligands. Results are expressed as fold induction compared to control (no ligand), which was arbitrarily set 1.0 . 

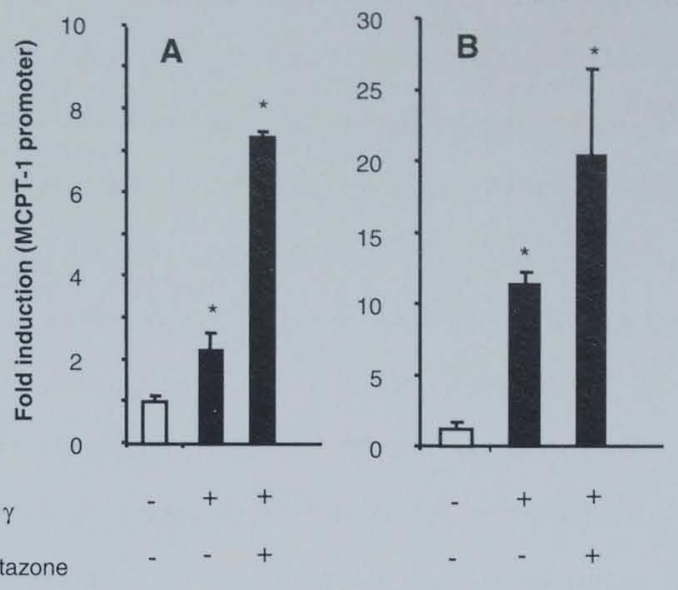

\section{Figure 5.7}

Effects of PPAR $\gamma$ over-expression on the activity of the MCPT-1 promoter (panel A) and a $3 \times$ PPRE containing minimal promoter construct PPRE3-TK-Luc (panel B) in the absence or presence of the selective PPAR $\gamma$ ligand Rosiglitazone $(10 \mu \mathrm{M})$ in cardiomyocytes. Induction of promoter activity is shown relative to vehicle $(0.1 \%$ DMSO) treated control cells (open bar), the luciferase activity of which was arbitrarily set at 1.0. Data are presented as means $\pm S D$ from three independent experiments. * Indicates significantly different $(\mathrm{p}<0.05)$ from control.

\section{Rosiglitazone}

\subsubsection{PPAR-isoforms and fatty acid oxidation}

To test whether the PPAR-mediated changes at the mRNA level were associated with functional alterations in FA metabolism the effects of the isoform-specific ligands on palmitate oxidation rate were determined (Fig. 5.8). In line with the mRNA data, ${ }^{14} \mathrm{CO}_{2}$ production from palmitate increased in cardiomyocytes pre-treated with the PPAR $\alpha$ ligand $\mathrm{W}_{\mathrm{y}}-14,643$ and the PPAR $\beta / \delta$ ligands L-165041 and GW501516, the latter being more potent. In contrast, the PPAR $\gamma$ ligands Ciglitazone and Rosiglitazone were both ineffective.
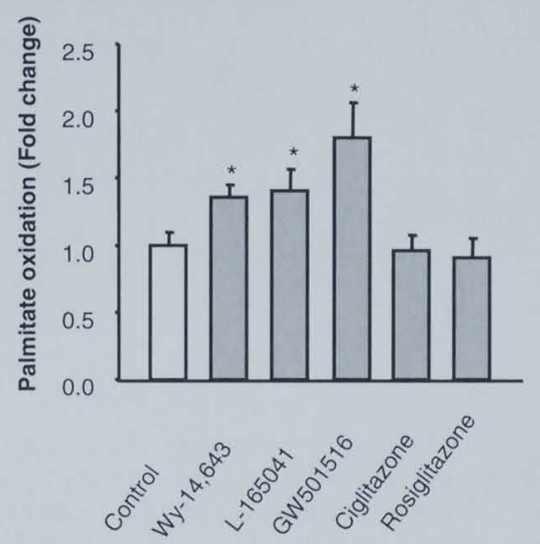

Figure 5.8

Effect of the PPAR isoform specific ligands on FA oxidation. The oxidation of radio-labeled palmitate was measured as the production of ${ }^{14} \mathrm{CO}_{2}$ during $30 \mathrm{~min}$ in cells pre-treated for $48 \mathrm{~h}$ with $10 \mu \mathrm{M}$ of either the PPAR $\alpha$ ligand $W_{y}-14,643$, the PPAR $\beta / \delta$ ligands $L-165041$ and GW501516, or the PPAR $\gamma$ ligands Ciglitazone and Rosiglitazone. Results are expressed as fold induction compared to control (no ligand), which was arbitrarily set 1.0 and corresponds with $0.15 \pm 0.04 \mathrm{nmol}$ palmitate per min per mg protein. Data presented as means $\pm S D(n=9$ of 3 different cultures). * Indicates significantly different $(p<0.05)$ from vehicle treated cells. 


\subsection{DISCUSSION}

The present findings demonstrate for the first time that the long-chain FA-induced increase in the expression of genes in cardiac muscle cells is mediated not only by PPAR $\alpha$, but also by PPAR $\beta / \delta$. With the use of a panel of PPAR isoform-specific ligands it is demonstrated that in neonatal cardiomyocytes PPAR $\alpha$ and PPAR $\beta / \delta$, but not PPAR $\gamma$, selectively increase the expression of genes involved in cardiac FA metabolism. The transient transfection studies with the MCPT-1 promoter indicate that these effects are mediated at the transcriptional level. As a consequence, the FA oxidation rate in cardiomyocytes showed to be enhanced. The fact that in $\mathrm{H} 9 \mathrm{c} 2$ cells, which only express the PPAR $\beta / \delta$ isoform, the effects of FA can only be reproduced by the PPAR $\beta / \delta$-specific ligand further substantiates the notion that FA act as endogenous ligands for PPAR $\beta / \delta$ in the cardiac muscle context.

\subsubsection{PPAR $\gamma$ and cardiomyocyte gene expression}

Whereas the presence of PPAR $\alpha$ and $\operatorname{PPAR} \beta / \delta$ in cardiac tissue has been firmly established ${ }^{21,22}$, the presence of PPAR $\gamma$ is controversial. PPAR $\gamma$ mRNA was detected either at low levels ${ }^{17,22-24}$, or could not be detected at all in the intact heart ${ }^{19,25}$. Recently, however, Takano et al. demonstrated the presence of PPAR $\gamma \mathrm{mRNA}$ and immunoreactivity in primary cultures of neonatal rat cardiomyocytes ${ }^{20}$. In the present study PPAR $\gamma$ mRNA appeared to be undetectable by northern blotting, but was detectable using a more sensitive method as RTPCR (data not shown) in freshly isolated neonatal and adult cardiomyocytes. Moreover, PPAR $\gamma$ immunoreactivity was detectable, albeit weak, revealing small amounts of PPAR $\gamma$ protein in cardiac myocytes and tissue. Our results corroborate the findings of Escher and colleagues ${ }^{24}$ who showed by quantitative RT-PCR that in the adult heart the mRNA content of PPAR $\gamma$ was low as compared to that of PPAR $\alpha$ and PPAR $\beta / \delta$.

The absence of significant effects of the PPAR $\gamma$ ligands Ciglitazone and Rosiglitazone on mRNA levels of all genes investigated, MCPT-1 promoter activity, and cellular FA oxidation rate argues against a role for PPAR $\gamma$ in the regulation of cardiac lipid metabolism. Even FAT/CD36, a gene that has convincingly been shown to behave as a PPAR $\gamma$ target gene in 
macrophages ${ }^{26}$ did not respond to PPAR $\gamma$ ligands in neonatal cardiomyocytes (unpublished observation). As the forced over-expression of PPAR $\gamma$ in cardiomyocytes is accompanied with basal and ligand-activated transcription of the MCPT-1 promoter, it is conceivable that the virtual absence of PPAR $\gamma$-mediated effects on FA metabolism resides in its low abundance in this cell type.

Other studies, however, revealed effects of PPAR $\gamma$ ligands on cardiomyocyte and skeletal muscle cell function and phenotype. In skeletal muscle the stimulatory effects of the thiazolidinediones on mitochondrial fuel oxidation were demonstrated to be independent of PPAR $\gamma$-mediated gene expression, suggesting that the drugs exerted PPAR $\gamma$ independent effects $^{27}$. Indeed, other signaling pathways, among which the NF- $\mathrm{BB}$ pathway, have been shown to be modulated by PPAR $\gamma$ ligands, involving both PPAR $\gamma$-dependent and PPAR $\gamma$ independent mechanisms ${ }^{28,29}$. Collectively, these observations suggest that, notwithstanding the limited relevance of PPAR $\gamma$ in cardiac lipid metabolism, a biological role for PPAR $\gamma$ in other processes in the heart cannot be dismissed.

\subsubsection{Role of PPAR $\alpha$ and $P P A R \beta / \delta$}

Both in vitro and in vivo studies demonstrated PPAR $\alpha$ to be instrumental in the regulation of the expression of genes coding for proteins involved in cardiac FA metabolism ${ }^{4,30,31}$. The present findings with respect to the PPAR isoform expression pattern and the effect of the PPAR $\alpha$ ligand Wy-14,643 on gene expression and FA oxidation corroborate these earlier observations.

Along with PPAR $\alpha$, the PPAR $\beta / \delta$ isoform was shown to be present in cardiomyocytes. However, in myoblasts and myotubes of the embryonic heart-derived cell line H9c2 PPAR $\beta / \delta$ turned out to be the only isoform present. In contrast to the other isoforms, the biological role of PPAR $\beta / \delta$ has remained largely enigmatic up to now. Interestingly, in $\mathrm{H} 9 \mathrm{c} 2$ cells the effects of FA on gene expression was mimicked by the PPAR $\beta / \delta$ ligand only. This effect was most obvious for the uncoupling proteins. In H9c2 myoblasts FA and L-165041 induced UCP2 mRNA levels to a similar extent, whereas in myotubes UCP3 responded in a similar way. These findings support the notion that FA function as ligands for PPAR $\beta / \delta$ in these cells and, 
by inference, in the cardiac muscle cell as well. Indeed, several recent studies are indicative for a role of PPAR $\beta / \delta$ in cellular lipid metabolism. In skeletal muscle cells PPAR $\beta / \delta$ was shown to be the PPAR-subtype responsible for the induction of UCP-3 and UCP-2 mRNA ${ }^{32,33}$. In cultured brain cells and keratinocytes the PPAR $\beta / \delta$-specific ligand L-165041 increased expression of the acyl-CoA synthetase isoform ACS2 and FAT/CD36, respectively ${ }^{34,35 .}$ Furthermore, Oliver and colleagues demonstrated increased transcription of the cholesterol transport protein ABCA1 by the highly specific PPAR $\beta / \delta$ ligand GW501516 in macrophages?.

The current findings indicate that activation of $\operatorname{PPAR} \beta / \delta$ also modulates neonatal cardiomyocyte gene expression. The mRNA and promoter/reporter studies reveal that the human MCPT-1 gene, previously shown to be responsive to PPAR $\alpha$, is equally responsive to the PPAR $\beta / \delta$-specific ligands L-165041 and GW501516. On the other hand, differences in response to $\alpha$-and $\beta / \delta$-ligands have to be appreciated too, as the rise in endogenous ACS and LCAD mRNA levels is less pronounced with L-165041 than with Wy-14,643 when applied at equimolar doses (see Fig. 5.4 and 5.5). Whether the differences in response of individual genes to PPAR $\alpha$ and PPAR $\beta / \delta$ ligands are related to the potency of the respective ligands, on the one hand, or to subtle differences within PPAR-response elements or flanking sequences, on the other, awaits further investigation. In this respect it is worth mentioning that differences in the consensus PPAR $\alpha$ and PPAR $\beta / \delta$ binding sites have indeed been reported ${ }^{36}$.

The present findings strongly suggest that $\operatorname{PPAR} \alpha$ and $\operatorname{PPAR} \beta / \delta$ share similar functions. Indeed, administration of $\operatorname{PPAR} \beta / \delta$ agonists to $\operatorname{PPAR} \alpha$ null mice induces peroxisome proliferation in liver ${ }^{37}$, a phenomenon formerly exclusively ascribed to PPAR $\alpha$. Similarly, in PPAR $\alpha(-/-)$ mice the fasting-induced up-regulation of several PPAR-responsive genes in liver and heart is attenuated, but not completely blunted ${ }^{30}$. The latter findings suggest a residual effect, or partial compensation, involving $\operatorname{PPAR} \beta / \delta$. Furthermore, the recent obscrvation by Muoio and co-workers that fatty acid oxidation in skeletal muscle of PPAR $\alpha$ (/-) mice is not impaired also led these investigators to conclude that PPAR $\beta / \delta$ compensates for the lack of PPAR $\alpha$ in these mice ${ }^{38}$.

Taken together, the present findings argue against a significant role for PPAR $\gamma$ in the regulation of metabolic gene expression in heart muscle cells. Furthermore, unequivocal 
evidence is presented that, next to $\operatorname{PPAR} \alpha, \operatorname{PPAR} \beta / \delta$ is an important regulator of the expression of genes involved in cardiac lipid metabolism. Accordingly, further investigation into the role of PPAR $\beta / \delta$ isoform in the regulation of cardiac FA homeostasis during cardiac disease is warranted.

\section{Acknowledgements}

The authors thank E.M.H. Cuijpers and R.L.M. Lotz. for technical support. The research was funded by grants of the Netherlands Heart Foundation (NHS 1998T015 to MvB, NHS 1997B093 to FRvdL), by the European Union (QLG1-1999-01007 to GC) and Leducq Foundation and the FEDER/Conseil Régional Nord/Pas-de-Calais (Genopole 01360124) to BS. 


\section{REFERENCES}

1. Van Bilsen M, van der Vusse GJ, Reneman RS. Transcriptional tegulation of metabolic Processes: implications for cardiac metabolism. Eur J Physiol. 1998;437:2-14.

2. Taegtmeyer $\mathrm{H}$. Genetics of energetics: transcriptional responses in cardiac metabolism. Ann Biomed Eng. 2000;28:871-876.

3. Brandt JM, Djouadi F, Kelly DP. Fatty acids activate transcription of the Muscle Carnitine Palmitoyltransferase I gene in cardiac myocytes via the Peroxisome Proliferator-Activated Receptor- $\alpha$. J Biol Chem. 1998;273:23786-23792.

4. Van der Lee KAJM, Vork MM, De Vries JE, Willemsen PHM, Glatz JFC, Reneman RS, Van der Vusse GJ, Van Bilsen M. Long-chain fatty acid-induced changes in gene expression in neonatal cardiac myocytes. J Lipid Res. 2000;41:41-47.

5. Schoonjans K, Staels B, Auwerx J. The peroxisome proliferator activated receptors (PPARs) and their effects on lipid metabolism and adipocyte differentiation. Biochim Biopbys Acta. 1996;1302:93109.

6. Yu K, Bayona W, Kallen CB, Harding HP, Ravera CP, McMahon G, Brown M, Lazar MA. Differential activation of Peroxisome Proliferator-Activated Receptors by eicosanoids. $J$ Biol Chem. 1995;270:23957-23983.

7. Willson TM, Brown PJ, Sternbach DD, Henke BR. The PPARs: From orphan receptors to drug discovery. J Med Cbem. 2000;43:527-550.

8. Berger J, Leibowitz MD, Doebber TW, Elbrecht A, Zhang B, Zhou G, Biswas C, Cullinan CA, Hayes NS, Li Y, Tanen M, Ventre J, Wu MS, Berger GD, Mosley R, Marquis R, Santini C, Sahoo SP, Tolman RL, Smith RG, Moller DE. Novel Peroxisome Proliferator-Activated Receptor (PPAR)- $\gamma$ and PPAR $\delta$ ligands produce distinct biological effects. J Biol Chem. 1999;274:6718-6725.

9. Oliver WR, Jr., Shenk JL, Snaith MR, Russell CS, Plunket KD, Bodkin NL, Lewis MC, Winegar DA, Sznaidman ML, Lambert MH, Xu HE, Sternbach DD, Kliewer SA, Hansen BC, Willson TM. A selective Peroxisome Proliferator-Activated Receptor- $\delta$ agonist promotes reverse cholesterol transport. Proc Natl Acad Sci USA. 2001;98:5306-5311.

10. De Vries JE, Vork MM, Roemen THM, de Jong YF, Cleutjens JPM, Van der Vusse GJ, Van Bilsen M. Saturated but not mono-unsaturated fatty acids induce apoptotic cell death in neonatal rat ventricular myocytes. J Lipid Res. 1997;38:1384-1394.

11. Jans SWS, de Jong YF, Reutelingsperger CPM, Van der Vusse GJ, Van Bilsen M. Differential expression and localization of annexin $\mathrm{V}$ in cardiac myocytes during growth and hypertrophy. Mol Cell Biocbem. 1998;178:229-236.

12. Van der Lee KAJM, Willemsen PHM, Van der Vusse GJ, Van Bilsen M. Effects of fatty acids on Uncoupling Protein-2 expression in the rat heart. FASEB J. 2000;14:495-502.

13. Van der Lee KAJM, Willemsen PHM, Samec S, Seydoux J, Dulloo AG, Pelsers MMAL, Glatz JFC, Van der Vusse GJ, Van Bilsen M. Fasting-induced changes in the expression of genes controlling substrate metabolism in the rat heart. J Lipid Res. 2001; 42:1752-1758.

14. van der Leij FR, Takens J, van der Veen AY, Terpstra P, Kuipers JR. Localization and intron usage analysis of the human CPT1B gene for Muscle-type Carnitine Palmitoyltransferase I. Biochim Biopbys Acta. 1997;1352:123-128.

15. Vu Dac N, Schoonjans K, Kosykh V, Dallongeville J, Fruchart JC, Staels B, Auwerx J. Fibrates increase human Apolipoprotein A-II expression through activation of the Peroxisome ProliferatorActivated Receptor. J Clin Invest. 1995;96:741-750.

16. Shubeita HE, Martinson EA, Van Bilsen M, Chien KR, Brown JH. Transcriptional activation of the cardiac myosin light chain 2 and atrial natriuretic factor genes by Protein Kinase $\mathrm{C}$ in neonatal rat ventricular myocytes. Proc Natl Acad Sci U S A. 1992;89:1305-1309. 
17. Aperlo C, Pognonec P, Saladin R, Auwerx J, Boulukos KE. cDNA cloning and characterization of the transcriptional activities of the hamster Peroxisome Proliferator-Activated Receptor- $\gamma$ haPPAR $\gamma$. Gene. 1995;162:297-302.

18. Wallenstein S, Zucker CL, Fleiss JL. Some statistical methods useful in circulation research. Circ Res. 1980;47:1-9.

19. Braissant O, Foufelle F, Scotto C, Dauça M, Wahli W. Differential expression of peroxisome proliferator-activated receptors (PPARs): tissue distribution of PPAR $\alpha,-\beta$, and $-\gamma$ in the adult rat. Endocrinology. 1996;137:354-366.

20. Takano H, Nagai T, Asakawa M, Toyozaki T, Oka T, Komuro I, Saito T, Masuda Y. Peroxisome proliferator-activated receptor activators inhibit lipopolysaccharide-induced Tumor Necrosis Factor- $\alpha$ expression in neonatal tat cardiac myocytes. Circ Res. 2000;87:596-602.

21. Mukherjee R, Jow L, Noonan D, McDonnell DP. Human and rat Peroxisome Proliferator Activated Receptors (PPARs) demonstrate similar tissue distribution but different responsiveness to PPAR activators. J Steroid Biocbem Molec Biol. 1994;51:157-166.

22. Kliewer SA, Forman BM, Blumberg B, Ong ES, Borgmeyer U, Mangelsdorf DJ, Umesono K, Evans RM. Differential expression and activation of a family of murine Peroxisome ProliferatorActivated Receptors. Proc Natl Acad Sci USA. 1994;91:7355-7359.

23. Zhu Y, Alvares K, Huang Q, Rao MS, Reddy JK. Cloning of a new member of the Peroxisome Proliferator-Activated Receptor gene family from mouse liver. J Biol Chem. 1993;268:26817-26820.

24. Escher P, Braissant O, Basu-Modak S, Michalik L, Wahli W, Desvergne B. Rat PPARs: quantitative analysis in adult rat tissues and regulation in fasting and refeeding. Endocrinology. 2001;142:41954202.

25. Jones PS, Savory R, Barratt P, Bell AR, Gray TJB, Jenkins NA, Gilbert DJ, Copeland NG, Bell DR. Chromosomal localisation, inducibility, tissue-specific expression and strain differences in three murine Peroxisome Proliferator-Activated Receptor genes. Eur J Biochem. 1995;233:219-226.

26. Tontonoz P, Nagy L, Alvarez JGA, Thomazy VA, Evans RM. PPAR $\gamma$ promotes monocyte/macrophage differentiation and uptake of oxidized LDL. Cell. 1998;93:241-252.

27. Brunmair B, Gras F, Neschen S, Roden M, Wagner L, Waldhausl W, Furnsinn C. Direct thiazolidinedione action on isolated rat skeletal muscle fuel handling is independent of Peroxisome Proliferator-Activated Receptor- $\gamma$-mediated changes in gene expression. Diabetes. 2001;50:23092315.

28. Yamamoto K, Ohki R, Lee RT, Ikeda U, Shimada K. Peroxisome Proliferator-Activated Receptor- $\gamma$ activators inhibit cardiac hypertrophy in cardiac myocytes. Circulation. 2001;104:1670-1675.

29. Castrillo A, Díaz-Guerra MJ, Hortelano S, Martin-Sanz P, Boscá L. Inhibition of I $k B$ kinase and IкB phosphorylation by 15 -deoxy- $\mathrm{D}^{12,14}$-prostaglandin $\mathrm{J}_{2}$ in activated murine macrophages. Mol Cell Biol. 2000;20:1692-1698.

30. Leone TC, Weinheimer CJ, Kelly DP. A critical role for the Peroxisome Proliferator-Activated Receptor- $\alpha$ (PPAR $\alpha$ ) in the cellular fasting response: The PPAR $\alpha$-null mouse as a model of fatty acid oxidation disorders. Proc Natl Acad Sci USA. 1999;96:7473-7478.

31. Watanabe K, Fujii H, Takahashi T, Kodama M, Aizawa Y, Ohta Y, Ono T, Hasegawa G, Naito M, Nakajima T, Kamijo Y, Gonzalez FJ, Aoyama T. Constitutive regulation of cardiac fatty acid metabolism through Peroxisome Proliferator-Activated Receptor- $\alpha$ associated with age-dependent cardiac toxicity. J Biol Chem. 2000;275:22293-22299.

32. Nagase I, Yoshida S, Canas X, Irie Y, Kimura K, Yoshida T, Saito M. Up-regulation of uncoupling protein 3 by thyroid hormone, Peroxisome Proliferator-Activated Receptor ligands and 9-cis retinoic acid in L6 myotubes. FEBS Lett. 1999;461:319-322.

33. Chevillotte $E$, Rieusset J, Roques $M$, Desage $M$, Vidal $H$. The regulation of Uncoupling Protein-2 gene expression by $\omega-6$ polyunsaturated fatty acids in human skeletal muscle cells involves multiple 
pathways, including the nuclear receptor Peroxisome Proliferator-Activated Receptor- $\beta$. $J$ Biol Chem. 2001;276:10853-10860.

34. Basu-Modak S, Braissant O, Escher P, Desvergne B, Honegger P, Wahli W. Peroxisome Proliferator-Activated Receptor- $\beta$ regulates Acyl-CoA Synthetase 2 in reaggregated rat brain cell cultures. J Biol Chem. 1999;274:35881-35888.

35. Westergaard M, Henningsen J, Svendsen ML, Johansen C, Jensen UB, Schrøder HD, Kratchmarova I, Berge RK, Iversen L, Bolund L, Kragballe K, Kristiansen K. Modulation of keratinocyte gene expression and differentiation by PPAR-selective ligands and tetradecylthioacetic acid. I Invest Dermatol. 2001;116:702-712.

36. He TC, Chan TA, Vogelstein B, Kinzler KW. PPAR $\delta$ is an APC-regulated target of nonsteroidal anti-inflammatory drugs. Cell. 1999;99:335-345.

37. DeLuca JG, Doebber TW, Kelly LJ, Kemp RK, Molon-Noblot S, Sahoo SP, Ventre J, Wu MS, Peters JM, Gonzalez FJ, Moller DE. Evidence for Peroxisome Proliferator-Activated Receptor (PPAR) $\alpha$-independent peroxisome proliferation: effects of PPAR $\gamma / \delta$-specific agonists in PPAR $\alpha$ null mice. Mol Pharmacol. 2000;58:470-476.

38. Muoio DM, MacLean PS, Lang DB, Li S, Houmard JA, Way JM, Winegar DA, Corton JC, Dohm GL, Kraus WE. Fatty acid homeostasis and induction of lipid regulatory genes in skeletal muscles of Peroxisome Proliferator-Activated Receptor (PPAR)- $\alpha$ knock-out mice. Evidence for compensatory regulation by PPAR $\delta$. J Biol Chem. 2002;277:26089-26097. 


$$
6 .
$$




\subsection{ABSTRACT}

The transcription factor Peroxisome Proliferator-Activated Receptor (PPAR) is a major regulator of long-chain fatty acid (FA) metabolism. At present three isoforms of this ligand activated receptor have been identified, i.e., PPAR $\alpha, \operatorname{PPAR} \beta / \delta$, and PPAR $\gamma$. Only PPAR $\alpha$ and $\operatorname{PPAR} \beta / \delta$ are actively involved in the transcriptional regulation of cardiac FA metabolism. The co-existence of these two PPAR isoforms in the cardiac muscle cell raises the question about the functional significance, on the one hand, and the potential differences in the way how they exert their regulatory action on the other. In the present study, the main focus was on possible differences between PPAR $\alpha$ and PPAR $\beta / \delta$ in promoter regulation.

Using the Muscle-type Carnitine Palmitoyl Transferase-1 (MCPT-1) promoter as a readout the ligand dependency of $\operatorname{PPAR} \alpha$ and $\operatorname{PPAR} \beta / \delta$ and their interaction with their heterodimer partner $\operatorname{RXR} \alpha$ and the transcriptional co-activator PPAR $\gamma$ Co-activator-1 $\alpha$ (PGC-1 $\alpha$ ) were studied in neonatal rat cardiomyocytes as well as the non-cardiomyocytes cell-line HEK293. In both cardiomyocytes and HEK293 cells differences between PPAR $\alpha$ and PPAR $\beta / \delta$ in MCPT-1 promoter activation were observed. Unlike PPAR $\alpha$, exogenous PPAR $\beta / \delta$ from different species did not show ligand-independent (cryptic) trans-activation activity in cardiomyocytes. Activation of endogenous and exogenous RXR $\alpha$ with the cognate ligand 9-cis-retinoic acid enhanced transcription in both cell types. However, in HEK293 cells, but not in cardiomyocytes, RXR $\alpha$ over-expression decreased the PPAR $\alpha$ and PPAR $\beta / \delta$ mediated MCPT-1 promoter activation via an as yet un-identified mechanism. PGC-1 $\alpha$ overexpression resulted in MCPT-1 promoter activation in both cardiomyocytes and HEK293 cells. In summary, this study shows differences in MCPT-1 promoter activation between PPAR $\alpha$ and $\operatorname{PPAR} \beta / \delta$ as well as cell-type specific mechanisms in promoter activation, warranting further research into the molecular mechanisms underlying these events. 


\subsection{INTRODUCTION}

Peroxisome Proliferator-Activated Receptors (PPARs) are ligand-activated receptors belonging to the super-family of nuclear hormone receptors. Thus far three different isoforms of PPAR have been identified, i.e., PPAR $\alpha$ (Nuclear Receptor 1 Class 1 or NR1C1), PPAR $\beta / \delta$ (NR1C2), and PPAR $\gamma$ (NR1C3), each encoded by a different gene (recently reviewed in ${ }^{1-3}$ ). All three isoforms have a distinct tissue distribution pattern ${ }^{4}$. PPAR $\alpha$ is predominantly expressed in heart, liver and skeletal muscle, whereas PPAR $\gamma$ is mainiy expressed in adipose tissue. In contrast to the other two isoforms, PPAR $\beta / \delta$ shows a ubiquitous distribution pattern ${ }^{4}$. Pharmacological and molecular interventions have led to the partial elucidation of the function of the PPAR isoforms, varying from the regulation of fatty acid (FA) metabolism in oxidative tissues by PPAR $\alpha$ to adipocyte differentiation by PPAR $\gamma$. Until recently, little if anything was known about the biological function of $\operatorname{PPAR} \beta / \delta$.

We and others demonstrated that in the cardiac muscle cell, similar to PPAR $\alpha$, $\operatorname{PPAR} \beta / \delta$ is involved in the transcriptional regulation of the FA oxidative pathway, ${ }^{5,6}$. These findings were corroborated by studies in skeletal muscle cells and endothelial cells, indicating that PPAR $\alpha$ and PPAR $\beta / \delta$ might share a common function ${ }^{7-9}$. The latter observations raise the question regarding the functional significance of the co-existence of these two isoforms within the cardiac muscle cell. It is feasible that, depending on variations in the consensus PPAR-binding sequence or in neighbouring sequences, PPAR $\alpha$ and $\operatorname{PPAR} \beta / \delta$ preferentially activate different subsets of target genes. In this respect, it is worthy to note that $\operatorname{PPAR} \beta / \delta$ was

found to bind to a response element distinct from the consensus PPRE ${ }^{10}$. More recently, Dressel and colleagues ${ }^{8}$ reported that the promoter of the muscle-type carnitine palmitoyl transferase-I (MCPT-1) is PPAR $\beta / \delta$ - rather than PPAR $\alpha$-responsive. Alternatively, PPAR $\alpha$ and PPAR $\beta / \delta$ may differ in their affinity for natural ligands and/or affinity for the Retinoic-Xreceptor (RXR), their common dimerization partner, or for proteins that act as co-repressor (e.g. the Nuclear Co-Repressor, NCoR) or co-activator (e.g the PPAR $\gamma$ Co-activator-1 $\alpha$, PGC$1 \alpha)$ of the PPAR/RXR dimer ${ }^{11-13}$. In particular the role of the latter protein is receiving widespread attention, as it was shown to be an important co-activator for PPAR $\alpha^{14}$. Besides, 
PGC- $1 \alpha$ is abundantly expressed in skeletal and cardiac myocytes ${ }^{15,16}$, further underscoring the potential biological relevance of this co-activator in the myocardium. On the contrary, detailed information on the factors governing PPAR $\beta / \delta$-mediated regulation of cardiac gene expression is lacking.

It is conceivable that the functional significance of the co-existence of these two PPAR isoforms in the cardiac muscle cell may reside in subtle differences in the way in which these transcription factors get activated. Accordingly, to investigate potential differences in transcriptional regulation between $\operatorname{PPAR} \alpha$ and $\operatorname{PPAR} \beta / \delta$, primary cultures of rat neonatal cardiomyocytes were treated with isoform-specific synthetic PPAR agonists in the absence or presence of the bona fide RXR-ligand 9-cis-retinoic acid (9cis-RA), using the MCPT-1 promoter as read-out. To determine whether differences in the interaction with auxiliary proteins play a role, cells were also transfected with RXR or with PGC-1 $\alpha$. Similar experiments were conducted with cardiomyocytes in which exogenous PPAR $\alpha$ or PPAR $\beta / \delta$ was introduced by transient transfection. For comparison, in a subset of transfection experiments the effect of exogenous PPAR $\gamma$ was studied as well. To test whether differences in transcriptional activation were dependent on the cellular context, experiments were conducted on cardiomyocytes as well as on a human embryonic kidney cell-line, HEK293.

\subsection{MATERIALS AND METHODS}

\subsubsection{Cell Culture}

Neonatal rat ventricular cardiomyocytes were isolated and cultured as described previously ${ }^{17}$. The experiments were approved by the Institutional Animal Care and User Committee at the Maastricht University. The human embryo kidney cell-line HEK293 (BD Biosciences, Brussels, Belgium) was cultured in DMEM with L-glutamine $(2 \mathrm{mM})$, fetal bovine serum $(10 \%)$, and gentamicin $(50 \mu \mathrm{g} / \mathrm{ml})$. The experimental medium for transfections consisted of a 4:1 mixture of DMEM/M199, gentamicin $(50 \mathrm{mg} / \mathrm{L})$ with glucose $(10 \mathrm{mM})$ as the sole substrate enriched with $0.25 \mathrm{mM} \mathrm{L}$-carnitine, $0.25 \mathrm{mU} / \mathrm{ml}$ insulin and $0.15 \mathrm{mM}$ bovine serum albumin (BSA; A7906, Sigma, St. Louis MO, USA). 


\subsubsection{Nuclear Receptor Ligands}

Isoform specific ligands for PPAR $\alpha$, Wy-14,643 (Biomol, Plymouth Meeting, PA, USA), PPAR $\beta / \delta$, GW501516 (a gift from Dr. B. Staels INSERM, Lille, France), and PPAR $\gamma$, Rosiglitazone (Rosiglitazone-maleate, LKT Laboratories, Inc., St. Paul, MN, USA) were used. In accordance with previous experiments ${ }^{5}$ the concentrations of the PPAR isoform specific

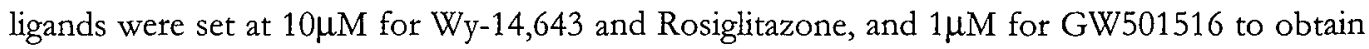
equipotent concentrations. 9-cis-retinoic acid (9cis-RA) was purchased from Biomol. The ligands were dissolved to the indicated concentrations in DMSO, which was also added as vehicle $(0.1 \% \mathrm{v} / \mathrm{v})$ to the medium of control cells.

\subsubsection{Transient Transfection}

For transient transfection cardiomyocytes were seeded on 6-well plates at a density of $2.5 \times 10^{5}$ cells in $2 \mathrm{ml}$ of medium per well. HEK293 cells were grown on 6-well plates to approximately $80 \%$ confluency before use. Cells were transfected using the transfection reagent FuGENE 6 (Roche, Indianapolis IN, USA) 16 hours before addition of experimental media. Cells were transfected with $0.5 \mu \mathrm{g}$ of MCPT-1-luc ${ }^{5}$, or a construct containing three copies of the human ApoA-II PPRE linked to the minimal thymidine kinase promoter ( $3 *$ PPRE-construct) ${ }^{18}$. The CMV- $\beta$-galactosidase containing vector pON249 $(0.25 \mu \mathrm{g})$ was co-transfected to correct for differences in transfection efficiency ${ }^{19}$. In a sub-set of experiments $0.25 \mu \mathrm{g}$ of the pSG5 expression vector containing the cDNA of mouse PPAR $\alpha$, human $\operatorname{PPAR} \beta / \delta$, or hamster PPAR $\gamma$ (kindly provided by Dr. Staels, Institut Pasteur, Lille, France) were co-transfected unless indicated otherwise. Additionally, depending on the experiment, $0.25 \mu \mathrm{g}$ pSG5 expression vector harbouring mouse $\operatorname{RXR} \alpha$ (a generous gift from Dr. Chambon, INSERM, Strasbourg, France) and mouse PGC-1 $\alpha$ were co-transfected (Kindly provided by Dr. Kelly, Washington University, St. Louis, MO, USA). The total amount of plasmid DNA per well and the ratio of plasmid DNA $(\mu \mathrm{g})$ over FUGENE $(\mu \mathrm{l})$ were kept constant by adding empty pSG5 vector (Promega, Madison, WI, USA), according to the manufacturers instructions. Cells were harvested $24 \mathrm{~h}$ after addition of experimental medium and immediately processed for the 
determination of reporter activity. Luciferase activity was determined using a commercial firefly luciferase assay according to the suppliers instructions (Steady Glo, Promega) in white 96-well plates (Nalge Nunc International, Maperville, IL, USA) and FluorS imager (Bio-Rad) for measuring luminescence. $\beta$-Galactosidase activity was determined as previously described ${ }^{5}$.

\subsubsection{Statistics}

Results are obtained from triplicate incubations of at least three independent cardiomyocyte isolations or HEK293 cell cultures and presented as sample means \pm SD. Comparison between groups was performed with one-way analysis of variance (ANOVA). In case the F-ratio obtained indicated that significant differences between groups were present, a Bonferronis adjustment for multiple comparison ${ }^{20}$ was applied. Differences were considered significant at $\mathrm{p}<0.05$.

A

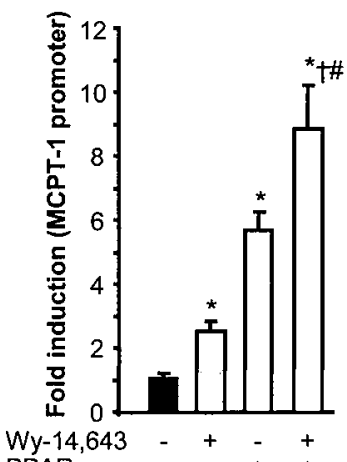

B
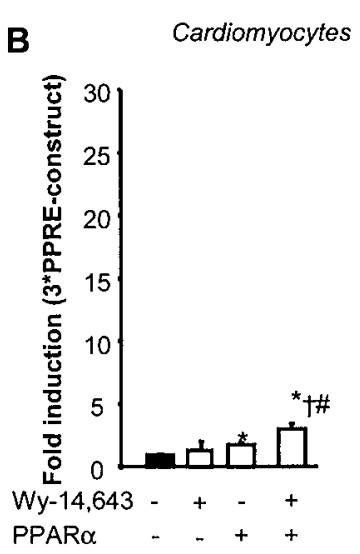

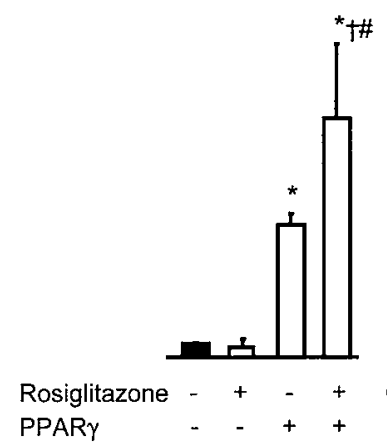

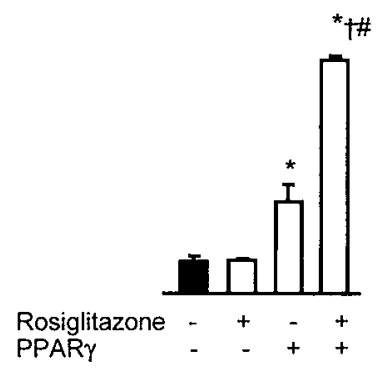

Rosiglitazone PPAR $\gamma$

\section{ow}

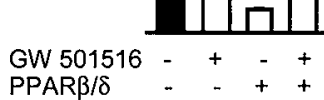

(1) 


\subsection{RESULTS}

\subsubsection{PPAR isoform specific promoter-activation}

First, the regulation of promoter activation by the three PPAR isoforms was studied in neonatal cardiomyocytes using the MCPT-1 promoter as read-out. In accordance with previous observations $^{5}$, the experimental findings show activation of the MCPT-1 promoter by the PPAR $\alpha$ and PPAR $\beta / \delta$ specific ligands $W_{y}-14,643$ and GW501516, respectively. The PPAR $\gamma$ specific ligand Rosiglitazone, however, was unable to activate the MCPT-1 promoter (Fig. 6.1A). Next it was investigated whether the forced over-expression of either PPAR $\alpha$, $\operatorname{PPAR} \beta / \delta$ or PPAR $\gamma$ resulted in the transcriptional activation of the MCPT- 1 promoter. As shown in Figure 6.1A, in the absence of synthetic ligand the over-expression of PPAR $\alpha$ and PPAR $\gamma$ was already sufficient to activate the MCPT-1 promoter, suggesting either that these isoforms possesses some cryptic activity in the un-liganded state or that the intracellular concentration of endogenous ligands was sufficiently high to activate these two isoforms. The co-addition of the cognate ligands further boosted transcriptional activity of PPAR $\alpha$ and PPAR $\gamma$. As far as PPAR $\gamma$ is concerned, this experiment shows that when in the cardiomyocytes exogenous PPAR $\gamma$ is introduced, its behaviour is similar to PPAR $\alpha$. In contrast, the mere overexpression of PPAR $\beta / \delta$ did not lead to any transcriptional activation and the simultaneous addition of the PPAR $\beta / \delta$ ligand GW501516 did not show an additive effect. In fact, overexpression of PPAR $\beta / \delta$ along with the administration of GW501516 activated the MCPT-1 promoter to a level equal to that of GW501516 alone. This observation suggests that transactivation of $\operatorname{PPAR} \beta / \delta$ is regulated in a manner different from that of PPAR $\alpha$.

Experiments were repeated with a human PPAR $\beta / \delta$ expression vector. No differences were observed in the (lack of) trans-activating properties of mouse PPAR $\beta / \delta$ and human PPAR $\beta / \delta$, thereby excluding the possibility that this typical feature of $\operatorname{PPAR} \beta / \delta$ was species dependent (data not shown).

Next, the cardiomyocytes were transfected with a minimal thymidine kinase promoter construct under the control of 3 copies of the PPRE of the Apo A-II gene (3xPPREconstruct). In contrast to the MCPT-1 promoter, the mere addition of isoform specific ligands 
was not sufficient to activate the 3xPPRE-construct (Fig. 6.1B). Over-expression of the PPAR $\alpha$ led to a modest, though statistically significant, increase in gene transcription, which was further enhanced by the administration of its cognate ligand $W_{y}-14,643$. Over-expression of PPAR $\gamma$ in the absence or presence of Rosiglitazone led to comparable results, albeit that the level of induction was far more outspoken. Interestingly, ectopic expression of PPAR $\beta / \delta$ was unable to activate the $3 \times P P R E$-construct, irrespective of the absence or presence of its specific ligand GW501516.

\subsubsection{PPAR-mediated gene expression in HEK293 cells}

To investigate PPAR isoform-specific promoter activation in a non-cardiac cell type, HEK293 cells were transiently transfected with the MCPT-1 promoter and its response to PPAR activation was determined (Fig. 6.2). Administration of the PPAR $\alpha$ ligand Wy-14,643 did not activate the MCPT-1 promoter. In contrast, administration of either Rosiglitazone or GW501516 significantly enhanced the promoter activity.

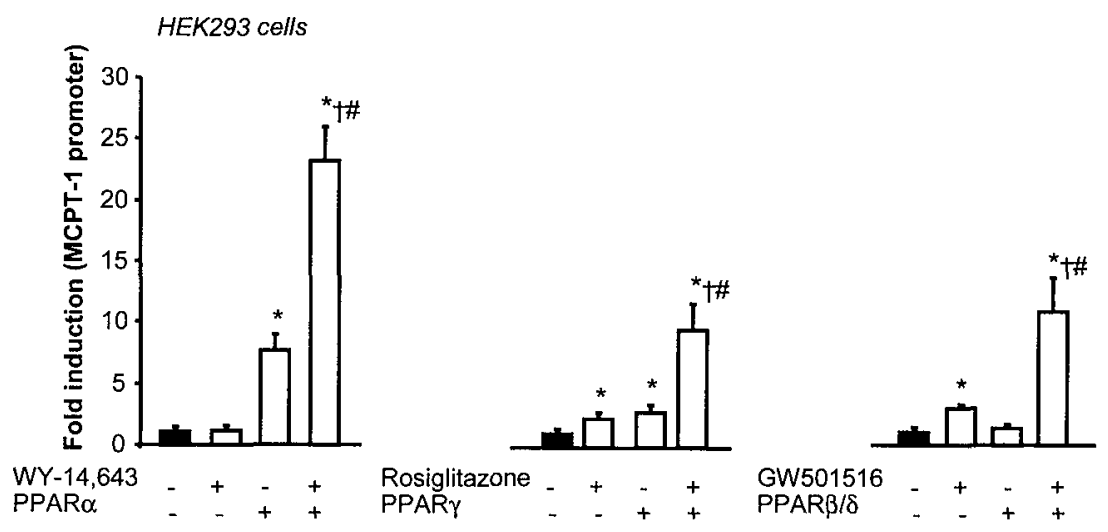

\section{Figure 6.2}

Response of the human muscle-type carnitine palmitoyl transferase-1 promoter (MCPT-1) to endogenous and exogenous PPAR isoform activation, in the human embryonic kidney cell-line HEK293 in the absence or presence of ligand (Wy14,643 and Rosiglitazone, both at $10 \mu \mathrm{M}$, and GW501516 at $1 \mu \mathrm{M}$ ). Results are expressed as fold induction compared to vehicle (DMSO 0.1\%) treated controls (black bar), the average value of which was arbitrarily set $1.0 .{ }^{*}$ Indicates significantly different $(p<0.05)$ compared to vehicle treated control. $\dagger$ indicates significantly different $(p<0.05)$ compared to PPAR isoform specific ligand treatment alone. \# indicates significantly different $(p<0.05)$ compared to PPAR isoform overexpression in the absence of ligand. 
These results suggest the presence of sufficient amounts of endogenous PPAR $\gamma$ and $\operatorname{PPAR} \beta / \delta$, while PPAR $\alpha$ appears to be lacking in HEK293 cells. Mere over-expression either of PPAR $\alpha$ or PPAR $\gamma$ resulted in MCPT-1 promoter activation. This response was profo undly stimulated by the co-addition of their cognate ligands. Like in the cardiomyocytes, over-expression of $\operatorname{PPAR} \beta / \delta$ did not affect MCPT-1 promoter activity. However, in contrast to cardiomyocytes, in HEK293 cells trans-activation of exogenous PPAR $\beta / \delta$ by GW501516 was associated with a marked induction of MCPT-1 promoter activity.

\subsubsection{Interaction between $P P A R s$ and their common beterodimer partner $R X R \alpha$}

Next, the involvement of the PPAR hetero-dimer partner RXR $\alpha$ in MCPT-1 promoter regulation was investigated. Activation of endogenous $\operatorname{RXR} \alpha$ through addition of its bona fide ligand 9cis-RA increased MCPT-1 promoter activity in cardiomyocytes (Fig. 6.3A) as well as in HEK293 cells (Fig. 6.3B). Likewise, over-expression of $\mathrm{RXR} \alpha$ resulted in an increased promoter activity in both cell types. In cardiomyocytes over-expression of $R X R \alpha$ in combination with the addition of its ligand 9cis-RA did not increase promoter activity. Remarkably, in HEK293 cells exposed to 9cis-RA the level of induction of the MCPT1 promoter was significantly lower when the cells expressed exogenous RXR $\alpha$.

A Cardiomyocytes

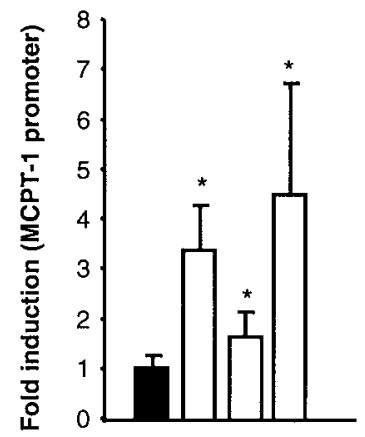

9 cis-RA

$\mathrm{RXRo}$
B

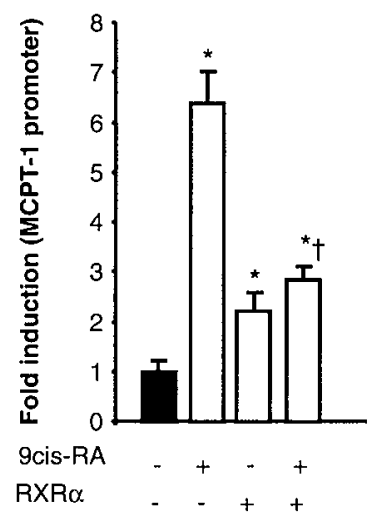

Figure 6.3

Response of the human muscle-type carnitine palmitoyl transferase-1 promoter (MCPT-1) to endogenous and exogenous $\operatorname{RXR} \alpha$ activation in cardiomyocytes (3A) and HEK293 cells (3B) in the absence or presence of its ligand 9-cis retinoic acid $(9 \mathrm{cis}-$ RA) at $10 \mu \mathrm{M}$. Results are expressed as fold induction compared to vehicle (DMSO 0.1\%) treated controls (black bar), the average value of which was arbitrarily set 1.0. * Indicates significantly different $(p<0.05)$ compared to vehicle treated control. + indicates significantly different $(p<0.05)$ compared to 9 -cis RA treatment alone. 
In a subsequent series of experiments either PPAR $\alpha$ or $\operatorname{PPAR} \beta / \delta$ were over-expressed in cardiomyocytes and HEK293 cells, and the effect of RXR $\alpha$ over-expression on MCPT-1 transcription, whether or not in combination with specific ligands, was investigated. In cardiomyocytes over-expressing PPAR $\alpha$ (Fig. 6.4A), the concurrent expression of exogenous $\mathrm{RXR} \alpha$ resulted in a moderate increase in promoter activity. The co-addition of either 9cis-RA or Wy-14,643 did not further enhance transcription. However, in the presence of both 9cis-RA

A

Cardiomyocytes, PPARQ

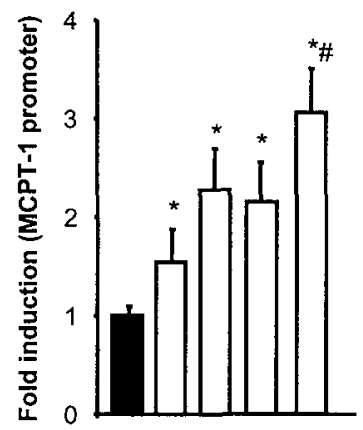

$\mathrm{RXR} \alpha$

9cis-RA

Wy-14,643
B
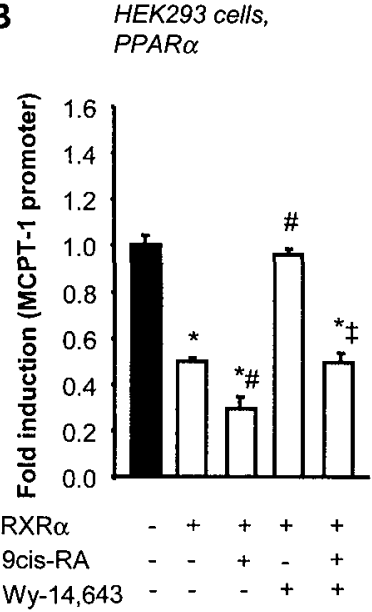

C

Cardiomyocytes, $P P A R \beta / \delta$

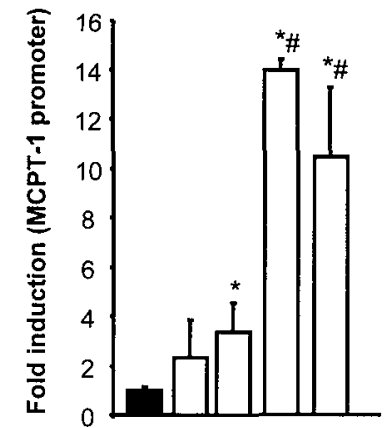

$\mathrm{RXR} \alpha$ 9cis-RA GW501516

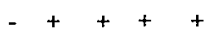

$-\ldots++$
D

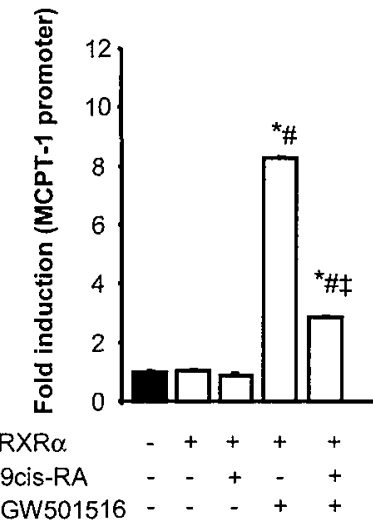
HEK293 cells,
PPAR $\beta / \delta$
Figure 6.4

Response of the human muscletype carnitine palmitoyl transferase- 1 promoter (MCPT1) to $\operatorname{RXR} \alpha$ activation in cardiomyocytes (4A and 4C) and HEK293 (4B and 4C), respectively, over-expressing either PPAR $\alpha$ or PPAR $\beta / \delta$. In a subset of incubations $\operatorname{RXR} \alpha$, $\operatorname{PPAR} \alpha$, and PPAR $\beta / \delta$ were activated by their cognate ligands, 9cis-RA $(10 \mu \mathrm{M}), \mathrm{W}_{\mathrm{y}-}$ $14,643(10 \mu \mathrm{M})$, and GW501516 $(1 \mu \mathrm{M})$, tespectively. Results are expressed as fold induction compared to vehicle (DMSO $0.1 \%$ ) treated controls (black bar), the average value of which was arbitrarily set 1.0 . * Indicates significantly different $(p<0.05)$ compared to vehicle treated control. \# indicates significantly different $(p<0.05)$ compared to $\operatorname{RXR} \alpha$ overexpression in the abscnce of ligand(s). $\neq$ indicates significantly different $(p<0.05)$ compared to $R X R \alpha$ over-expression in the presence of the PPAR ligand.

and Wy-14,643 the additional increase in the transcriptional activation of the MCPT-1 promoter reached the level of significance. 
In HEK293 cells over-expressing PPAR $\alpha$ (Fig. 6.4B), simultaneous over-expression of $\operatorname{RXR} \alpha$ decreased, rather than increased, promoter activity. This inhibitory effect was even more pronounced when 9cis-RA was present at the same time. Treatment with the PPAR $\alpha$ ligand Wy-14,643 nullified the RXR $\alpha$ mediated decrease in promoter activity. However, concomitant exposure to 9cis-RA reduced promoter activity once again.

In cardiomyocytes over-expressing PPAR $\beta / \delta$ (Fig. 6.4C), the over-expression of RXR $\alpha$ did not significantly increase MCPT-1 promoter activity. However, in combination with 9 cis-RA a 2.3 -fold $(p<0.05)$ increase was observed. In cardiomyocytes over-expressing both $\operatorname{PPAR} \beta / \delta$ and $\operatorname{RXR} \alpha$, the addition of the PPAR $\beta / \delta$ specific ligand GW501516 increased promoter activity $>10$ fold. Co-treatment with the RXR $\alpha$ ligand 9cis-RA did not alter promoter activity to a significant extent.

A Cardiomyocytes

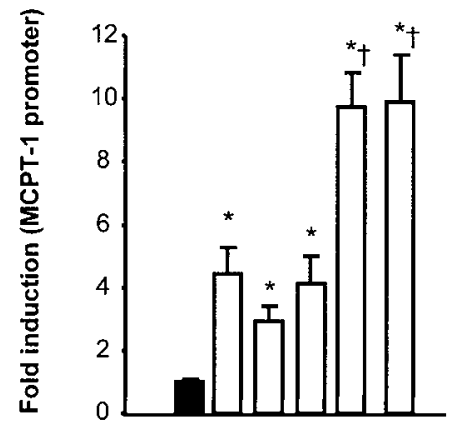

PGC-1 $\alpha$ Wy-14,643 GW501516
B HEK293 cells

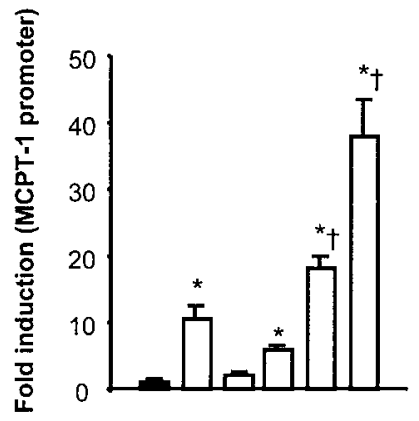

PGC-1 $\alpha$

Wy-14,643

GW501516

Figure 6.5

Response of the human muscle-type carnitine palmitoyl transferase-1 promoter (MCPT-1) to over-expression of the transcriptional co-activator PPAR $\gamma$ Co-activator-1 $\alpha$ (PGC-1 $\alpha$ ) in cardiomyocytes $(5 A)$ and HEK293 (5B), in the absence or presence of PPAR $\alpha$ and PPAR $\beta / \delta$ ligand, $W y-14,643(10 \mu \mathrm{M})$ and $G W 501516(1 \mu \mathrm{M})$, respectively. Results are expressed as fold induction compared to vehicle (DMSO 0.1\%) treated controls (black bar), the average value of which was arbitrarily set 1.0. * Indicates significantly different $(p<0.05)$ compared to vehicle treated control. $\dagger$ indicates significantly different $(\mathrm{p}<$ 0.05) compared to PGC- $1 \alpha$ over-expression alone.

Finally, in HEK293 cells over-expressing PPAR $\beta / \delta$ (Fig. 6.4D), the over-expression of $\mathrm{RXR} \alpha$, either in the absence or presence of its cognate ligand 9cis-RA, did not sort any effect on the transcriptional activity of the MCPT-1 promoter. When both PPAR $\beta / \delta$ and $\operatorname{RXR} \alpha$ 
were introduced in HEK293 cells the additional treatment with GW501516 resulted in more than 8-fold increase in promoter activity. Interestingly, under these conditions the co-addition of the cognate $R X R \alpha$ ligand 9cis-RA substantially decreased promoter activity.

\subsubsection{Interaction between PPARs and the co-activator protein PGC-1 $\alpha$}

To investigate whether the differences between PPAR $\alpha$ - and PPAR $\beta / \delta$-mediated MCPT-1 promoter activation were somehow related to co-activator recruitment, the involvement of the transcriptional co-activator PPAR $\gamma$ Co-activator-1 $\alpha$ (PGC-1 $\alpha$ ) was scrutinized in cardiomyocytes and HEK293 cells (Fig. 6.5 and 6.6).

First, the effect of PGC-1 $\alpha$ over-expression on MCPT-1 transcription was investigated (Fig. 6.5). In both cardiomyocytes (Fig. 6.5A) and HEK293 cells (Fig. 6.5B), over-expression of PGC- $1 \alpha$ in the absence of synthetic PPAR ligands was sufficient to enhance MCPT-1 promoter activity. The activation of endogenous PPAR $\alpha$ as well as PPAR $\beta / \delta$ through addition of their cognate ligands was further potentiated in case PGC-1 $\alpha$ had been introduced into both cell types.

Second, the effect of PGC-1 $\alpha$ on PPAR-mediated MCPT-1 promoter regulation was investigated in cardiomyocytes and HEK293 cells over-expressing both PPAR $\alpha$ and RXR $\alpha$ (Fig. 6.6A and 6.6B). Under these conditions the mere co-expression of PGC-1 $\alpha$ was already sufficient to increase promoter activity approximately 5-fold in cardiomyocytes (Fig. 6.6A) as well as HEK293 cells (Fig. 6.6B). In the cardiomyocytes the co-addition of the PPAR $\alpha$ ligand Wy-14,643 alone or in conjunction with the RXR $\alpha$ ligand 9cis-RA did not lead to a further stimulation of MCPT-1 transcription. In the HEK293 cells, however, Wy-14,643 further enhanced promoter activity and the co-addition of 9cis-RA counteracted this stimulatory effect.

Finally, comparable experiments were conducted with cardiomyocytes and HEK293 cells over-expressing the PPAR $\beta / \delta$ isoform along with $R X R \alpha$. In cardiomyocytes the additional over-expression of PGC-1 $\alpha$ was associated with a 2.5 -fold increase in promoter activity, a difference that did not reach the level of significance $(\mathrm{p}=0.06)$ (Fig. 6.6C). The addition of the cognate PPAR $\beta / \delta$ ligand GW501516 to cardiomyocytes exerted a marked 
positive effect on MCPT-1 promoter activity. The degree of induction of promoter activity was not influenced by the simultaneous addition of 9 cis-RA.

In HEK293 cells expressing both exogenous PPAR $\beta / \delta$ and RXR $\alpha$ the concurrent overexpression of PGC-1 $\alpha$ in the absence of synthetic ligands increased MCPT-1 promoter activity (Fig. 6.6D). The simultaneous exposure to GW501516 further increased gene transcription, an effect that was blunted by the co-addition of the RXR $\alpha$ ligand 9cis-RA.

A

$$
\begin{aligned}
& \text { Cardiomyocytes, } \\
& P P A R \alpha, R X R \alpha
\end{aligned}
$$

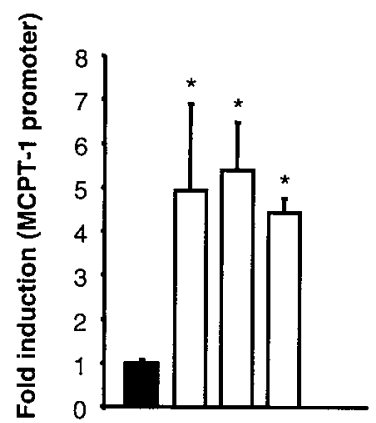

PGC- $1 \alpha$ Wy-14,643 +++ gcis-RA -++

C Cardiomyocytes, $P P A R \beta / \delta, \quad R X R \alpha$

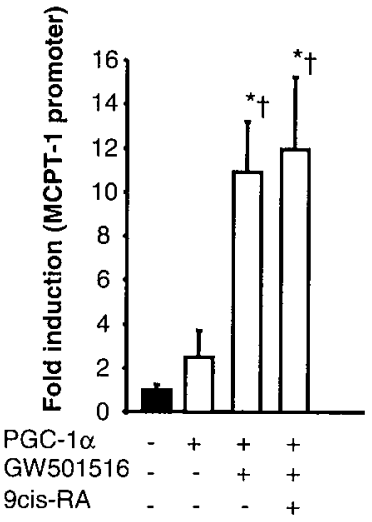

B

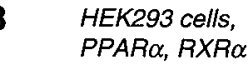

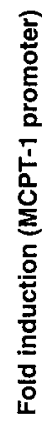

$P G C-1 \alpha$ Wy-14,643 9 cis-RA

\section{HEK293 cells, $P P A R \beta / \delta, R X R \alpha$}

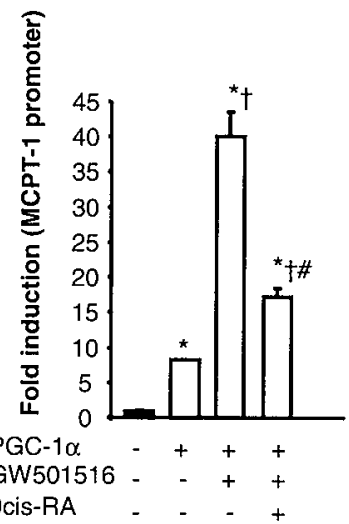

Figure 6.6

Response of the human muscletype carnitine palmitoyl transferase-1 promoter (MCPT-1) to over-expression of the transcriptional co-activator PPAR $\gamma$ Co-activator-1 $\alpha$ (PGC$1 \alpha$ ) in cardiomyocytes ( $6 A$ and $6 \mathrm{C}$ ) and HEK293 (6B and 6C), respectively, over-expressing $\operatorname{RXR} \alpha$ together with either $\operatorname{PPAR} \alpha$ or $\operatorname{PPAR} \beta / \delta$. $\operatorname{RXR} \alpha$, $\operatorname{PPAR} \alpha$, and $\operatorname{PPAR} \beta / \delta$ were activated by their cognate ligands 9cis-RA $\quad(10 \mu \mathrm{M}), \quad W_{y}-14,643$ $(10 \mu \mathrm{M})$, and GW501516 (1 $\mu \mathrm{M})$, respectively. Results are expressed as fold induction compared to vehicle (DMSO 0.1\%) treated controls (black bar), the average value of which was arbitrarily set 1.0. * Indicates significantly different $(p<0.05)$ compared to vehicle treated control. $\nmid$ indicates significantly different $(\mathrm{p}<0.05)$ compared to PGC-1 $\alpha$ overexpression alone. \# indicates significantly different $(\mathrm{p}<0.05)$ compared to PGC-1 $\alpha$ overexpression in the presence of the PPAR ligand as sole transactivator. 


\subsection{DISCUSSION}

It has been known for decades that long-chain fatty acids (FA) constitute the prime substrate for cardiac energy conversion ${ }^{21,22}$. Later it was shown that chronic alterations in plasma FA levels, changes in workload and neurohumoral status alter the capacity of the heart to utilize FA via the adjustment of the expression of genes encoding for proteins involved in cardiac FA transport and metabolism ${ }^{23-25}$. To a large extent, these genomic adjustments in cardiac lipid metabolism were believed to be mediated by PPAR $\alpha$, a member of the ligandactivated nuclear hormone receptor family, for which FA serve as natural ligands ${ }^{26}$. Recently, we and others disclosed the functional importance of a second PPAR isoform, i.e., PPAR $\beta / \delta$, in the cardiac muscle cell5,6. The functional significance of the coexistence of these two PPAR isoforms in cardiomyocytes is, however, incompletely understood. It is conceivable that these two PPAR isoforms become trans-activated under slightly different conditions, depending on subtle differences in the affinity for natural ligands or interaction with auxiliary proteins. Here we show that unlike PPAR $\alpha, \operatorname{PPAR} \beta / \delta$ lacks the ability to activate the MCPT-1 promoter in the absence of ligand. This transcriptional difference between PPAR $\alpha$ and PPAR $\beta / \delta$ is independent of the availability of the heterodimer partner $\operatorname{RXR} \alpha$ and the transcriptional coactivator PGC-1 $\alpha$. Furthermore, activation of RXR $\alpha$ in HEK293 cells results in a significant attenuation of PPAR-mediated promoter activation.

\subsubsection{Trans-activation of endogenous and exogenous PPARs}

Recapitulating earlier findings ${ }^{5}$, the mere administration of isoform-specific PPAR ligands to neonatal cardiomyocytes reveals ligand-mediated activation of the MCPT-1 promoter by endogenous PPAR $\alpha$ and PPAR $\beta / \delta$, but not by PPAR $\gamma$. These findings are consistent with the very low abundance of the latter isoform in cardiac muscle cells. In the cardiomyocytes none of the ligands was able to activate a reporter construct consisting of a concatemerized PPRE (3*PPRE construct) linked to a minimal thymidine kinase promoter. The latter observation is consistent with previous findings in HeLa cells using the same $3 *$ PPRE construct $^{18}$. The introduction either of exogenous PPAR $\alpha$ or PPAR $\gamma$ results in activation of the MCPT-1 promoter and of the 3*PPRE construct both in cardiomyocytes and HEK293 cells, 
an effect that was further accentuated by the simultaneous addition of their cognate synthetic ligands. The fact that PPAR $\alpha$ and PPAR $\gamma$ are already activated to some extent in the absence of synthetic ligands, implies that either natural ligands, normally present in the cells, are able to enhance PPAR activity or that these isoforms possess cryptic trans-activating capacity.

Remarkably, the behaviour of exogenous PPAR $\beta / \delta$ did not fit into this pattern as the mere overexpression of PPAR $\beta / \delta$ was not sufficient to activate the MCPT- 1 promoter or the $3 *$ PPRE construct. Furthermore, in cardiomyocytes addition of the synthetic ligand resulted in a comparable level of promoter activity, independent of the absence or presence of exogenous $\operatorname{PPAR} \beta / \delta$. At first sight, the latter observation could be interpreted as such that the expression vector simply does not give rise to a functional protein. However, this possibility can be discarded on the basis of two independent observations. First, identical results were obtained when cells were transfected with a vector expressing human PPAR $\beta / \delta$. Second, in HEK293 cells the level of MCPT-1 promoter activation by GW501516 was several fold higher in case exogenous PPAR $\beta / \delta$ had been introduced into these cells. These combined observations indicate that the behaviour of PPAR $\beta / \delta$ differs in several aspects from PPAR $\alpha$ and PPAR $\gamma$. Furthermore, the observed behaviour is not unique to PPAR $\beta / \delta$ of a single species, but is observed with PPAR $\beta / \delta$ derived from both rodents and human species.

The mechanism underlying the observation that the mere overexpression of PPAR $\beta / \delta$, unlike PPAR $\alpha$ and PPAR $\gamma$, does not lead the activation of target promoters in both cardiomyocytes and HEK293 cells remains to be clarified. It seems less likely that this difference is based on the existence of endogenous compounds, that serve as ligands for $\operatorname{PPAR} \alpha$ and $\operatorname{PPAR} \gamma$, but are ineffective towards $\operatorname{PPAR} \beta / \delta$. To our knowledge, there are no studies that refer to such marked differences in affinity towards natural ligands ${ }^{27-29}$. It seems more reasonable to assume that, in contrast to PPAR $\alpha$ and PPAR $\gamma$, exogenous PPAR $\beta / \delta$ lacks cryptic activity. Cryptic activity of nuclear hormones was observed first when studying the human Estrogen Receptor and was found to reside in a constitutive activation function domain $(A F-1)$ in the $\mathrm{N}$-terminal end of this protein ${ }^{30}$. This domain is also present in all three PPAR isoforms ${ }^{31}$. The AF-1 domain possesses multiple phosphorylation sites $^{32,33}$ and its transactivating function has indeed been shown to differ between $\operatorname{PPAR} \alpha, \operatorname{PPAR} \beta / \delta$, and $\operatorname{PPAR} \gamma$, 
suggesting that the AF-1 site confers some kind of selectivity to the different PPAR isoforms ${ }^{34}$. Close inspection of the AF-1 domain of PPAR $\alpha, \operatorname{PPAR} \beta / \delta$, and PPAR $\gamma$ might give an answer to the question whether this domain, possibly via its (de)phosphorylation, is involved in isoform specific regulation of gene expression.

\subsubsection{Cell type dependent trans-activation and the effect of $R X R \alpha$ and PGC-1 thereon.}

In the present study differences are observed between $\operatorname{PPAR} \alpha, \operatorname{PPAR} \beta / \delta$, and PPAR $\gamma$ in their ability to activate the MCPT-1 promoter within one cell type. Moreover, differences in PPAR-mediated activation of the MCPT-1 promoter are also observed between the two cell types, i.e., cardiomyocytes and HEK293 cells, applied in our study. This is particularly true for $\operatorname{PPAR} \beta / \delta$. The fact that a synergistic effect of GW501516 and exogenous PPAR $\beta / \delta$ is observed in HEK293 cells, but not in cardiac muscle cells, clearly indicates that the regulation of trans-activating capacity depends on the cellular context.

Apart from the presence of a PPAR isoform and the availability of natural ligands within the cell, there are several additional factors that may modulate the trans-activating capacity of nuclear receptors, including the affinity for the common heterodimer partner RXR $\alpha$ as well as specific co-activator and co-repressor proteins ${ }^{31}$, the expression level of which may differ from cell type to cell type.

To obtain insight into the role of the common heterodimer partner in the transactivation of PPAR $\alpha$ and PPAR $\beta / \delta$, cardiomyocytes and HEK293 cells were allowed to overexpress RXR $\alpha$. Either over-expression of RXR $\alpha$ or the mere addition of 9cis-RA was sufficient to activate to MCPT-1 promoter. The over-expression of RXR $\alpha$ along with the administration of 9 cis-RA had no obvious synergistic effect in cardiomyocytes, but surprisingly resulted in an attenuation of promoter activity in HEK293 cells. The difference in response towards RXR $\alpha$ between cardiomyocytes and HEK293 cells was very consistent as it was present under all conditions examined, i.e., in a background of cells only expressing endogenous levels of PPARs as well as in cells over-expressing either PPAR $\alpha$ and $\operatorname{PPAR} \beta / \delta$, whether or not in combination with isoform-specific ligands. Even in HEK293 cells over-expressing both the heterodimer partner RXR $\alpha$ and the co-activator PGC1 $\alpha$, along with either PPAR $\alpha$ or PPAR $\beta / \delta$, the subsequent addition of 9cis-RA has a marked inhibitory effect on MCPT-1 transcription. This 
effect was absent in cardiomyocytes. Accordingly, this subset of studies did not reveal notable differences in the behaviour of $\operatorname{PPAR} \alpha$ and $\operatorname{PPAR} \beta / \delta$ towards $R X R \alpha$, but rather revealed a difference in the response of the two cell types examined. To the best of our knowledge this is the first time that such a cell type-specific inhibitory effect of $R X R \alpha$ and its cognate ligand on PPAR activity has been reported. At this stage we can only speculate about the mechanism involved.

First of all, it is possible that the cognate $\operatorname{RXR} \alpha$ ligand 9cis-RA also acts as a PPAR ligand as was recently shown for all-trans retinoic acid ${ }^{35}$. In this manner 9cis-RA alone would be able to activate the MCPT-1 promoter in a PPAR-dependent manner in both cardiomyocytes and HEK293 cells. Alternatively, the 9cis-RA-mediated MCPT-1 promoter activation may well be a result of $\operatorname{RXR} \alpha / \operatorname{RXR} \alpha$ homodimer formation and subsequent binding of this homodimer to the PPRE, thereby competing with PPAR/RXR heterodimers for the PPRE-site ${ }^{36}$. Although interactions between nuclear receptors are known ${ }^{37}$, promoter activation in one cell type and repression in another, within the same nuclear receptor pathway, has not been disclosed previously. Due to the fact that $\operatorname{RXR} \alpha$ is a dimerization partner for multiple members of the nuclear receptor family ${ }^{38}$ it is feasible that RXR $\alpha$, when activated, interacts with nuclear receptors other than PPAR in HEK293 cells 39 .

Apart from increasing the transcriptional activity of PPAR isoforms through the modulatory action of transcriptional co-activators, PPARs are also targets for transcriptional co-repressors $^{11,40}$. It has been shown previously that $\operatorname{PPAR} \beta / \delta$, as compared to $\operatorname{PPAR} \alpha$, is more sensitive towards repression by the transcriptional co-repressors Nuclear Co-Repressor $(\mathrm{NCoR})^{41}$ and Silencing Mediator for Retinoid and Thyroid hormone receptors (SMRT) ${ }^{42}$. Such differences in affinity between $\operatorname{PPAR} \alpha$ and $\operatorname{PPAR} \beta / \delta$ have also been reported for the transcriptional co-activator Steroid Receptor Co-activator (SRC) ${ }^{42}$. The role of PGC-1 $\alpha$, a functionally important co-activator in cardiomyocytes ${ }^{43,44}$ and other cell-types ${ }^{14,16}$, in differential $\operatorname{PPAR} \alpha$ and PPAR $\beta / \delta$ promoter regulation, has not been addressed so far. In this respect, it is of interest to note that inhibition of the p38-MAPK pathway rendered PPAR $\alpha$, but not PPAR $\gamma$, insensitive towards PGC-1 $\alpha^{13}$. The present findings disclose no obvious differences between the PPARs with respect to PGC-1 $\alpha$ activation. In both cardiomyocytes and HEK293 
cells PGC- $1 \alpha$ was able to activate PPAR $\alpha$ - and PPAR $\beta / \delta$-mediated MCPT- 1 promoter activity, demonstrating that PGC-1 $\alpha$ serves as co-activator of both PPAR isoforms.

In conclusion, the collective findings stress the notion that the transactivating activity of $\operatorname{PPAR} \alpha$ and PPAR $\beta / \delta$ is cell-type dependent, as shown by the differences in ligandindependent promoter activation between these two isoforms in cardiomyocytes and HEK293 cells. These properties may be based on differences in the ligand-independent trans-activating properties of the AF-1 domain. Furthermore, the present findings point to a previously unrecognised role of RXR $\alpha$ and its cognate ligand 9cis-RA in PPAR-mediated gene expression, i.e., the ability to attenuate gene transcription in a manner, which is strongly dependent on the cellular context.

\section{Acknowledgements:}

$\mathrm{MvB}$ is an established investigator of the Netherlands Heart Foundation (1998T015). 


\section{REFERENCES}

1. Gilde AJ and Van Bilsen M. Peroxisome Proliferator-Activated Receptors (PPARs): regulators of gene expression in heart and skeletal muscle. Acta Pbysiol Scant. 2003;178:425-434.

2. Ferre P. The Biology of Peroxisome Proliferator-Activated Receptors: Relationship with lipid metabolism and insulin sensitivity. Diabetes. 2004;53 Suppl 1:S43-50.

3. Marx N, Duez H, Fruchart JC and Staels B. Peroxisome Proliferator-Activated Receptors and atherogenesis: Regulators of gene expression in vascular cells. Circ Res. 2004;94:1168-1178.

4. Escher P, Braissant O, Basu-Modak S, Michalik L, Wahli W and Desvergne B. Rat PPARs: quantitative analysis in adult rat tissues and regulation in fasting and refeeding. Endocrinology. 2001;142:4195-4202.

5. Gilde AJ, van der Lee KA, Willemsen PH, Chinetti G, van der Leij FR, van der Vusse GJ, Staels B and van Bilsen M. Peroxisome Proliferator-Activated Receptor (PPAR) $\alpha$ and PPAR $\beta / \delta$, but not PPAR $\gamma$, modulate the expression of genes involved in cardiac lipid metabolism. Circ Res. 2003;92:518-524.

6. Cheng L, Ding G, Qin Q, Xiao Y, Woods D, Chen YE and Yang Q. Peroxisome ProliferatorActivated Receptor- $\delta$ activates fatty acid oxidation in cultured neonatal and adult cardiomyocytes. Biochem Biopbys Res Commun. 2004;313:277-286.

7. Rival Y, Beneteau N, Taillandier T, Pezet M, Dupont-Passelaigue E, Patoiseau JF, Junquero D, Colpaert FC and Delhon A. PPAR $\alpha$ and PPAR $\delta$ activators inhibit cytokine-induced nuclear translocation of NF-KB and expression of VCAM-1 in EAHY926 endothelial cells. Eur J Pharmacol. 2002;435:143-151.

8. Dressel U, Allen TL, Pippal JB, Rohde PR, Lau P and Muscat GE. The Peroxisome ProliferatorActivated Receptor- $\beta / \delta$ agonist, GW501516, regulates the expression of genes involved in lipid catabolism and energy uncoupling in skeletal muscle cells. Mol Endocrinol. 2003;17:2477-2493.

9. Tanaka T, Yamamoto J, Iwasaki S, Asaba $H$, Hamura $H$, Ikeda $Y$, Watanabe M, Magoori K, Ioka RX, Tachibana K, Watanabe Y, Uchiyama Y, Sumi K, Iguchi H, Ito S, Doi T, Hamakubo T, Naito M, Auwerx J, Yanagisawa M, Kodama $T$ and Sakai J. Activation of Peroxisome ProliferatorActivated Receptor- $\delta$ induces fatty acid $\beta$-Oxidation in skeletal muscle and attenuates metabolic syndrome. Proc Natl Acad Si USA. 2003;100:15924-15929.

10. He TC, Chan TA, Vogelstein B and Kinzler KW. PPAR $\delta$ is an APC-regulated target of nonsteroidal anti-inflammatory drugs. Cell. 1999;99:335-345.

11. Stanley TB, Leesnitzer LM, Montana VG, Galardi CM, Lambert MH, Holt JA, Xu HE, Moore LB, Blanchard SG and Stimmel JB. Subtype specific effects of Peroxisome Proliferator-Activated Receptor Ligands on corepressor affinity. Biocbemistry. 2003;42:9278-9287.

12. Shi $Y$, Hon $M$ and Evans RM. The Peroxisome Proliferator-Activated Receptor- $\delta$, an integrator of transcriptional repression and nuclear receptor signaling. Proc Natl Acad Sci USA. 2002;99:26132618.

13. Oberkofler H, Esterbauer H, Linnemayr V, Strosberg AD, Krempler F and Patsch W. Peroxisome Proliferator-Activated Receptor (PPAR) $\gamma$ Coactivator-1 recruitment regulates PPAR subtype specificity. J Biol Chem. 2002;277:16750-16757.

14. Vega RB, Huss JM and Kelly DP. The Coactivator PGC-1 cooperates with Peroxisome Proliferator-Activated Receptor $\alpha$ in transcriptional control of nuclear genes encoding mitochondrial fatty acid oxidation enzymes. Mol Cell Biol. 2000;20:1868-1876.

15. Lehman JJ, Barger PM, Kovacs A, Saffitz JE, Medeiros DM and Kelly DP. Peroxisome Proliferator-Activated Receptor- $\gamma$ Coactivator-1 promotes cardiac mitochondrial biogenesis. $J$ Clin Invest. 2000;106:847-856. 
16. Lin J, Wu H, Tarr PT, Zhang CY, Wu Z, Boss O, Michael LF, Puigserver P, Isotani E, Olson EN, Lowell BB, Bassel-Duby R and Spiegelman BM. Transcriptional Co-Activator PGC-1 $\alpha$ drives the formation of slow-twitch muscle fibres. Nature. 2002;418:797-801.

17. De Vries JE, Vork MM, Roemen THM, de Jong YF, Cleutjens JPM, van der Vusse GJ and van Bilsen M. Saturated but not ono-unsaturated fatty acids induce apoptotic cell death in neonatal rat ventricular myocytes. J Lipid Res. 1997;38:1384-1394.

18. Vu Dac N, Schoonjans K, Kosykh V, Dallongeville J, Fruchart JC, Staels B and Auwerx J. Fibrates increase human Apolipoprotein A-II expression through activation of the Peroxisome ProliferatorActivated Receptor. J Clin Invest. 1995;96:741-750.

19. Shubeita HE, Martinson EA, Van Bilsen M, Chien $K R$ and Heller Brown J. Transcriptional activation of the cardiac Myosin Light Chain 2 and Atrial Natriuretic Factor genes by Protein Kinase C in neonatal rat ventricular cells. Proc Natl Acad Sci USA. 1992;89:1305-1309.

20. Wallenstein S, Zucker CL and Fleiss JL. Some statistical methods useful in Circulation Research. Circ Res. 1980;47:1-9.

21. Taegtmeyer $H$, Hems $R$ and Krebs HA. Utilization of energy-providing substrates in the isolated working rat heart. Biochem J. 1980;186:701-711.

22. Van der Vusse GJ, Glatz JFC, Stam HCG and Reneman RS. Fatty acid homeostasis in the normoxic and ischemic heart. Pbysiol Rev. 1992;72:881-940.

23. Sack MN, Rader TA, Park S, Bastin J, McCune SA and Kelly DP. Fatty acid oxidation enzyme gene expression is downregulated in the failing heart. Circulation. 1996;94:2837-2842.

24. Stanley WC and Chandler MP. Energy metabolism in the normal and failing heart: Potential for therapeutic interventions. Heart Fail Rev. 2002;7:115-130.

25. Van Bilsen M, Smeets PJ, Gilde AJ and van der Vusse GJ. Metabolic Remodelling of the Failing Heart: The Cardiac Burn-out Syndrome? Cardiovasc Res. 2004;61:218-226.

26. Djouadi F, Brandt JM, Weinheimer CJ, Leone TC, Gonzalez FJ and Kelly DP. The Role of the Peroxisome Proliferator-Activated Receptor $\alpha$ (PPAR $\alpha$ ) in the control of cardiac lipid metabolism. Prostaglandins Leukot Essent Fatty Acids. 1999;60:339-343.

27. Forman BM, Chen J and Evans RM. Hypolipidemic drugs, polyunsaturated fatty acids, and eicosanoids are ligands for Peroxisome Proliferator-Activated Receptors a and $\delta$. Proc Natl Acad Sci USA. 1997;94:4312-4317.

28. Wahli W, Devchand PR, IJpenberg A and Desvergne B. Fatty acids, eicosanoids, and hypolipidemic agents regulate gene expression through direct binding to Peroxisome Proliferator-Activated Receptors. Advances in Experimental Medical Biology. 1999;447:199-209.

29. Uauy R, Mena P and Rojas C. Essential fatty acids in early life: Structural and functional role. Proc Nutr Soc. 2000;59:3-15.

30. Tora L, White J, Brou C, Tasset D, Webster N, Scheer E and Chambon P. The human Estrogen Receptor has two independent non-acidic transcriptional activation functions. Cell. 1989;59:477487.

31. Desvergne B and Wahli W. Peroxisome Proliferator-Activated Receptors: Nuclear control of metabolism. Endocrine Rev. 1999;20:649-688.

32. Juge-Aubry CE, Hammar E, Siegrist-Kaiser C, Pernin A, Takeshita A, Chin WW, Burger AG and Meier CA. Regulation of the transcriptional activity of the Peroxisome Proliferator-Activated Receptor $\alpha$ by phosphorylation of a ligand-independent trans-activating domain. $J$ Biol Chem. 1999;274:10505-10510.

33. Barger PM, Browning AC, Garner AN and Kelly DP. P38 Mitogen-Activated Protein Kinase activates Peroxisome Proliferator-Activated Receptor- $\alpha$ : A potential role in the cardiac metabolic stress response. J Biol Chem. 2001;276:44495-44501. 
34. Juge-Aubry CE, Kuenzli S, Sanchez JC, Hochstrasser D and Meier CA. Peroxisomal Bifunctional Enzyme binds and activates the Activation Function-1 region of the Peroxisome ProliferatorActivated Receptor- $\alpha$. Biochem J. 2001;353:253-258.

35. Shaw N, Elholm M and Noy N. Retinoic Acid is a high affinity selective ligand for the Peroxisome Proliferator-Activated Receptor- $\beta / \delta$. J Biol Chem. 2003;278:41589-41592.

36. IJpenberg A, Tan NS, Gelman L, Kersten S, Seydoux J, Xu J, Metzger D, Canaple L, Chambon P, Wahli W and Desvergne B. In vivo activation of PPAR target genes by RXR homodimers. EMBO J. 2004;23:2083-2091.

37. Hunter J, Kassam A, Winrow CJ, Rachubinski RA and Capone JP. Crosstalk between the Thyroid Hormone and Peroxisome Proliferator-Activated Receptors in regulating Peroxisome ProliferatorResponsive genes. Mol Cell Endocrinol. 1996;116:213-221.

38. Vivat-Hannah V, Bourguet W, Gottardis M and Gronemeyer H. Separation of Retinoid X Receptor homo- and heterodimerization functions. Mol Cell Biol. 2003;23:7678-7688.

39. Mangelsdorf DJ and Evans RM. The RXR heterodimers and Orphan Receptors. Cell. 1995;83:841850.

40. Xu HE, Stanley TB, Montana VG, Lambert MH, Shearer BG, Cobb JE, McKee DD, Galardi CM, Plunket KD, Nolte RT, Parks DJ, Moore JT, Kliewer SA, Willson TM and Stimmel JB. Structural basis for antagonist-mediated recruitment of nuclear co-repressors by PPAR $\alpha$. Nature. 2002;415:813-817.

41. Krogsdam AM, Nielsen CA, Neve S, Holst D, Helledie T, Thomsen B, Bendixen C, Mandrup S and Kristiansen K. Nuclear Receptor Corepressor-dependent repression of Peroxisome-ProliferatorActivated Receptor- $\delta$-mediated transactivation. Biochem J. 2002;363:157-165.

42. Lim HJ, Moon I and Han K. Transcriptional cofactors exhibit differential preference towards Peroxisome Proliferator-Activated Receptors- $\alpha$ and $\delta$ in uterine cells. Endocrinology. 2004;145:28862895.

43. Cook SA, Matsui T, Li L and Rosenzweig A. Transcriptional effects of chronic AKT activation in the heart. J Biol Chem. 2002;277:22528-22533.

44. Russell LK, Mansfield CM, Lehman JJ, Kovacs A, Courtois M, Saffitz JE, Medeiros DM, Valencik ML, McDonald JA and Kelly DP. Cardiac-specific induction of the transcriptional coactivator Peroxisome Proliferator-Activated Receptor- $\gamma$ Coactivator- $1 \alpha$ promotes mitochondrial biogenesis and reversible cardiomyopathy in a developmental stage-dependent manner. Circ Res. 2004;94:525533. 


\section{GENERAL DISCUSSION}




\subsection{INTRODUCTION}

Long-chain fatty acids (FA) are the main energy providing substrates for the healthy heart. It has been found that under a variety of (patho)-physiological circumstances such as cardiac hypertrophy or diabetes cardiac FA metabolism is altered ${ }^{1,2}$. To fully understand the causes and consequences of chronic alterations in cardiac FA handling, it is important to obtain extensive knowledge of the transcriptional regulation of FA handling genes in the heart. Of the family of nuclear hormone receptors the Peroxisome Proliferator-Activated Receptors (PPAR) are one of the main factors involved in the transcriptional regulation of FA metabolism. Experimental findings suggest that the activity of one of the PPAR isoforms (PPAR $\alpha$ ) is attenuated in cardiac hypertrophy and failure, resulting in a shift away from FA to glucose utilization in the affected heart ${ }^{3}$. The exact mechanism by which FA metabolism is modulated in cardiac hypertrophy and failure and the extent to which PPAR isoforms or/and related factors are involved are, however, incompletely understood.

In the present thesis several issues concerning the genetic regulation of cardiac FA metabolism have been addressed. The effect of an increased supply of FA to the heart on cardiac expression of PPAR-regulated genes has been studied in vivo. Furthermore, in cultures of isolated neonatal rat cardiomyocytes the effect of hypertrophic stimuli on the transcriptional regulation of FA metabolism was subject of study. We also explored the involvement of the three PPAR isoforms in the transcriptional control of FA metabolism in cardiomyocytes. Finally, possible differences in promoter activation between PPAR $\alpha$ and $\operatorname{PPAR} \beta / \delta$ were investigated. 


\subsection{ADVANTAGES AND DISADVANTAGES OF IN VITRO MODELS}

\subsubsection{The use of neonatal rat cardiomyocytes}

In this thesis primary cultures of neonatal ventricular cardiomyocytes (NCM) were used to investigate the involvement of PPAR isoforms in the regulation of cardiac FA handling. The NCM model is a well defined and commonly used model in cardiac hypertrophy research ${ }^{4,5}$.

In addition to NCM other in vitro models are regularly applied in cardiac research. In this respect the use of cultured cell-lines instead of primary cells is worth mentioning. For instance the embryonic heart-derived $\mathrm{H} 9 \mathrm{c} 2$ myoblasts cell-line has been applied in cardiac research ${ }^{6.8}$. This cell-line differs from neonatal and adult cardiomyocytes in several aspects, e.g. these cells do not express two key proteins involved in FA metabolism, i.e., FAT? and PPAR $\alpha^{10}$. An alternative model is the atrium derived HI,-1 cell-line ${ }^{11}$. Although this cell-line has some characteristics of adult cardiomyocytes, it remains an atrial cell-model and our interest is the myocardial ventricle. Furthermore, with respect to metabolic research this cell-line is poorly defined demanding extensive validation before it could be used in our studies. Isolated adult cardiomyocytes resemble the in vivo heart best, but they de-differentiate within days after isolation. Moreover, they are resistant to transient transfection ${ }^{12}$ and thus less suitable for the study of transcriptional regulation.

Regarding the substrate preference of NCM, the studies performed in this thesis show not only the ability of this cell model to oxidize $F \Lambda$, they also show that $F \Lambda$ is oxidized as readily as glucose ${ }^{10}$. These results indicate the presence of mature FA metabolic machinery already in primary cultures derived from 1-3 day old neonatal rats. Furthermore, the studics performed by Cheng and co-workers and by ourselves investigating the involvement of $P P \wedge R \alpha$ and PPAR $\beta / \delta$ in cardiac FA metabolism show functional activity of these PPAR isoforms, since palmitate oxidation rate was increased after cxposure to the PPAR $\alpha$ ligand Wy-14,643 and PPAR $\beta / \delta$ ligand $G W 0742^{13}$.

\subsubsection{In vitro models compared to in vivo models}

In vitro models have advantages and disadvantages compared to in wivo models. Cell systems are very well suited to study the effect of individual stimuli $5,10,12,14,15$. Since the heart 
consist of different cell types cell-specific effects can only be studied in isolated cell preparations such as cardiomyocytes, fibroblasts, smooth muscle cells, or endothelial cells ${ }^{16}$. In this way, observations made in vivo can be deduced to a specific cell-type and/or pathway.

It should be realized however that in contrast to the intact heart, isolated cardiomyocytes, neonatal or adult, have a low metabolic rate ${ }^{17}$. This low metabolic rate can only be corrected to some extent by electrical stimulation of the isolated cardiomyocytes ${ }^{18}$.

In conclusion, although certain limitations as to their (patho)physiological relevance have to be taken into account, neonatal tat cardiomyocytes are a suitable in vitro model for the systematic analysis of the involvement of transcription factors in cardiac fatty acid metabolism as well as the effect of hypertrophic stimuli on fatty acid metabolism.

\subsection{PPARs IN CARDIAC (PATHO)PHYSIOLOGY}

In cardiomyocytes it was established that FA regulate their own metabolic rates at the transcriptional level through the activation of the ligand dependent PPAR isoforms ${ }^{14,19}$. For in vivo conditions in which plasma FA levels are elevated such as diabetes, fasting, or a high-fat diet, it can be anticipated that the cardiac expression of FA handling genes is increased ${ }^{20-22}$ (Chapter 3). On the other hand, in situations where FA supply is decreased for instance during high-carbohydrate/low-FA diet feeding the expression of FA metabolising genes is decreased ${ }^{23}$.

In the hypertrophied and failing heart some investigators showed that FA oxidative capacity is decreased 24,25 . This decline in FA oxidation would be a result of the reduced activity of PPAR $\alpha$ resulting in a decreased expression of FA handling genes ${ }^{5,26}$. This notion has been disputed by others ${ }^{27}$ since an early study in NYHA class III and IV heart failure patients showed an increase in cardiac FA oxidation tates ${ }^{28}$. This increase in FA oxidation rate was probably caused by the increased plasma FA levels mediated by the enhanced catecholamine induced lipolysis. It is still unclear whether a decrease in FA oxidation capacity is either a cause or a consequence of cardiac hypertrophy and failure, or whether the FA oxidative capacity is affected at all. 
Arguments in favour of the causal role for decreased FA handling in cardiac failure can be obtained from models characterized by an impaired FA uptake and utilization due to genetic $^{29-31}$ or pharmacological ${ }^{32,33}$ inhibition that demonstrate cardiac hypertrophy. On the basis of these result it can therefore be hypothesized that an impaired energy substrate uptake and utilization of the heart results in hypertrophy due to a decrease in ATP generation ${ }^{34}$. This notion is supported by the findings that a diet consisting of mainly medium-chain FA, bypassing protein-facilitated FA transport, was able to rescue cardiac function of hypertrophic hearts in FAT knockout mice ${ }^{30}$, or as a result of MCPT-1 inhibition by etomoxir treatment ${ }^{35}$.

In contrast, the reverse has also been reported. A genetic modification resulting in an increased cardiac uptake and/or metabolism of FA due to cardiac specific PPAR $\alpha$ overexpression also resulted in cardiac hypertrophy probably due to an increased oxidative stress $^{36,37}$.

A fairly new concept of the development of cardiac hypertrophy and failure is the "Response to Injury". Prolonged exposure to inflammatory mediators can lead to cardiac remodelling through the activation of pro-hypertrophic signal-transduction pathways ${ }^{38}$ as well as a decreased cardiac FA utilization ${ }^{39}$. The decreased cardiac FA metabolism is a result of a decreased expression of the nuclear receptors PPAR $\alpha, \operatorname{PPAR} \beta / \delta$, and $\operatorname{RXR} \alpha$ and several important transcriptional co-activators including PGC-1 $\alpha^{39}$, resulting in a decreased expression of FA handling genes ${ }^{40}$ and, hence, decreased FA oxidation rate.

In this perspective, the recent discoveries of anti-hypertrophic properties of PPAR $\alpha$ and PPAR $\gamma$-specific ligands in viv $3^{38,41,42}$ and in vitro ${ }^{43,44}$ are of interest. As shown in Chapter 5 of this thesis, cardiomyocytes express only functional amounts of PPAR $\alpha$ and PPAR $\beta / \delta$, but not PPAR $\gamma$, as far as FA metabolism is concerned ${ }^{10}$. This raises the question whether a PPARdependent or PPAR-independent pathway is involved in the anti-hypertrophic effect of PPAR ligands. It is of note that PPAR $\gamma$ specific ligands do exhibit anti-hypertrophic properties in neonatal cardiomyocytes exposed to cyclic strain ${ }^{43}$, Angiotensin II ${ }^{42}$, and Endothelin- $1^{44}$ suggesting a PPAR-independent mechanism for the anti-hypertrophic effects of PPAR $\gamma$ ligands. It still remains to be established how PPAR ligands attenuate hypertrophy in vitro or in vivo and whether cardiomyocytes or other cell-types are the target. Data thus far suggest that the pro-hypertrophic and pro-inflammatory transcription factor $\mathrm{NF}-\mathrm{KB} 45,46$ is a target for PPAR 
ligands, sorting an anti-hypertrophic effect ${ }^{47}$. Although several studies propose a mechanism by which NF- $\mathrm{KB}$ is inhibited ${ }^{48-50}$, the exact mechanism is still unknown.

\subsection{TRANSCRIPTIONAL REGULATION BY PPARs}

Before appreciating the effects of PPAR ligands on the heart in vivo, one first has to understand the mechanisms by which PPARs mediate gene expression. It is known that PPAR $\alpha$ regulates FA metabolism in oxidative tissues as heart and liver and that PPAR $\gamma$ promotes adipocyte differentiation. A clear role for the ubiquitously expressed PPAR $\beta / \delta$ was not proposed. Recently, we and others showed a prominent role for PPAR $\beta / \delta$ besides PPAR $\alpha$ in the regulation of FA metabolism in cardiomyocytes via transcriptional control of FA handling genes (Chapter 5) ${ }^{10,13}$. Although these studies point towards a function of PPAR $\beta / \delta$ in the heart it still remains unclear whether different pathways are regulated by the different PPAR isoforms.

The differences between PPAR $\alpha$ and PPAR $\beta / \delta$ in function probably reside in subtle differences in molecule structure. Of interest is the N-terminal AF-1 domain of nuclear receptors ${ }^{51}$. This region appears to be less conserved among PPARs. PPAR $\beta / \delta$ possesses a shorter AF-1 domain than PPAR $\alpha$ and PPAR $\gamma^{2}$ making it a potential target for PPAR-isoform differential activation. It was reported that phosphorylation of and co-activator binding to the AF-1domain are isoform specific 5 , 53-55. Apart from the reported structural differences that might influence PPAR isoform specific action, differences in affinity for of endogenous PPAR ligands should be taken into account, since a wide variety of lipophilic compounds have been identified as natural PPAR ligands ranging from long-chain saturated and un-saturated FA ${ }^{56-58}$ to prostanoids ${ }^{59-61}$.

In contrast to activation of PPARs relatively little is known about pharmacological inhibition of PPARs. In this light we can appreciate the PPAR inhibitory effect of compound MK886, an inhibitor of the lipid binding protein 5-Lipoxigenase Activating Protein (FLAP) ${ }^{62}$. FLAP activates 5-lipoxigenase, an enzyme that plays a prominent role in the initiation of 
arachidonic acid metabolism to leukotrienes, known PPAR ligands ${ }^{59}$, 63. It is unclear whether MK886 inhibits PPAR activity via direct binding with PPAR or through inactivation of FLAP. Personal observations showed that MK886 exert an inhibitory effect on PPAR $\alpha$-, PPAR $\beta / \delta$-, and PPAR $\gamma$-mediated MCPT-1 promoter regulation. In addition to MK886 three other compounds are known to antagonize PPAR activity, i.e., GW647164, Bisphenol A diglycidyl ether (BADGE) ${ }^{50}$, and SR-20265. Both BADGE and SR-202 attenuate PPAR $\gamma$ activity by different mechanisms, i.e. through competition with PPAR $\gamma$ ligand (BADGE) or through inhibition of co-activator recruitment by PPAR $\gamma$ and inhibition of ligand-mediated transactivation (SR-202). GW6471 suppresses PPAR $\alpha$ activation by stabilizing co-repressor binding, thus preventing the AF-2 domain to become available for ligand binding. Inhibitors of PPAR function are useful tools to elucidate the involvement of PPAR-dependent and PPARindependent mechanisms in vitro. This kind of information will open new avenues for therapeutic treatment of cardiac disorders in which FA handling and regulatory action of PPARs therein plays a crucial role.

\subsection{FUTURE PERSPECTIVES}

From a mechanistic point of view it is of great interest to identify the PPAR isoform specific pathways. Till now it is unclear whether FA themselves are able to regulate transcription independent of PPAR. Furthermore, it is not clear whether PPAR $\alpha$ and $\operatorname{PPAR} \beta / \delta$ regulate the transcription of the same set of genes. Under comparable circumstances this aspect can be unravelled by genomic studies aiming to identify the transcriptional targets of the different PPAR isoforms in cardiomyocytes. In addition, proteomic studies can predict the functional consequences of PPAR isoform activation. Furthermore, the identification of unique transcriptional co-activators in the heart is worth pursuing by focusing on the AF-1 domains of $\operatorname{PPAR} \alpha$ and $\operatorname{PPAR} \beta / \delta$. Apart from investigating the molecular mechanisms regarding PPARmediated transcriptional regulation the protective effects of PPAR ligands in hypertrophy and ischemia/reperfusion injury are fields of interest. For the treatment of hyperlipidemia and 
diabetes Type II, PPAR $\alpha$ (Fenofibrate, Gemfibrozil) and PPAR (Rosiglitazone, Pioglitazone) agonists are already therapeutically in use. In this light the therapeutic potential of PPAR $\beta / \delta$ agonists are worth pursuing ${ }^{66}$. In addition to the above-mentioned effects, it is of interest to study the potential therapeutic applicability of PPAR ligands in attenuating atherosclerosis, cardiac hypertrophy and failure, and stabilizing cardiac tissue after myocardial infarction ${ }^{57,67-69 .}$

Altogether both basic and applied research is warranted to study PPARs in cardiac as well a whole body energy homeostasis, especially since cardiac disease is the main cause of death in the Western World and obesity and diabetes Type II are now also a threat to children and young adults. 


\section{REFERENCES}

1. Van Bilsen M, Smeets PJ, Gilde AJ and van der Vusse GJ. Metabolic Remodelling of the Failing Heart: The Cardiac Burn-out Syndrome? Cardiovasc Res. 2004;61:218-226.

2. Taegtmeyer $\mathrm{H}, \mathrm{McNulty} \mathrm{P}$ and Young ME. Adaptation and maladaptation of the heart in diabetes: Part I: General Concepts. Circulation. 2002;105:1727-1733.

3. Lehman JJ and Kelly DP. Gene regulatory mechanisms governing energy metabolism during cardiac hypertrophic growth. Heart Fail Rev. 2002;7:175-185.

4. Bogoyevitch MA, Glennon PE and Sugden PH. Endothelin-1, phorbol esters and phenylephrine stimulate MAP Kinase Activities in ventricular cardiomyocytes. FEBS Lett. 1993;317:271-275.

5. Barger PM, Brandt JM, Leone TC, Weinheimer CJ and Kelly DP. Deactivation of Peroxisome Proliferator-Activated Receptor- $\alpha$ during cardiac hypertrophic growth. J Clin Invest. 2000;105:17231730.

6. Kim JM, Yoon M, Kang I, Kim SS and Ha J. Evidence that Acetyl-Coa Carboxylase isoforms play different biological roles in H9c2 cardiomyocyte. Biochem Biophys Res Commun. 1998;248:490-496.

7. Ménard C, Pupier S, Mornet D, Kitzmann M, Nargeot J and Lory P. Modulation of L-type calcium channel expression during Retinoic Acid-induced differentiation of $\mathrm{H} 9 \mathrm{c} 2$ cardiac cells. $J$ Biol Chem. 1999;274:29063-29070.

8. Hasselbaink DM, Roemen TH and van der Vusse GJ. Protein acylation in the cardiac muscle like cell line, H9c2. Mol Cell Biochem. 2002;239:101-112.

9. Van Nieuwenhoven FA, Luiken JJFP, De Jong YF, Grimaldi PA, Van der Vusse GJ and Glatz JFC. Stable transfection of Fatty Acid Translocase (CD36) in a rat heart muscle cell line (H9c2). J Lipid Res. 1998;39:2039-2047.

10. Gilde AJ, van der Lee KA, Willemsen PH, Chinetti G, van der Leij FR, van der Vusse GJ, Staels B and van Bilsen M. Peroxisome Proliferator-Activated Receptor (PPAR)- $\alpha$ and PPAR $\beta / \delta$, but not PPAR $\gamma$, modulate the expression of genes involved in cardiac lipid metabolism. Circ Res. 2003;92:518-524.

11. Claycomb WC, Lanson NA, Jr., Stallworth BS, Egeland DB, Delcarpio JB, Bahinski A and Izzo NJ, Jr. HL-1 Cells: A cardiac muscle cell line that contracts and retains phenotypic characteristics of the adult cardiomyocyte. Proc Natl Acad Sci USA. 1998;95:2979-2984.

12. Schaub MC, Hefti MA, Harder BA and Eppenberger HM. Various hypertrophic stimuli induce distinct phenotypes in cardiomyocytes. J Mol Med. 1997;75:901-920.

13. Cheng L, Ding G, Qin Q, Xiao Y, Woods D, Chen YE and Yang Q. Peroxisome ProliferatorActivated Receptor- $\delta$ activates fatty acid oxidation in cultured neonatal and adult cardiomyocytes. Biochem Biopbys Res Commun. 2004;313:277-286.

14. Van der Lee KAJM, Vork MM, De Vries JE, Willemsen PHM, Glatz JFC, Reneman RS, Van der Vusse GJ and Van Bilsen M. Long-chain fatty acid-induced changes in gene expression in neonatal cardiac myocytes. J Lipid Res. 2000;41:41-47.

15. Ruwhof C, van Wamel AE, Egas JM and van der Laarse A. Cyclic stretch induces the release of growth promoting factors from cultured neonatal cardiomyocytes and cardiac fibroblasts. Mol Cell Biochem. 2000;208:89-98.

16. van Wamel AJ, Ruwhof C, van der Valk-Kokshoorn LJ, Schrier PI and van der Laarse A. Rapid effects of stretched myocardial and vascular cells on gene expression of neonatal rat cardiomyocytes with emphasis on autocrine and paractine mechanisms. Arch Biochem Biophys. 2000;381:67-73.

17. Barr RL and Lopaschuk GD. Methodology for masuring in vitro/ex vivo cardiac energy metabolism. $J$ Pharmacol Toxicol Metbods. 2000;43:141-152.

18. Luiken JJ, Willems J, van der Vusse GJ and Glatz JF. Electrostimulation enhances FAT/CD36mediated long-chain fatty acid uptake by isolated rat cardiac myocytes. Am J Pbysiol. 2001;281:E704$\mathrm{E} 712$. 
19. Brandt JM, Djouadi F and Kelly DP. Fatty Acids Activate Transcription of the Muscle Carnitine Palmitoyltransferase I gene in cardiac myocytes via the Peroxisome Proliferator-Activated Receptor- $\alpha$. J Biol Chem. 1998;273:23786-23792.

20. Van der Lee KAJM, Willemsen PHM, Samec S, Seydoux J, Dulloo AG, Pelsers MMAL, Glatz JFC, van der Vusse GJ and van Bilsen M. Fasting-induced changes in the expression of genes controlling substrate metabolism in the rat heart. J Lipid Res. 2001;42:1752-1758.

21. Young ME, Patil S, Ying J, Depre C, Ahuja HS, Shipley GL, Stepkowski SM, Davies PJ and Taegtmeyer $H$. Uncoupling Protein 3 transcription is regulated by Peroxisome ProliferatorActivated Receptor- $\alpha$ in the adult rodent heart. FASEB J. 2001;15:833-845.

22. Holness MJ, Smith ND, Bulmer K, Hopkins T, Gibbons GF and Sugden MC. Evaluation of the role of Peroxisome-Proliferator-Activated Receptor- $\alpha$ in the regulation of cardiac Pyruvate Dehydrogenase Kinase 4 Protein expression in response to starvation, high-fat feeding and hyperthyroidism. Biochem J. 2002;364:687-94.

23. Young ME, Patil S, Ying J, Depre C, Ahuja HS, Shipley GL, Stepkowski SM, Davies PJ and Taegtmeyer $H$. Uncoupling Protein 3 transcription is regulated by Peroxisome ProliferatorActivated Receptor- $\alpha$ in the adult rodent heart. FASEB J. 2001;15:833-45.

24. Allard MF, Schonekess BO, Henning SL, English DR and Lopaschuk GD. Contribution of oxidative metabolism and glycolysis to ATP production in hypertrophied hearts. Am J Physiol. 1994;267:H742-H750.

25. Davila-Roman VG, Vedala G, Herrero P, de las Fuentes L, Rogers JG, Kelly DP and Gropler RJ. Altered myocardial fatty acid and glucose metabolism in idiopathic dilated cardiomyopathy. $J \mathrm{Am}$ Coll Cardiol. 2002;40:271-277.

26. Kanda H, Nohara R, Hasegawa K, Kishimoto $C$ and Sasayama S. A nuclear complex containing PPAR $\alpha / R X R \alpha$ is markedly downregulated in the hypertrophied rat left ventricular myocardium with normal systolic function. Heart Vessels. 2000;15:191-196.

27. Stanley WC and Chandler MP. Energy metabolism in the normal and failing heart: Potential for therapeutic interventions. Heart Fail Rev. 2002;7:115-130.

28. Paolisso G, Gambardella A, Galzerano D, D'Amore A, Rubino P, Verza M, Teasuro P, Varricchio $\mathrm{M}$ and $\mathrm{D}^{\prime}$ Onofrio $\mathrm{F}$. Total-body and myocardial substrate oxidation in congestive heart failure. Metabolism. 1994;43:174-179.

29. Febbraio M, Abumrad NA, Hajjar DP, Sharma K, Cheng W, Pearce SF and Silverstein RL. A null mutation in murine CD36 reveals an important role in fatty acid and lipoprotein metabolism. $J$ Biol Chem. 1999;274:19055-19062.

30. Irie $H$, Krukenkamp IB, Brinkmann JF, Gaudette GR, Saltman AE, Jou W, Glatz JF, Abumrad NA and Ibrahimi A. Myocardial recovery from ischemia is impaired in CD36-null mice and restored by myocyte CD36 expression or medium-chain fatty acids. Proc Natl Acad Si USA. 2003;100:68196824.

31. Binas B, Danneberg H, McWhir J, Mullins L and Clark AJ. Requirement for the Heart-Type Fatty Acid Binding Protein in cardiac fatty acid utilization. FASEB J. 1999;13:805-812.

32. Vetter $\mathrm{R}$ and Rupp H. CPT-1 inhibition by etomoxir has a chamber-related action on cardiac sarcoplasmic reticulum and isomyosins. Am J Physiol. 1994;267:H2091-H2099.

33. Kusaka Y, Tanaka T, Okamoto F, Terasaki F, Matsunaga Y, Miyazaki H and Kawamura K. Effect of Sulfo-N-Succinimidyl Palmitate on the rat heart: Myocardial long-chain fatty acid uptake and cardiac hypertrophy. J Mol Cell Cardiol. 1995;27:1605-1612.

34. Crilley JG, Boehm EA, Blair E, Rajagopalan B, Blamire AM, Styles P, McKenna WJ, Ostman-Smith I, Clarke $\mathrm{K}$ and Watkins $\mathrm{H}$. Hypertrophic cardiomyopathy due to sarcomeric gene mutations is characterized by impaired energy metabolism irrespective of the degree of hypertrophy. J Am Coll Cardiol. 2003;41:1776-1782. 
35. Rupp H, Schulze W and Vetter R. Dietary medium-chain triglycerides can prevent changes in myosin and SR due to CPT-1 inhibition by etomoxir. Am J Pbysiol. 1995;269:R630-R640.

36. Finck BN, Lehman JJ, Leone TC, Welch MJ, Bennett MJ, Kovacs A, Han X, Gross RW, Kozak R, Lopaschuk GD and Kelly DP. The cardiac phenotype induced by PPAR $\alpha$ overexpression mimics that caused by diabetes mellitus. J Clin Invest. 2002;109:121-130.

37. Takemoto M, Node K, Nakagami H, Liao Y, Grimm M, Takemoto Y, Kitakaze M and Liao JK. Statins as antioxidant therapy for preventing cardiac myocyte hypertrophy. $J$ Clin Invest. 2001;108:1429-1437.

38. Shiomi T, Tsutsui H, Hayashidani S, Suematsu N, Ikeuchi M, Wen J, Ishibashi M, Kubota T, Egashira $\mathrm{K}$ and Takeshita A. Pioglitazone, a Peroxisome Proliferator-Activated Receptor- $\gamma$ agonist, attenuates left ventricular remodeling and failure after experimental myocardial infarction. Circulation. 2002;106:3126-3132.

39. Feingold K, Kim MS, Shigenaga J, Moser A and Grunfeld C. Altered expression of nuclear hormone receptors and coactivators in mouse heart during the acute-phase response. Am J Pbysiol. 2004;286:E201-E207.

40. Memon RA, Feingold KR, Moser AH, Fuller J and Grunfeld C. Regulation of Fatty Acid Transport Protein and Fatty Acid Translocase mRNA levels by endotoxin and cytokines. $A m J$ Pbysiol. 1998;274:E210-E217.

41. Sakai S, Miyauchi T, Irukayama-Tomobe $\mathrm{Y}$, Ogata T, Goto K and Yamaguchi I. Peroxisome Proliferator-Activated Receptor- $\gamma$ activators inhibit Edothelin-1-related cardiac hypertrophy in rats. Clin Sici (Lond). 2002;103 Suppl 48:16S-20S.

42. Asakawa M, Takano $H$, Nagai $T$, Uozumi $H$, Hasegawa $H$, Kubota N, Saito T, Masuda $Y$, Kadowaki $\mathrm{T}$ and Komuro I. Peroxisome Proliferator-Activated Receptor $\gamma$ plays a critical role in inhibition of cardiac hypertrophy in vitro and in vivo. Circulation. 2002;105:1240-1246.

43. Yamamoto K, Ohki R, Lee RT, Ikeda U and Shimada K. Peroxisome Proliferator-Activated Receptor- $\gamma$ activators inhibit cardiac hypertrophy in cardiac myocytes. Circulation. 2001;104:16701675.

44. Liang F, Wang F, Zhang $S$ and Gardner DG. Peroxisome Proliferator-Activated Receptor- $\alpha$ (PPAR $\alpha$ ) agonists inhibit hypertrophy of neonatal tat cardiac myocytes. Endocrinology. 2003;144:4187-4194.

45. Rouet-Benzineb P, Gontero B, Dreyfus P and Lafuma C. Angiotensin II induces Nuclear Factor$\mathrm{\kappa B}$ activation in cultured neonatal rat cardiomyocytes through Protein Kinase $\mathrm{C}$ signaling pathway. J Mol Cell Cardiol. 2000;32:1767-1778.

46. Purcell NH, Tang G, Yu C, Mercurio F, DiDonato JA and Lin A. Activation of NF- $\mathrm{KB}$ is required for hypertrophic growth of primary rat neonatal ventricular cardiomyocytes. Proc Natl Acad Sci USA. 2001;98:6668-6673.

47. Straus DS, Pascual G, Li M, Welch JS, Ricote M, Hsiang CH, Sengchanthalangsy LL, Ghosh G and

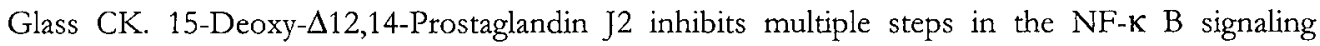
pathway. Proc Natl Acad Sci USA. 2000;97:4844-4849.

48. Jump DB and Clarke SD. Regulation of gene expression by dietary fat. Annu Rev Nutr. 1999;19:6390.

49. Kim YS, Han CY, Kim SW, Kim JH, Lee SK, Jung DJ, Park SY, Kang H, Choi HS, Lee JW and Pak YK. The orphan nuclear receptor small heterodimer partner as a novel coregulator of Nuclear Factor- $\mathrm{KB}$ in oxidized low density lipoprotein-treated macrophage cell line Raw 264.7. J Biol Chem. 2001;276:33736-33740.

50. Nakamuta M, Enjoji M, Uchimura K, Ohta S, Sugimoto R, Kotoh K, Kato M, Irie T, Muta T and Nawata H. Bisphenol A Diglycidyl Ether (BADGE) suppresses Tumor Necrosis Factor- $\alpha$ 
production as a PPAR $\gamma$ agonist in the murine macrophage-like cell line, Raw 264.7. Cell Biol Int. 2002;26:235-241.

51. Warnmark A, Treuter E, Wright AP and Gustafsson JA. Activation Functions 1 and 2 of nuclear receptors: Molecular strategies for transcriptional activation. Mol Endocrinol. 2003;17:1901-1909.

52. Desvergne B and Wahli W. Peroxisome Proliferator-Activated Receptors: Nuclear Control of Metabolism. Endocrine Rev. 1999;20:649-688.

53. Castillo G, Brun RP, Rosenfield JK, Hauser S, Park CW, Troy AE, Wright ME and Spiegelman BM. An adipogenic cofactor bound by the differentiation domain of PPAR $\gamma$. EMBO J. 1999;18:36763687.

54. Barger PM, Browning AC, Garner AN and Kelly DP. p38 Mitogen-Activated Protein Kinase activates Peroxisome Proliferator-Activated Receptor- $\alpha$ : A potential role in the cardiac metabolic stress response. J Biol Chem. 2001;276:44495-44501.

55. Oberkofler H, Esterbauer H, Linnemayr V, Strosberg AD, Krempler F and Patsch W. Peroxisome Proliferator-Activated Receptor (PPAR) $\gamma$ Coactivator-1 recruitment regulates PPAR subtype specificity. J Biol Cbem. 2002;277:16750-16757.

56. Moya-Camarena SY and Belury MA. Species differences in the metabolism and regulation of gene expression by conjugated linoleic acid. Nutr Rev. 1999;57:336-340.

57. Yu Y, Correll PH and Vanden Heuvel JP. Conjugated linoleic acid decreases production of proinflammatory products in macrophages: Evidence for a PPAR $\gamma$-dependent mechanism. Biocbim Biopbys Acta. 2002;1581:89-99.

58. Bull AW, Steffensen KR, Leers J and Rafter JJ. Activation of PPAR $\gamma$ in colon tumor cell lines by oxidized metabolites of linoleic acid, endogenous ligands for PPAR $\gamma$. Carcinogenesis. 2003; 24:17171722.

59. Wahli W, Devchand PR, IJpenberg A and Desvergne B. Fatty Acids, eicosanoids, and hypolipidemic agents regulate gene expression through direct binding to Peroxisome ProliferatorActivated Receptors. Advances in Experimental Medical Biology. 1999;447:199-209.

60. Nixon JB, Kamitani H, Baek SJ and Eling TE. Evaluation of eicosanoids and NSAIDs as PPAR $\gamma$ ligands in colorectal carcinoma cells. Prostaglandins Leukot Essent Fatty Acids. 2003;68:323-330.

61. Li Q, Cheon YP, Kannan A, Shanker S, Bagchi IC and Bagchi MK. A novel pathway involving Progesterone Receptor, 12/15-Lipoxygenase-derived eicosanoids, and Peroxisome ProliferatorActivated Receptor- $\gamma$ regulates implantation in mice. J Biol Chem. 2004;279:11570-11581.

62. Kehrer JP, Biswal SS, La E, Thuillier P, Datta K, Fischer SM and Vanden Heuvel JP. Inhibition of Peroxisome-Proliferator-Activated Receptor (PPAR) $\alpha$ by MK886. Biocbem J. 2001;356:899-906.

63. Forman BM, Chen J and Evans RM. Hypolipidemic drugs, polyunsaturated fatty acids, and eicosanoids are ligands for Peroxisome Proliferator-Activated Receptors- $\alpha$ and $\delta$. Proc Natl Acad Sci USA. 1997;94:4312-4317.

64. Xu HE, Stanley TB, Montana VG, Lambert MH, Shearer BG, Cobb JE, McKee DD, Galardi CM, Plunket KD, Nolte RT, Parks DJ, Moore JT, Kliewer SA, Willson TM and Stimmel JB. Structural basis for antagonist-mediated recruitment of nuclear co-repressors by PPAR $\alpha$. Nature. 2002;415:813-817.

65. Rieusset J, Touri F, Michalik L, Escher P, Desvergne B, Niesor E and Wahli W. A new selective Peroxisome Proliferator-Activated Receptor- $\gamma$ antagonist with antiobesity and antidiabetic activity. Mol Endocrinol. 2002;16:2628-2644.

66. Oliver WR, Jr., Shenk JL, Snaith MR, Russell CS, Plunket KD, Bodkin NL, Lewis MC, Winegar DA, Sznaidman ML, Lambert MH, Xu HE, Sternbach DD, Kliewer SA, Hansen BC and Willson TM. A selective Peroxisome Proliferator-Activated Receptor- $\delta$ agonist promotes reverse cholesterol transport. Proc Natl Acad Sci USA. 2001;98:5306-5311. 
67. Kersten S, Desvergne B and Wahli W. Roles of PPARs in Health and Disease. Nature. 2000;405:421-424.

68. Lee CH, Chawla A, Urbiztondo N, Liao D, Boisvert WA and Evans RM. Transcriptional repression of atherogenic inflammation: modulation by PPAR $\delta$. Science. 2003;302:453-457.

69. Iglarz M, Touyz RM, Viel EC, Paradis P, Amiri F, Diep QN and Schiffrin EL. Peroxisome Proliferator-Activated Receptor- $\alpha$ and Receptor- $\gamma$ activators prevent cardiac fibrosis in mineralocorticoid-dependent hypertension. Hypertension. 2003;42: 737-743. 



\section{SUMMARY}

The heart provides itself and other organs in the body with oxygen-rich blood via the systemic circulation. Oxidizable nutrients reach the blood stream during post-prandial absorption from the small intestines or after release from adipocytes and liver. Like any other organ in the body also the cardiac muscle itself relies on an adequate supply of both oxygen and energy substrates to function properly. Roughly $65 \%$ of the energy generated by the heart originates from the oxidation of long-chain fatty acids (FA) and 30\% from glucose. The capacity of the cardiac muscle cells to generate high-energy phosphates from FA oxidation is regulated at the transcriptional level by Peroxisome Proliferator- Activated Receptors (PPARs), members of the nuclear-hormone receptor family of transcription factors.

Chapter 2 reviews the role of PPARs in the regulation of gene expression in cardiac and skeletal muscle. The PPAR family consists of three isoforms, i.e., $\operatorname{PPAR} \alpha, \operatorname{PPAR} \beta / \delta$, and PPAR\%. PPARs can be activated by several FA species ranging form saturated to polyunsaturated and branched FA. Furthermore, they can be activated by synthetic isoform specific ligands. Previously it was described that PPAR $\alpha$ regulates FA oxidation in oxidative tissues and PPAR $\gamma$ regulates the differentiation of adipocytes. A specific function for PPAR $\beta / \delta$ has not been described yet.

To investigate the genomic response of the heart in vivo to a rise in circulating FA levels, rats were subjected either to fasting, diabetes, or to high-fat diet (long-chain or medium-chain FA) or treated with the PPAR $\alpha$ ligand Wy-14,643 or the PPAR $\gamma$ ligand Rosiglitazone (Chapter 3). In fasted and diabetic, but not high-fat treated rats, a marked decrease in cardiac expression of genes involved in glucose metabolism was observed (GLUT4 and Hexokinase II). The fasting, diabetes and high-fat diet- induced rise in plasma FA was consistently associated with enhanced cardiac expression of PPAR-responsive genes. Administration of Wy-14,643 resulted in a dramatic increase in expression of FA handling genes in liver, but not in heart. Prolonged treatment with Rosiglitazone had limited effects on hepatic gene expression. Remarkably, the latter treatment resulted in a substantial reduction of the expression of PPAR-responsive genes in cardiac muscle. Collectively, these findings reveal a differential response of heart and liver to metabolic interventions, suggesting the involvement of both PPAR-dependent and 
independent processes in the transcriptional control of cardiac as well as hepatic energy metabolism.

Previous experimental findings have suggested that the activity of one of the PPAR isoforms (PPAR $\alpha$ ) is attenuated in cardiac hypertrophy and failure, resulting in a shift away from FA to glucose utilization in the affected heart. Accordingly, Chapter 4 addresses the PPAR-mediated transcriptional regulation of FA handling genes under hypertrophic conditions in vitro. The hypertrophic stimuli phenylephrine and thyroid hormone affected neither the basal nor PPAR-mediated expression of a panel of lipid metabolising genes. At the promoter level phenylephrine and thyroid hormone attenuated the PPAR-mediated promoter activity of the human muscle-type carnitine palmitoyl transferase-I promoter (MCPT-1). Functionally, however, phenylephrine substantially increased the oxidation rate of palmitate in cardiomyocytes while glucose and pyruvate oxidation rates were unaltered. The collective data challenge the concept that cardiac hypertrophy is associated with a decline in PPAR $\alpha$ activity and, consequently, reduced expression of lipid metabolising genes and impaired FA oxidation rate.

To further elucidate the role of the three PPAR isoforms in cardiac FA metabolism, cardiomyocytes in vitro were treated with PPAR isoform specific ligands (Chapter 5). Consistent with the PPAR isoform expression pattern, the FA oxidation rate increased in cardiomyocytes exposed to PPAR $\alpha$ and PPAR $\beta / \delta$ ligands, but not in response to PPAR $\gamma$ ligands. Likewise, the FA-mediated expression of FA-handling proteins was mimicked by PPAR $\alpha$ and PPAR $\beta / \delta$, but not by PPAR $\gamma$ ligands. In embryonic rat heart-derived $\mathrm{H} 9 \mathrm{c} 2$ cells, that only express $\operatorname{PPAR} \beta / \delta$, the FA-induced expression of genes was mimicked by the PPAR $\beta / \delta$ ligand only, underscoring the notion that the natural ligand, $F A$, also interact with the $\operatorname{PPAR} \beta / \delta$ isoform. In cardiomyocytes addition of PPAR $\alpha$ and PPAR $\beta / \delta$ ligands dose-dependently induced MCPT-1 promoter activity. In contrast, PPAR $\gamma$ ligands did not activate MCPT-1 promoter activity. Collectively, the present findings demonstrate that, next to PPAR $\alpha, \operatorname{PPAR} \beta / \delta$ plays a prominent role in the regulation of cardiac lipid metabolism. PPAR $\gamma$, however, does not play a part in this process. Further research into the role of PPAR $\beta / \delta$ in cardiac diseases and the therapeutic potential of PPAR $\beta / \delta$ ligands is warranted. 
The co-existence of PPAR $\alpha$ and PPAR $\beta / \delta$ in the cardiac muscle cell raises the question to what extent functional differences exist. In Chapter 6 the question was addressed whether the activation of these isoforms is regulated in a different manner. In both cardiomyocytes and HEK293 cells differences between PPAR $\alpha$ and PPAR $\beta / \delta$ in MCPT- 1 promoter activation were observed. Unlike PPAR $\alpha, \operatorname{PPAR} \beta / \delta$ over-expression did not show ligand-independent (cryptic) trans-activation activity in cardiomyocytes. Activation of the endogenous PPAR hetero-dimer partner Retinoic X Receptor $\alpha(\mathrm{RXR} \alpha)$ with its cognate ligand 9-cis-retinoic acid enhanced MCPT-1 promoter activity in both cell types. In addition, over-expression of RXR $\alpha$ both in the absence and presence of 9-cis-retinoic acid, enhanced promoter activity. However, in HEK293 cells, but not in cardiomyocytes, over-expression of RXR $\alpha$ decreased the exogenous PPAR $\alpha$ - and PPAR $\beta / \delta$-mediated MCPT-1 promoter activation via an as yet unidentified mechanism. Over-expression of the transcriptional co-activator PPAR $\gamma$ coactivator-1 $\alpha($ PGC-1 $\alpha)$ resulted in MCPT-1 promoter activation in both cardiomyocytes and HEK293 cells. In summary, these studies reveal differences in PPAR $\alpha$ - and PPAR $\beta / \delta$ mediated MCPT-1 promoter activation. In addition, cell-type specific mechanisms in MCPT-1 promoter activation were observed, suggesting functional differences in the regulatory role of these two PPAR isoforms.

Concluding this thesis, Chapter 7 discusses the models and techniques used with respect to the questions addressed as well as the role and function of PPAR in cardiac (patho)physiology. Furthermore, future research topics are presented. 


\section{SAMENVATTININ}

Het hart voorziet zowel zichzelf als andere organen in het lichaam van zuurstofrijk bloed via de systemische circulatie. Voedingstoffen worden direct na de maaltijd via de dunne darm in het bloed opgenomen of worden door het vetweefsel of de lever afgegeven aan het bloed. Net als elk ander orgaan is het hart afhankelijk van een continue aanvoer van zuurstof en voedingstoffen om in zijn energiebehoefte te voorzien. Onder normale omstandigheden is ongeveer $65 \%$ van de in het hart gegenereerde energie afkomstig van de oxidatie van langketenige vetzuren (VZ), terwijl ongeveer 30\% afkomstig is uit glucose oxidatie. De cardiale capaciteit om VZ te oxideren wordt op transcriptie-niveau gereguleerd door Peroxisome Proliferator-Activated Receptors (PPARs). Deze PPARs zijn transcriptie factoren die deel uitmaken van de familie van nucleaire hormoon-receptoren.

In Hoofdstuk 2 wordt een overzicht gegeven van de functie die PPARs vervullen in de regulatie van de expressie van genen in het hart en de skeletspier. De PPAR familie bestaat uit 3 leden, te weten PPAR $\alpha$, PPAR $\beta / \delta$ en PPAR $\gamma$. Elk van hen kan door specifieke verbindingen (zgn. liganden) geactiveerd worden. Tot de natuurlijke liganden behoren ondermeer verzadigde en meervoudig onverzadigde VZ. Daarnaast kunnen PPARs door isovorm-specifieke synthetische liganden geactiveerd worden. Uit eerder onderzoek is gebleken dat PPAR $\alpha$ de VZ oxidatieve capaciteit reguleert in weefsels met een hoog zuurstofverbruik (o.a de hartspier), terwijl PPAR $\gamma$ de differentiatie van vetcellen reguleert. Een specifieke functie voor PPAR $\beta / \delta$ is tot nu toe nog niet beschreven.

Om het effect van een verhoogd aanbod van VZ op genexpressie in het intacte hart te onderzoeken, werden ratten onderworpen aan een regime van vasten, gevoed met een hoogvet dieet of diabeet gemaakt. Deze interventies leidden tot een stijging van de VZ concentratie in het bloed. Daarnaast werd het effect van de specifieke PPAR $\alpha$-ligand Wy-14,643 en de specifieke PPAR $\gamma$-ligand Rosiglitazone op de expressie van cardiale genen onderzocht (Hoofdstuk 3). In tegenstelling tot een hoog-vet dieet onderdrukten vasten en diabetes de expressie van GLUT4 en Hexokinase-II, genen die betrokken zijn bij de cellulaire opname en metabole omzetting van glucose. Daarentegen leidden alle drie de interventies tot een verhoogde expressie van PPAR-gereguleerde genen in het hart. Blootstelling aan Wy-14,643 
resulteerde in een dramatische toename van mRNA expressie in de lever, maar niet in het hart. Langdurige toediening van Rosiglitazone had een relatief mild effect op de lever. Opmerkelijk genoeg leidde blootstelling aan dezelfde ligand tot een significante verlaging van de expressie van PPAR-gereguleerde genen in de hartspier. Samenvattend kan gesteld worden dat een interventie, die resulteert in een verhoogd aanbod van VZ aan het hart, leidt tot een tegengestelde respons van glucose (verlaging) en VZ metaboliserende genen (verhoging). Daarnaast laat de behandeling met synthetische PPAR liganden zien dat er zowel PPARafhankelijke als onafhankelijke mechanismen bijdragen aan de transcriptionele regulatie van de cardiale energiehuishouding.

Een aantal in de literatuur beschreven studies suggereren een afname in transcriptionele activiteit van PPAR $\alpha$ in het hypertrofe en falende hart, hetgeen geacht wordt te resulteren in een afname van de $\mathrm{VZ}$ oxidatie capaciteit en een verhoogd glucose gebruik. Om ons inzicht in dit proces te vergroten is in Hoofdstuk 4 de PPAR-afhankelijke transcriptie van VZ metaboliserende genen tijdens hypertrofie onderzocht in een in vitro model. De hypertrofe stimuli phenylephrine en schildklierhormoon bleken geen effect te hebben op de basale en PPAR-afhankelijke expressie van een scala van VZ metaboliserende genen. Op promoter niveau leidde de blootstelling van cardiomyocyten aan phenylephrine en schildklierhormoon tot een verlaging van de PPAR-afhankelijke activatie van het spiet-type cannitine palmitoyl transferase-I promoter (MCPT-1). Werd echter naar de functie gekeken, dan bleek blootstelling aan phenylephrine tot een verhoogde $\mathrm{VZ}$ oxidatie snelheid te leiden, terwijl de oxidatie snelheid van zowel glucose als pyruvaat niet beïnvloed werd. Geconcludeerd kan worden dat deze studie het concept ter discussie stelt waarin een afgenomen expressie van VZ metaboliserende genen, welke leiden tot een afname van de VZ oxidatie capaciteit tijdens hypertrofie, het resultaat zou zijn van een verminderde PPAR $\alpha$ activiteit.

Om de betekenis van de drie PPAR isovormen voor de regulatie van het cardiale VZ metabolisme nader te onderzoeken, werden cardiomyocyten in vitro blootgesteld aan PPARisovorm specifieke, synthetische liganden (Hoofdstuk 5). Overeenkomstig aan het expressie patroon van de te onderscheiden PPAR isovormen in hartweefsel, resulteerde de blootstelling aan PPAR $\alpha$ - en PPAR $\beta / \delta$-liganden in een verhoogde VZ oxidatie snelheid, terwijl PPAR $\gamma$ liganden dit effect niet lieten zien. De VZ-geïnduceerde expressie van VZ-metaboliserende genen werd ook door PPAR $\alpha$ - en PPAR $\beta / \delta$-liganden nagebootst, maar niet door PPAR $\gamma$ - 
liganden. In H9c2 cellen, afkomstig van het embryonale rattenhart, komt alleen PPAR $\beta / \delta$ tot expressie. In dit cel-type was alleen een PPAR $\beta / \delta$-ligand in staat de expressie van VZmetaboliserende genen te activeren, hetgeen de hypothese onderbouwt dat VZ ook natuurlijke liganden zijn voor deze PPAR isovorm. In cardiomyocyten verhoogden PPAR $\alpha$ - en PPAR $\beta / \delta$ liganden, maar niet PPAR $\gamma$-liganden, de activiteit van de MCPT-1 promoter. Deze experimenten laten zien dat in de hattspier behalve PPAR $\alpha$ ook PPAR $\beta / \delta$ het $\mathrm{VZ}$ metabolisme reguleert. PPAR $\gamma$ lijkt niet betrokken te zijn bij dit proces. Verder onderzoek naar de rol van PPAR $\beta / \delta$ in het hart en de mogelijkheid om PPAR $\beta / \delta$-liganden als therapeutisch middel bij cardiale aandoeningen aan te wenden is dringend gewenst.

Nu blijkt dat PPAR $\alpha$ en PPAR $\beta / \delta$ beide in de hartspier tot expressie komen, rijst de vraag wat de functionele betekenis van beide PPAR isovormen is in dit orgaan. In Hoofdstuk 6 wordt onderzocht wat de overeenkomsten en verschillen zijn in het reguleren van de promoter activiteit door deze twee PPAR isovormen. In zowel cardiomyocyten als humane niercellen (HEK293) werden verschillen tussen PPAR $\alpha$ en PPAR $\beta / \delta$ aangetoond met betrekking tot MCPT-1 promoter activatie. Anders dan bij PPAR $\alpha$, leidde over-expressie van $\mathrm{PPAR} \beta / \delta$ niet tot een ligand-onafhankelijke (ktyptische) trans-activatie van de MCPT-1 promoter in de hartspiercel. Activatie van de endogene PPAR hetero-dimeer partner Retinoic $\mathrm{X}$ Receptor $\alpha(\mathrm{RXR} \alpha)$ door haar specifieke ligand 9-cis-retinoic acid verhoogde de MCPT-1 promoter activiteit in zowel cardiomyocyten als HEK293 cellen. Daarnaast deed over-expressie van $\operatorname{RXR} \alpha$ de promoter activiteit in zowel aan- als afwezigheid van 9-cis-retinoic acid toenemen. Echter, in HEK293 cellen werd de door exogeen PPAR $\alpha$ en PPAR $\beta / \delta$ gestimuleerde MCPT-1 promoter activiteit verlaagd door over-expressie van RXR $\alpha$. Het mechanisme hierachter is nog onduidelijk. Deze remmende werking werd niet aangetroffen in cardiomyocyten. Over-expressie van de transcriptionele co-activator PPAR $\gamma$ co-activator-1 $\alpha$ (PGC-1 $\alpha$ ) resulteerde in MCPT-1 promoter activatie in zowel cardiomyocyten als HEK293 cellen. Samenvattend kan worden gesteld dat in een aantal opzichten verschillen bestaan tussen PPAR $\alpha$ - en PPAR $\beta / \delta$-afhankelijke MCPT-1 promoter activatie. Daarnaast zijn cel-type gerelateerde verschillen aangetoond. Deze bevindingen suggereren in sterke mate dat er verschillen bestaan in de regulatie van de activiteit van PPAR $\alpha$ en $\operatorname{PPAR} \beta / \delta$. 
Ter afsluiting van dit proefschrift worden in Hoofdstuk 7 de gebruikte modellen en technieken bediscussieerd, evenals de functie van de PPARs in het normale en zieke hart. Daarnaast worden suggesties gedaan voor interessant vervolgonderzoek. 


\section{DANKWOORD}

Zoals bij ieder groot project veel mensen betrokken zijn is dat ook het geval bij een promotie onderzoek. Het is misschien wel te vergelijken met het fietsen van de Tour de France. Als "ploegleider" wil ik dan ook bedanken Marc van Bilsen. Beste Marc bedankt voor je vertrouwen in mij, het is altijd een gok om iemand van "buiten" aan te nemen en dan ook nog een niet-academicus. We hebben heel wat Alpen colletjes moeten nemen om bij de finish te komen, zelfs met gebroken ledematen, maar het is gelukt. Ik ben blij dat ik onder jouw dagelijkse leiding het onderzoek heb mogen doen. Naast de ploegleider was daar de "teammanager" Ger van der Vusse. Beste Ger, vooral in de laatste jaren fungeerde jij als sturende kracht in de totstandkoming van de verschillende hoofdstukken in dit proefschrift. Daarnaast heb ik je belangstelling voor de thuissituatie van deze renner en je tips voor zijn toekomst erg op prijs gesteld. Naast het coördineren van een ploeg door leidinggevenden is een "wegkapitein" onontbeerlijk voor het goed functioneren van een team. Peter Willemsen deze taak was voor jou weggelegd. Jij hebt er zorg voor gedragen dat op het lab alles voor elkaar was en is. Voor mij ben je niet alleen een steun geweest op het uitvoerende vlak, als er weer wind op kop stond, maar ook op het mentale vlak, als deze renner er even doorheen zat. Ik ben daarom ook blij dat je mij als paranimf terzijde wil staan voor de eindsprint. Verder wil ik onze "waterdrager", Martijn Lindhout, op deze plaats bedanken. Beste Martijn ik heb jou inzet binnen de groep erg op prijs gesteld en de resultaten die jij hebt gegenereerd hebben ook een essentiële bijdrage geleverd aan de totstandkoming van dit proefschrift. Jammer dat je de ploeg hebt moeten verlaten, maar ik hoop dat je snel je kwaliteiten elders kan inzetten. Dan hebben we nog de "nieuweling" in de ploeg. De ploegleider heeft een veelbelovende Belg weten te contracteren waarmee ik al een jaar lang heb mogen koersen. Pascal ik wil jou vooral bedanken voor je gezelligheid gedurende mijn schrijfperiode. Vooral je onuitputtelijke muziek collectie heeft in hoge mate bijgedragen aan de vooral nachtelijke trainingsexercities van deze renner. Als ex-lid van de Moleculaire-Fysiologie selectie wil ik de inmiddels al Doctor zijnde Karin van der Lee bedanken voor het voorbereidende werk van mijn project. Je hebt mij de fijne kneepjes van de cel-isolatie bijgebracht samen met transfectie en vetzuur-oxidatie. Verder natuurlijk onze oud renner Hans Degens, voor je gezelschap op de fiets en je filosofische discussies. Een niet te onderschatte bijdrage hebben de stagiaires Lisan Cuijpers en Raymond Lotz aan dit proefschrift geleverd. Lisan en Raymond, bedankt voor het vele werk dat jullie hebben verricht 
en natuurlijk de gezelligheid, veel geluk met jullie toekomst. Naast mijn eigen ploeg wil ik de renners van de overige selecties binnen de Fysiologie organisatie bedanken voor het brengen van discussie en een prettige werksfeer. Danny, Theo R., Ruben, Joep, Debby, Susan, Maurice, Daniëlle, Wil, Joost, Jan G., Anita, Miriam, Veerle, Jaqueline, Viviane, Miriam oE., Els, Suniva, Yuri, Sabine, Sander, Erik, Maura, Jan H., Ulli, Maurits, Henny, Mark, Richard, Frits, Luc, Claire, Jos, Vivian, Theo vd. N. en alle andere mannen en vrouwen van Fysiologie. Een speciale vermelding verdient mijn "zaakwaarnemer" Leo Ennen, dankzij wie ik in Maastricht beland ben. Leo kerel, zet hem op met je eigen onderzoek en nog veel plezier in Nijmegen en Tiel. De afgelopen jaren hier in het Maastrichtse zijn sportief opgeluisterd door de mannen en vrouwen van de "maandagavond UM-loopgroep". Ik weet dat ik de trainingen een beetje heb verwaarloosd maar de reden hiervan hebben jullie nu onder ogen. Bedankt voor jullie gezelligheid. Verder wil ik mijn fiets-maatje Ton bedanken voor zijn komst naar het zuiden, zijn inbreng in het ontdekken van nieuwe fiets routes en zijn vriendschap. Ton bedankt voor het aanhoren van de klaagliederen van deze aio.

Naast team makkers is het thuisfront erg belangrijk voor een jonge renner. Daarom wil ik mijn familie bedanken voor de steun die ze mij gegeven hebben in al zijn vormen. Vooral toen het tegen zat heb ik veel aan mijn ouders gehad. Pa en Ma, natuurlijk heb ik ook de mooie dingen met jullie mogen delen. Mijn broer, Melis Jan jou wil ik bedanken simpel weg om dat je mijn broer bent. Nu ik dit boekwerkje heb afgemaakt zal ik mijn neus weer eens wat vaker laten zien in het Oóóóósten van ons land, zodat we als vanouds weer eens een stukkie kunnen fietsen. "Last but not the least" bedank ik jou Jolanda. We zijn samen aan dit avontuur begonnen en we hebben het samen afgemaakt. Vooral de laatste 2 jaar is jouw steun onontbeerlijk geweest. Ik hoop dat we samen nog lang in deze prachtige omgeving kunnen wonen, werken en natuurlijk sporten. 


\section{CURRICULUM VITAE}

De auteur werd geboren op 24 juni 1970 te Delft. Zijn middelbare school tijd woonde hij in Lelystad waar hij in 1987 het MAVO-diploma behaalde. In de periode 1987-1991 werd het Middelbaar Laboratorium Onderwijs gevolgd aan zowel de Amersfoortse Laboratorium School als het voormalige Van Leeuwenhoek Instituut te Delft alwaar het diploma in 1991 werd verkregen met als afstudeerrichting Technische Microbiologie. In de periode 1991-1992 werd de militaire dienstplicht vervuld bij het 43ste Tankbataljon te Langenmannshof (BRD). In 1992 werd gestart met het Hoger Laboratorium Onderwijs aan de Hogeschool van Utrecht. In 1996 werd het diploma behaald in de Medisch Biologische richting na een afstudeerstage in het laboratorium voor Salmonella pathogenese, Department of Molecular Microbiology and Immunology van de Oregon Health Sciences University te Portland (Oregon, U.S.A.). De afstudeerscriptie getiteld "Distribution of virulence factors in the genus Salmonella" is tot stand gekomen onder begeleiding van Dr. I. Stojlijkovic en Dr. A. Bäumler. Tussen 1997 en 2000 vervulde de auteur de functie van onderzoeksanalist bij TNO Voeding te Zeist, Divisie Toxicologie. In 2000 werd gestart met het promotie onderzoek zoals beschreven in dit proefschrift.

The author of this thesis was borne on June 24th 1970 in Delft (The Netherlands). In 1987 he graduated from secondary school (MAVO) and started his studies in microbiology at the Van Leeuwenhoek Institute in Delft (Secondary vocational education) from which he graduated in 1991. From 1991-1992 he was drafted for military service and joined the 43rd Tank battalion at the Dutch NATO-base in Langenmannshof (Germany) as a member of the Medical Corps. In the summer of 1992 the author started his training in molecular biology at the University of Professional Education Utrecht from which he obtained his BSc degree in 1996. The BSc thesis "Distribution of virulence factors in the genus Salmonella" research was performed in the Salmonella pathogenesis lab at the Department of Molecular Microbiology and Immunology of the Oregon Health Sciences University in Portland (Oregon, U.S.A.) under the supervision of Dr. I. Stojiljkovic and Dr. A. Bäumler. After graduation he started as a research technician at the TNO Nutrition and Food Research Institute in Zeist, Toxicology Division. In 2000 he moved to Maastricht to start with the PhD research project as described in this thesis. 


\section{LIST OF PUBLICATIONS}

Gilde AJ, Willemsen PHM, Lindhout M, Hoeks J, Hesselink MKC, Schrauwen P, Benton CR, Bonen A, Van der Vusse GJ, and Van Bilsen M. PPAR-dependent and PPAR-independent changes in cardiac gene expression. submitted.

Degens H, De Brouwer K, Gilde AJ, Lindhout M, Willemsen PH, Janssen B, Van der Vusse GJ and Van Bilsen M. Cardiac metabolic adaptation: A late feature of the hypertrophic remodelling process. submitted.

Van Bilsen M, Smeets PJ, Gilde AJ and Van der Vusse GJ. Metabolic Remodelling of the Failing Heart: The Cardiac Burn-out Syndrome? Cardiovasc Res. 2004;61:218-226.

Gilde AJ and Van Bilsen M. Peroxisome Proliferator-Activated Receptors (PPARs): Regulators of gene expression in heart and skeletal muscle. Acta Pbysiol Scand. 2003;178:425-434.

Degens H, Gilde AJ, Lindhout M, Willemsen PH, Van der Vusse GJ and Van Bilsen M. Functional and metabolic adaptation of the heart to prolonged thyroid hormone treatment. Am J Pbysiol. 2003;284:H108-115.

Gilde AJ, Van der Lee KA, Willemsen PH, Chinetti G, Van der Leij FR, Van der Vusse GJ, Staels B and Van Bilsen M. Peroxisome Proliferator-Activated Receptor (PPAR) $\alpha$ and $\operatorname{PPAR} \beta / \delta$, but Not PPAR $\gamma$, modulate the expression of genes involved in cardiac lipid metabolism. Circ Res. 2003;92:518-524.

Versantvoort C, Onderwater RCA, Duizer E, van de Sandt JJM, Gilde AJ and Groten JP. Monolayers of IEC-18 cells as in vitro model for screening the passive transcellular and paracellular transport across the intestinal barrier: comparison of active and passive transport with the human colon carcinoma Caco-2 cell line. Environ Toxicol Pharmacol. 2002;11:335-344.

Van Bilsen M, Van der Vusse GJ, Gilde AJ, Lindhout M and Van der Lee KA. Peroxisome Proliferator-Activated Receptors: Lipid binding proteins controling gene expression. Mol Cell Biochem. 2002;239:131-138.

Duizer E, Gilde AJ, Versantvoort CH and Groten JP. Effects of Cadmium Chloride on the paracellular barrier function of intestinal epithelial cell lines. Toxicol Appl Pbarmacol. 1999;155:117-126.

Bäumler AJ, Gilde AJ, Tsolis RM, van der Velden AW, Ahmer BM and Heffron F. Contribution of horizontal gene transfer and deletion events to development of distinctive patterns of fimbrial operons during evolution of Salmonella serotypes. $J$ Bacteriol. 1997;179:317-322.

\section{SELECTED ABSTRACTS}

Gilde AJ, Van der Lee KA, Willemsen PH, Chinetti G, Van der Leij FR, Van der Vusse GJ, Staels B and Van Bilsen M. Transcriptional regulation of cardiac fatty acid metabolism: redundancy of ligandactivated nuclear hormone receptors PPAR $\alpha$ and PPAR $\beta / \delta$. Eur J Heart Fail Suppl. 2003 June;85:7.

Degens H, De Brouwer K, Gilde AJ, Lindhout M, Willemsen PH, Janssen B, Van der Vusse GJ and Van Bilsen M. Functional and metabolic adaptation of the rat heart during compensatory hypertrophy. Eur J Heart Fail Suppl. 2003 June;773:167.

\section{AWARDS}

Andries Gilde received an NIH scholarship, chosen by Dr Ronald M. Evans, to attend the Keystone meeting entitled "PPARs: Transcriptional Regulators of Metabolism and Metabolic Disease 2003". 


\section{PPARs RULE!!}

AJG 2004 